\title{
Drug Addiction: Hyperkatifeia/Negative Reinforcement as a Framework for Medications Development
}

\author{
George F. Koob \\ National Institute on Alcohol Abuse and Alcoholism and National Institute on Drug Abuse, National Institutes of Health, Bethesda, \\ Maryland
}

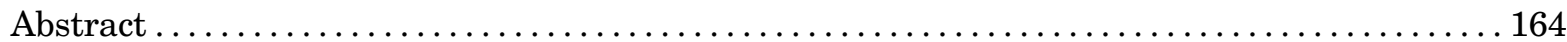

Significance Statement............................................... 164

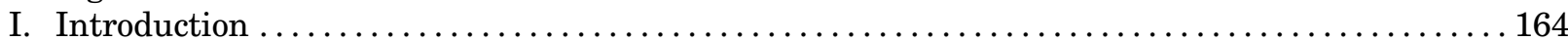

II. Addiction: Definition and Theoretical Framework.............................. 165

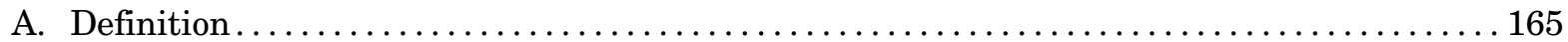

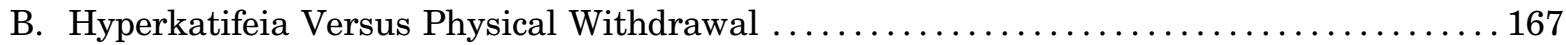

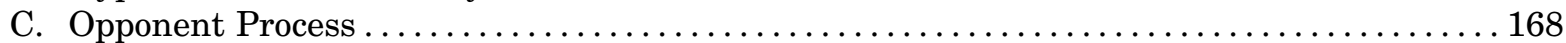

D. Validation of the Hyperkatifeia Construct in Humans.......................... 169

D. Validation of the Hyperkatifeia Construct in a Molecular-Neurocircuitry Study in an

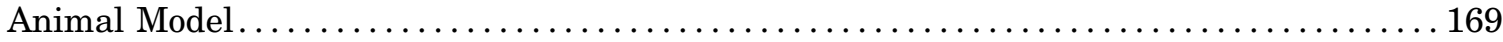

III. Within-System/Between-System Neurobiological Substrates for Hyperkatifeia Associated with Opioid and Alcohol Withdrawal .................................... 170

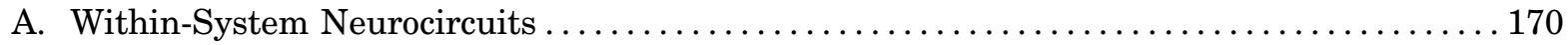

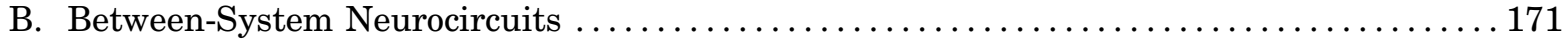

IV. Within-System Neurobiological Substrates for Hyperkatifeia Associated with Opioid and

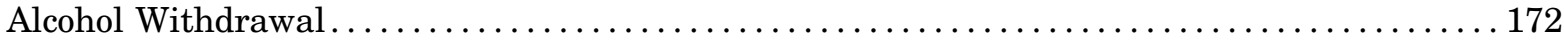

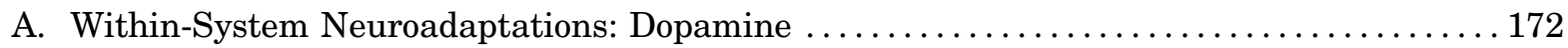

B. Within-System Neuroadaptations: Enkephalin/Endorphin Opioid Peptides............ 173

C. Within-System Neuroadaptations: GABA and Glutamate .................... 174

V. Between-System Neurobiological Substrates for Hyperkatifeia Associated with Opioid

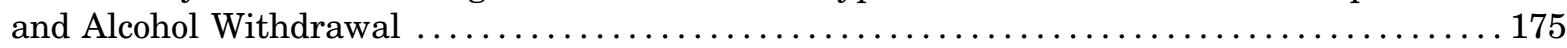

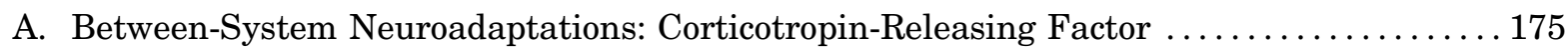

B. Between-System Neuroadaptations: Norepinephrine $\ldots \ldots \ldots \ldots \ldots \ldots \ldots \ldots \ldots \ldots \ldots$

C. Between-System Neuroadaptations: Glucocorticoids . . . . . . . . . . . . . . . . . . . . . . . 177

D. Between-System Neuroadaptations: Dynorphin/к-Opioid Receptors . . . . . . . . . . . . . 177

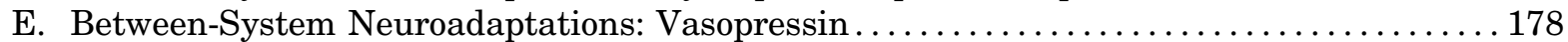

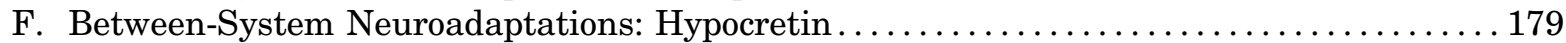

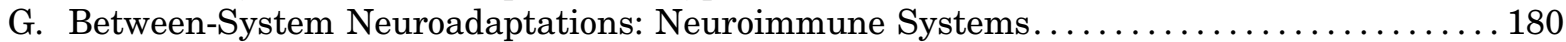

VI. Antistress Neurotransmitters/Neuromodulators and Hyperkatifeia ................... 181

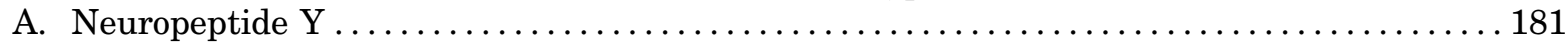

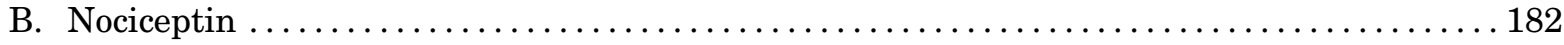

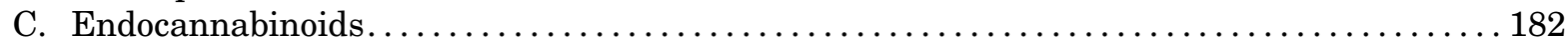

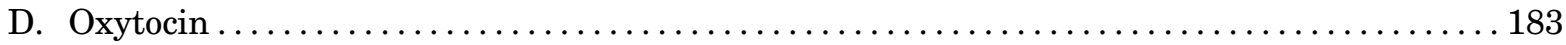

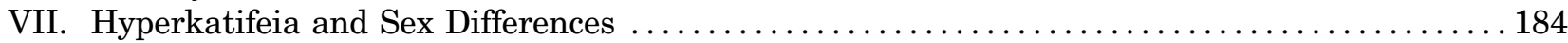

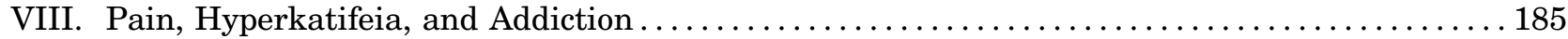

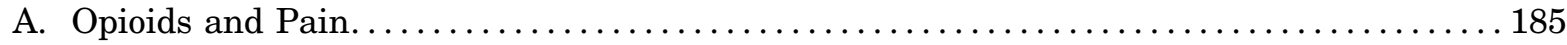

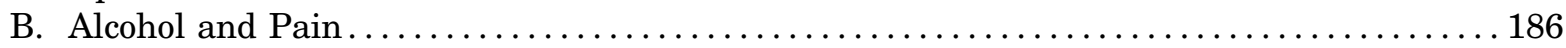

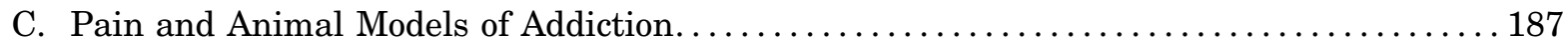

IX. Individual Differences in Hyperkatifeia..................................... 188

Address correspondence to: Dr. George F. Koob, National Institute on Alcohol Abuse and Alcoholism, National Institutes of Health, 5635 Fishers Lane, Room 2001, Suite 2000, Rockville, MD 20852. E-mail: george.koob@nih.gov 


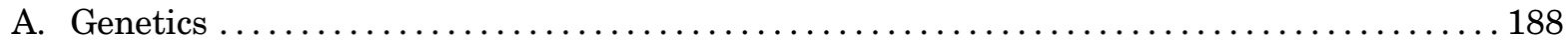

B. Development, Comorbidities, Epigenetics, and Hyperkatifeia ................... 188

X. The Case for Hyperkatifeia as a Target for Medications Development ................. 189

A. Reward Dysregulation, Stress Surfeit, Pain, and Negative Reinforcement ........... 189

B. Negative Results ............................................... 190

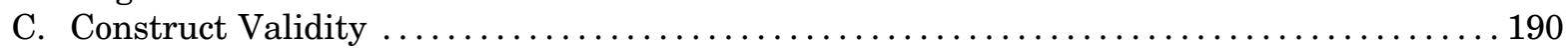

D. Conditioning in Withdrawal and Protracted Abstinence ...................... 191

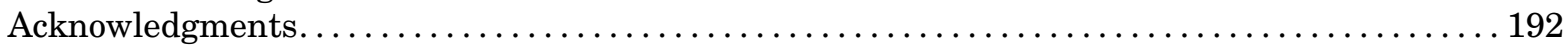

References........................................................ 192

\begin{abstract}
Compulsive drug seeking that is associated with addiction is hypothesized to follow a heuristic framework that involves three stages (binge/intoxication, withdrawal/negative affect, and preoccupation/ anticipation) and three domains of dysfunction (incentive salience/pathologic habits, negative emotional states, and executive function, respectively) via changes in the basal ganglia, extended amygdala/habenula, and frontal cortex, respectively. This review focuses on neurochemical/neurocircuitry dysregulations that contribute to hyperkatifeia, defined as a greater intensity of negative emotional/motivational signs and symptoms during withdrawal from drugs of abuse in the withdrawal/negative affect stage of the addiction cycle. Hyperkatifeia provides an additional source of motivation for compulsive drug seeking via negative reinforcement. Negative reinforcement reflects an increase in the probability of a response to remove an aversive stimulus or drug seeking to remove hyperkatifeia that is augmented by genetic/epigenetic vulnerability, environmental trauma, and psychiatric comorbidity. Neurobiological targets for hyperkatifeia in addiction involve neurocircuitry of the extended amygdala and its connections via within-system neuroadaptations in dopamine, enkephalin/endorphin opioid peptide, and $\gamma$-aminobutyric acid/glutamate
\end{abstract}

systems and between-system neuroadaptations in prostress corticotropin-releasing factor, norepinephrine, glucocorticoid, dynorphin, hypocretin, and neuroimmune systems and antistress neuropeptide $Y$, nociceptin, endocannabinoid, and oxytocin systems. Such neurochemical/ neurocircuitry dysregulations are hypothesized to mediate a negative hedonic set point that gradually gains allostatic load and shifts from a homeostatic hedonic state to an allostatic hedonic state. Based on preclinical studies and translational studies to date, medications and behavioral therapies that reset brain stress, antistress, and emotional pain systems and return them to homeostasis would be promising new targets for medication development.

Significance Statement — The focus of this review is on neurochemical/neurocircuitry dysregulations that contribute to hyperkatifeia, defined as a greater intensity of negative emotional/motivational signs and symptoms during withdrawal from drugs of abuse in the withdrawal/ negative affect stage of the drug addiction cycle and a driving force for negative reinforcement in addiction. Medications and behavioral therapies that reverse hyperkatifeia by resetting brain stress, antistress, and emotional pain systems and returning them to homeostasis would be promising new targets for medication development.

\section{Introduction}

Addiction remains a worldwide problem and a significant burden to public health. Three prominent addictive drugs from a public health perspective are tobacco, alcohol, and opioids. The annual costs to society in the United States of tobacco, alcohol, and opioid addiction are estimated to be $\$ 300$ billion (https://www.cdc.gov/ drugoverdose/pdf/pubs/2019-cdc-drug-surveillancereport.pdf), $\$ 249$ billion (https://www.drugabuse.gov/ related-topics/trends-statistics/overdose-death-rates), and $\$ 179.4$ billion (Sacks et al., 2015), respectively.

The present review explores the neurobiology of hyperkatifeia, defined as the manifestation of a negative emotional state during the withdrawal/negative affect stage of the addiction cycle, as a key driving force in addiction that overlaps with pathology that is associated with pain (Egli et al., 2012) and deaths of despair (Case and Deaton, 2015). The theoretical framework of addiction has generally been outlined previously in multiple reviews (Koob and Le Moal, 1997, 2005, 2008; Koob and Volkow, 2010). The focus of this review is on exploring the theoretical basis for hyperkatifeia, linking it to physical and emotional pain, and identifying key within-system and between-system neuroadaptations that mediate hyperkatifeia. With a focus on alcohol use disorder (AUD) and opioid use disorder (OUD), this knowledge of the neurobiology of hyperkatifeia is used as

ABBREVIATIONS: ACTH, adrenocorticotropic hormone; AEA, $N$-arachidonoylethanolamine; 2-AG, 2-arachidonoylglycerol; AUD, alcohol use disorder; BAL, blood alcohol level; BDNF, brain-derived neurotrophic factor; BNST, bed nucleus of the stria terminalis; CB, cannabinoid; CeA, central nucleus of the amygdala; CREB, cAMP response element binding protein; CRF, corticotropin-releasing factor; DSM, Diagnostic and Statistical Manual of Mental Disorders; FAAH, fatty acid amid hydrolase; Hcrt, hypocretin; HPA, hypothalamic-pituitary-adrenal; MAGL, monoacylglycerol lipase; msP, Marchigian Sardinian alcohol-preferring; NAc, nucleus accumbens; NMDA, $N$-methyl-D-aspartate; norBNI, nor-binaltorphimine; NPY, neuropeptide Y; OUD, opioid use disorder; P, alcohol-preferring; PKC, protein kinase C; PVN, paraventricular nucleus of the hypothalamus; SNP, single-nucleotide polymorphism; SRC, steroid receptor coactivator; TLR4, Toll-like receptor 4; $\mathrm{TNF} \alpha$, tumor necrosis factor $\alpha$; VTA, ventral tegmental area. 
a framework for the development of promising new targets for medication development and behavioral therapies that can reset brain stress, antistress, and emotional pain systems and return them to homeostasis.

The United States remains in the grips of an opioid crisis that began with misuse and death from prescription opioids in the late $1990 \mathrm{~s}$, followed by a rise in deaths from heroin and synthetic opioids around 2010 (https://www.cdc.gov/tobacco/data_statistics/fact_sheets/ economics/econ_facts/index.htm). Opioid-involved overdose deaths increased from 21,088 in 2010 to 46,802 in 2018 (https://www.soa.org/globalassets/assets/files/ resources/research-report/2019/econ-impact-non-medicalopioid-use.pdf). As with opioids, deaths that involve alcohol have increased over the past two decades. The number of alcohol-involved deaths, based on death certificates, increased from 35,914 in 1999 to 72,558 in 2017 (White et al., 2020). Using a combination of death certificates and estimates of alcohol-related deaths not indicated on death certificates, the Centers for Disease Control and Prevention estimated that alcohol was involved in 88,424 deaths in 2010 (https://www.cdc. gov/chronicdisease/resources/publications/factsheets/ alcohol.htm; Table 1). A steady increase in individuals with OUD has been seen, reaching 2.0 million in 2018 (https://www.cdc.gov/tobacco/data_statistics/fact_sheets/ economics/econ_facts/index.htm; Table 1). Note that estimates of the prevalence of AUD in the United States are considerably higher (14.4 million in 2018; https:// www.samhsa.gov/data/sites/default/files/cbhsq-reports/ NSDUHDetailedTabs2018R2/NSDUHDetTabsSect5pe2018. sbhtm\#tab5-4a; Table 1). Alcohol and opioids contribute in a major way to the three primary factors that drive "deaths of despair": overdoses (alcohol and opioids), suicides (alcohol and opioids), and liver disease (alcohol; Case and Deaton, 2015). Opioids were involved in $67.8 \%$ of all drug overdose deaths in 2017 (https://www. cdc.gov/tobacco/data_statistics/fact_sheets/economics/econ_ facts/index.htm). Alcohol contributed to roughly one in seven (14.7\%) opioid overdose deaths in 2017 (Tori et al., 2020). The combination of alcohol and opioids is particularly dangerous. A dose of $20 \mathrm{mg}$ oxycodone in healthy subjects reduced ventilation by $28 \%$. Alcohol at a blood alcohol level (BAL) of $0.10 \%$ reduced ventilation by another $19 \%$ from baseline and increased apneic events (van der Schrier et al., 2017). There were 47,173 suicides in the United States in 2017, representing a $33 \%$ increase since 1999 (Ranade et al., 2020). Opioids are present in $20 \%$ of suicides, and $26 \%$ of suicide decedents who were tested for alcohol had intoxicating BALs $(>0.08 \%)$ in their systems (Ertl et al., 2019). Alcohol causes roughly $50 \%$ of deaths from liver disease (https://pubs.niaaa.nih.gov/publications/surveillance111/ Cirr15.htm). Between 1999 and 2017, the number of deaths from alcohol-associated liver disease increased from 11,947 to 22,245 (White et al., 2020).
TABLE 1

Relative scope of the problem: opioids vs. alcohol

Data for opioid misuse, alcohol use, OUD, and AUD are from Substance Abuse and Mental Health Services Administration (2019). Data for opioid- and alcohol-related emergency department visits are from the Nationwide Emergency Department Sample (NEDS), Healthcare Cost and Utilization Project (HCUP), of the Agency for Healthcare Research and Quality, Rockville, MD (www.hcup-us.ahrq.gov/ nedsoverview.jsp) and White et al. (2018). Data for for opioid overdose deaths and combined alcohol + opioid overdose deaths are from Hedegaard et al. (2020) Data for alcohol-related deaths are from Centers for Disease Control and Prevention (www.cdc.gov/ARDI).

\begin{tabular}{ll}
\hline Opioids & \multicolumn{1}{c}{ Alcohol } \\
\hline $\begin{array}{l}\text { Misuse: } 10,250,000^{\alpha} \\
\% \text { of population: } 3.7 \%\end{array}$ & $\begin{array}{l}\text { Use: } 179,289,000 \\
\% \text { of population: } 65.5 \%\end{array}$ \\
$\begin{array}{ll}\text { Opioid use disorder: } 2,028,000 & \text { Alcohol use disorder: } 14,818,000 \\
\% \text { of population: } 0.7 \% & \% \text { of population: } 5.4 \%\end{array}$
\end{tabular}

Emergency department visits Primary reason: 408,079

All opioid-related: $1,461,770$

Deaths

Total overdoses: 46,802

Prescription opioids: 14,975

Fentanyl and similar: 31,335

Heroin: 14,996

Opioid + alcohol-related deaths: $7143^{b}$

${ }^{a}$ Any past-year heroin use or prescription opioid use other than as prescribed.

${ }^{b}$ Of all opioid overdose deaths in 2018, $15 \%$ involved alcohol.

\section{Addiction: Definition and Theoretical Framework}

\section{A. Definition}

Definitions of addiction vary but usually include compulsion to seek and take a drug and the loss of control in limiting intake. A third component is the emergence of a negative emotional state when access to the drug is prevented (Koob et al., 1998), setting the stage for the present thesis and review. The focus of this review is on this third component (emergence of a negative emotional state), termed hyperkatifeia (Shurman et al., 2010). Hyperkatifeia (derived from the Greek katifeia for dejection or negative emotional state) is defined as an increase in intensity of the constellation of negative emotional or motivational signs and symptoms of withdrawal from drugs of abuse.

A heuristic framework for addiction includes a threestage cycle-binge/intoxication, withdrawal/negative affect, and preoccupation/anticipation-that provides a starting point for exploring the relatively new construct of hyperkatifeia in the context of drug withdrawal (Koob and Le Moal, 1997; Koob, 2019). Under this addiction framework, stage-related dysregulation occurs in three functional domains (incentive salience/ habits, negative emotional states, and executive function) that are mediated by three major neurocircuitry elements (basal ganglia, extended amygdala, and prefrontal cortex, respectively; Koob and Le Moal, 1997). These three stages feed into each other, become more intense, and ultimately lead to the pathologic state of addiction or substance use disorder (Koob and Le Moal, 1997; Fig. 1). 


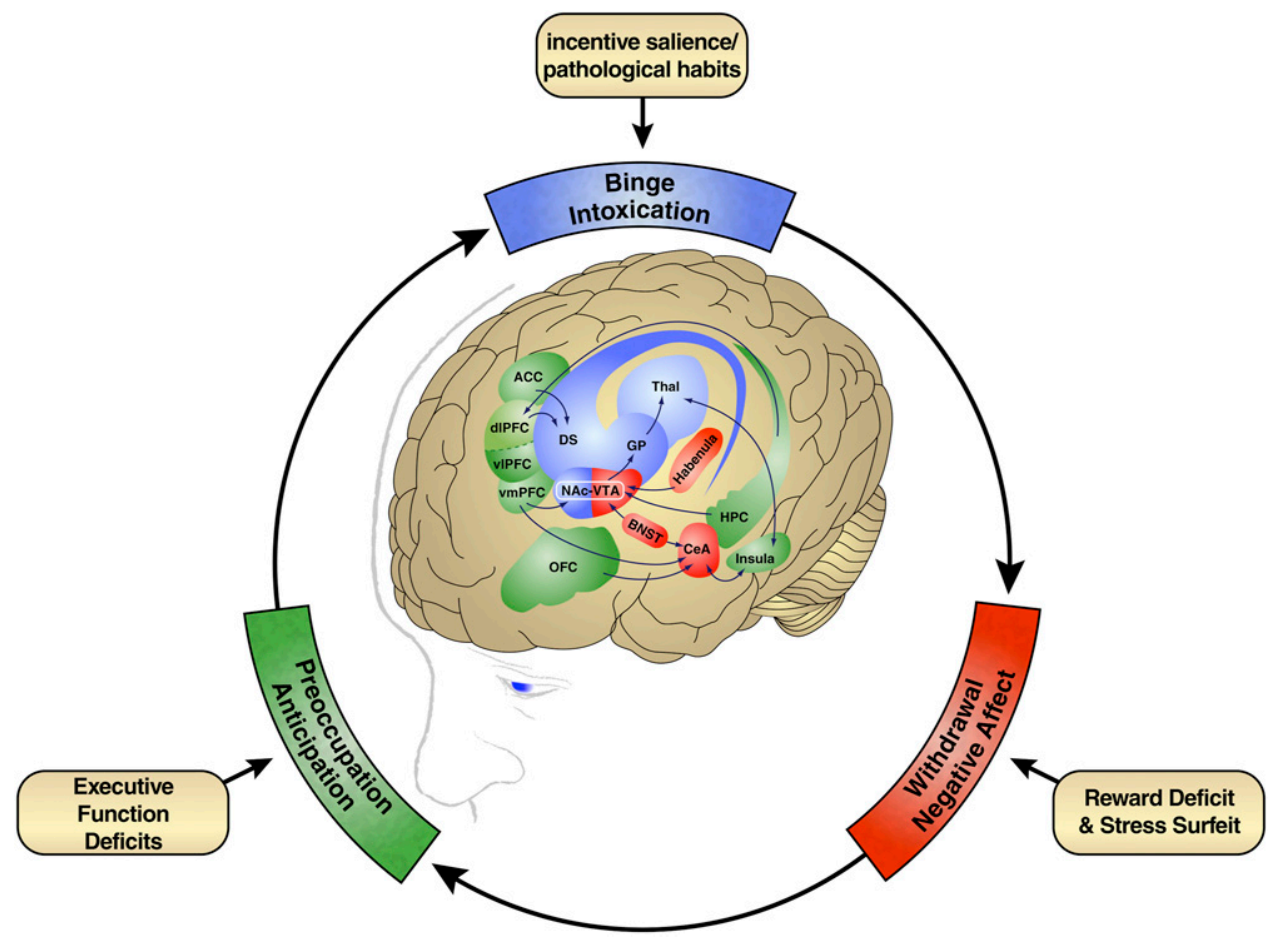

Fig. 1. Conceptual framework for the neurobiological basis of substance use disorders, involving a three-stage cycle—binge/intoxication, withdrawal/ negative affect, and preoccupation/anticipation. These three stages involve dysregulations in three functional domains (incentive salience/pathological habits, negative emotional states, and executive function) that are mediated by three major neurocircuitry elements (basal ganglia, extended amygdala, and prefrontal cortex, respectively). ACC, anterior cingulate cortex; dlPFC, dorsolateral prefrontal cortex; DS, dorsal striatum; GP, globus pallidus; HPC, hippocampus; OFC, orbitofrontal cortex; PAG, periaqueductal gray; Thal, thalamus; vlPFC, ventrolateral prefrontal cortex; vmPFC, ventromedial prefrontal cortex. [Modified with permission from Koob and Volkow (2010)].

From a physiologic perspective, entrance into the three-stage cycle at any stage can engage neuroadaptations that lead to hyperkatifeia. The argument here is that such engagement ultimately triggers a break from hedonic homeostasis and subsequent compensatory responses in brain reward and stress systems to generate the withdrawal/negative affect stage (Koob and Le Moal, 1997). Although all drugs of abuse have positive reinforcing properties, the termination of drug taking inevitably leads to negative emotional states of acute and protracted withdrawal in the withdrawal/negative affect stage, which generates a second motivational drive from negative reinforcement. Negative reinforcement can be defined as an increase in the probability of a response that is produced by the removal of an aversive event. Here, negative reinforcement becomes the source of motivation for drug seeking as the individual works to reduce, terminate, or prevent the negative emotional state or hyperkatifeia of drug withdrawal.

From a nosology perspective, substance use disorders are now considered spectrum disorders as described by the Diagnostic and Statistical Manual of Mental Disorders, 5th edition (DSM-5; American Psychiatric Association, 2013), which provides a framework for the intensity of symptoms with regard to the number of symptoms that are presented by the individual. Consistent with the spectrum and allostatic framework, an individual can enter the addiction cycle at different stages. Classically, with opioids and alcohol, individuals with a substance use disorder may start with recreational use of the drug during the binge/intoxication stage and progress to the withdrawal/negative affect stage as negative reinforcement evolves (Koob et al., 2019; Fig. 2). However, much of the misuse of opioids and alcohol also develops because negative reinforcement may be the initial starting point either via selfmedication or chronic pain (Ballantyne et al., 2019).

The classic drugs of addiction are opioids and alcohol. The pattern of misuse for each encompasses most of the patterns that are observed with other drugs of abuse. For this reason and because elements of hyperkatifeia have been extensively studied in opioid and alcohol addiction, the focus of this review is on these two drugs. In opioid addiction or OUD, drug use includes intense initial intoxication that is associated with intravenous or smoked drug intake, followed by the development of profound tolerance and the consequent escalation of intake. An inability to obtain the drug and the resulting abstinence results in physical discomfort, somatic signs of withdrawal, and profound hyperkatifeia. Hyperkatifeia, which often precedes somatic signs of withdrawal, signals pronounced preoccupation with obtaining opioids (craving). Craving in OUD is linked to stimuli that are associated with obtaining the drug and stimuli that are associated with withdrawal and internal and 


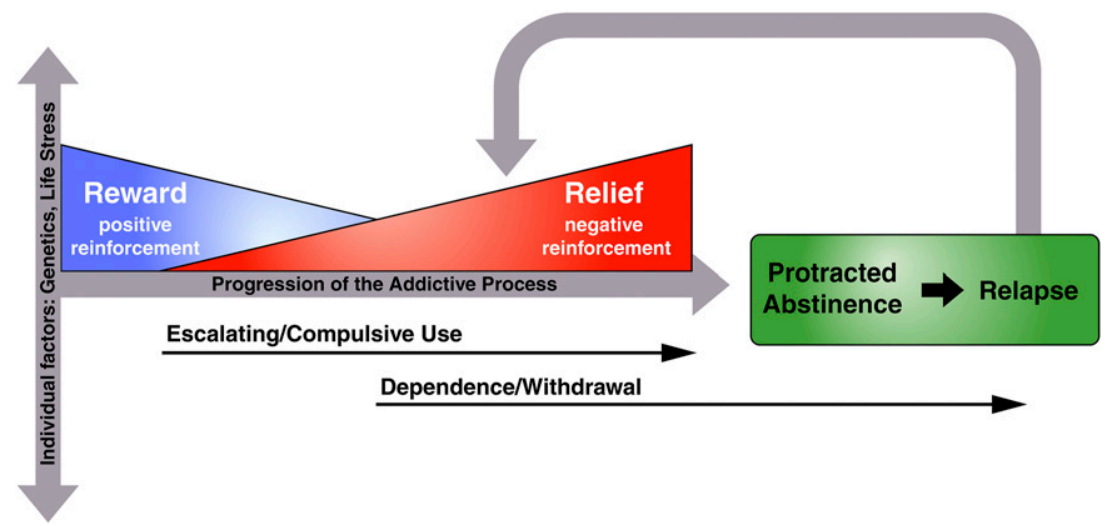

Fig. 2. Conceptual framework of sources of reinforcement in addiction. Positive reinforcement, in which the drug typically engenders positive hedonic effects, is defined as an increase in the probability of responding that is produced by the presentation of a drug. Positive reinforcement is associated with the early stages of addiction as part of the binge/intoxication stage but persists throughout the addiction cycle. Negative reinforcement is defined as an increase in the probability of responding for a drug to relieve hyperkatifeia or stress, in which drug withdrawal during the withdrawal/negative affect stage of the addiction cycle typically engenders hyperkatifeia and stress. Both sources of reinforcement can coexist and be perpetuated by protracted abstinence and cue-, drug-, and stress-induced reinstatement in the preoccupation/anticipation stage of the addiction cycle. [Figure modified from an original diagram from Dr. Loren Parsons].

external states of stress. A classic pattern evolves in which the individual must administer the drug to avoid the severe dysphoria and discomfort that are associated with abstinence (Koob et al., 2019).

In alcohol addiction or AUD, a broader spectrum of drug misuse evolves that can range from binges of alcohol intake that can be daily episodes or prolonged days of heavy drinking to constant drinking for fear of withdrawal, similar to opioids. A binge can be defined as consuming five standard drinks for males and four standard drinks for females in a 2-hour period or obtaining a BAL of $0.08 \mathrm{~g} \%$ (National Institute on Alcohol Abuse and Alcoholism, 2004). Many individuals with AUD continue with a binge/withdrawal pattern for extended periods; for others, the pattern evolves into an opioid-like substance use disorder, in which they must have alcohol available at all times to avoid the consequences of abstinence (Koob et al., 2019). Withdrawal from an alcohol binge or chronic high alcohol intake is characterized by a severe emotional and somatic withdrawal syndrome and intense craving for alcohol that is often driven by both negative emotional states and positive emotional states, similar to opioids. The hypothesis in this review is that neural substrates of hyperkatifeia are a driving force of addiction, are multidetermined components of key motivational neurocircuits, and have been largely neglected in the search for pharmacotherapies for addiction.

\section{B. Hyperkatifeia Versus Physical Withdrawal}

Historically, the terms withdrawal and dependence have been defined differently in different contexts and have led to significant confusion. Withdrawal can be defined simply as abstinence from or the removal of chronic drug use, usually characterized by signs and symptoms that are opposite to the acute effects of the drug (Koob et al., 2019). Withdrawal from drugs of abuse is one symptom of what is defined symptomatically as substance use disorder in the DSM-5 and Drug Dependence in the International Statistical Classification of Diseases and Related Health Problems, 10th revision (World Health Organization, 1992). The word dependence, though, has multiple meanings. Dependence is defined as the manifestation of a withdrawal syndrome upon the cessation of drug use. Under this definition, any drug, even drugs without abuse potential, can produce dependence. However, the term dependence was also part of the diagnostic term "substance dependence" in the DSM-IV (American Psychiatric Association, 1994) and remains part of the International Statistical Classification of Diseases and Related Health Problems terminology for "drug dependence" (World Health Organization, 1992). Dependence was initially defined as "an arbitrary term used to denote the presence of an acquired abnormal state wherein the regular administration of adequate amount of a drug has, through previous prolonged use, become requisite to physiologic equilibrium. Since it is not yet possible to diagnose physical dependence objectively without withholding drugs, the sine qua non of physical dependence remains the demonstration of a physical abstinence syndrome" (Himmelsbach, 1943).

This authoritative definition evolved into the definition of physical dependence, an intense physical disturbance when drug use is discontinued. Psychologic dependence was later defined as a "condition in which a drug produces a feeling of satisfaction and a psychic drive that require periodic or continuous administration of the drug to produce pleasure or to avoid discomfort" (Eddy et al., 1965).

However, both somatic and psychologic symptoms are mediated by physiological changes in the body and brain, but the argument here is that the symptoms that are associated with hyperkatifeia have significantly 
more motivational significance than somatic signs of withdrawal (Koob, 2019). Physical symptoms of withdrawal are reflected by signs and symptoms of a physical nature that are usually opposite to the acute effects of the drug itself. For example, with opioids, pupillary dilation is a telltale sign of opioid withdrawal, whereas pupillary constriction is a telltale sign of opioid intoxication. Similarly, for alcohol, sympathetic-like responses, such as hyperthermia, indicate withdrawal, whereas hypothermia characterizes acute intoxication. However, from the perspective of negative reinforcement, drug seeking and craving that are associated with acute and protracted abstinence are key to the thesis outlined herein, in which somatic measures of withdrawal can be an index of dependence but do not always reflect the more motivational measures of withdrawal or hyperkatifeia. Notably, however, hyperkatifeiaassociated symptoms of withdrawal generally have an earlier onset and are manifested at lower doses of chronic drug intake.

Under this framework in the withdrawal/negative affect stage, the manifestation of a withdrawal syndrome after the cessation of chronic drug administration can be defined not only in terms of the classic "physical" signs of withdrawal but more importantly in terms of motivational aspects of dependence, such as the emergence of hyperkatifeia when access to the drug is prevented. The emphasis on motivational aspects of withdrawal has been largely ignored, but some theoreticians have actually argued that the development of such a negative affective state can define dependence as it relates to addiction: "The notion of dependence on a drug, object, role, activity or any other stimulus-source requires the crucial feature of negative affect experienced in its absence. The degree of dependence can be equated with the amount of this negative affect, which may range from mild discomfort to extreme distress, or it may be equated with the amount of difficulty or effort required to do without the drug, object, etc." (Russell, 1976).

Thus, the conceptual framework herein focuses on hyperkatifeia in AUD and OUD (Koob, 2019). Several medications that target hyperkatifeia have been approved by the U.S. Food and Drug administration for the treatment of AUD and OUD. For alcohol, these treatments are limited to acamprosate. For opioids, they are mostly drugs that are opioids themselves and substitute for opioids. The present review explores the rich neurobiology of hyperkatifeia in the context of animal models of opioid and alcohol addiction, with a focus on neuroadaptations that break with homeostasis and can possibly be reversed to facilitate recovery from addiction.

\section{Opponent Process}

The theoretical basis of hyperkatifeia as a driving force in negative reinforcement in addiction has its roots in opponent process theory. Early theorists argued that counteradaptations can explain the physiological (physical, somatic) effects of opioid withdrawal in the domain of body temperature (Himmelsbach, 1943; Martin, 1968). Later, counteradaptations were invoked to explain how the initial acute hedonic effects of a drug are opposed or counteracted by homeostatic changes in systems that mediate the primary effects of the drug (Solomon and Corbit, 1974; Siegel, 1975; Poulos and Cappell, 1991). A key theory that was proposed was called opponent process theory (Solomon and Corbit, 1973, 1974; D'Amato, 1974; Hoffman and Solomon, 1974; Solomon, 1980; Koob and Bloom, 1988). In fact, opponent process theory was not only argued to be a counteraction to the hedonic actions of drugs of abuse; it was also argued to be a general phenomenon that is associated with hedonic breaks with homeostasis, including fear conditioning, tonic immobility, ulcer formation, eating disorders, jogging, peer separation, glucose preference, and even skydiving (Solomon and Corbit, 1973, 1974; Hoffman and Solomon, 1974; Solomon, 1980).

In opponent process theory, many affective control mechanisms in the brain are hypothesized to serve as an emotional stabilization system that counteracts or opposes departures from emotional neutrality or equilibrium, regardless of whether they are aversive or pleasant (Solomon and Corbit, 1974). A negative feedforward control construct was theorized that keeps mood in homeostatic balance, even with strong perturbations. Under this framework, the first, initial use of a drug triggers a primary affective process (a positive hedonic process), termed the "a-process," which has a short time constant. The signal from the a-process triggers an opposing "b-process," which responds with a slow rise and slow decay. Here, the b-process presents as a negative emotional state and is described as intensely aversive (Solomon and Corbit, 1974). This opponent process reduces the hedonic intensity of the a-process (i.e., the state that the input initially activated). The two opposing responses are temporally linked (a triggers b), with the b-process subtracting the impact of the already existing a-process. With repeated stimulation (e.g., drug taking), the b-process is strengthened so that it has a faster onset and greater intensity and takes longer to decay (Solomon and Corbit, 1974). As discussed by Solomon and Corbit (1974), the quickest and possibly most effective way of removing the b-process is to produce the a-process by taking the drug again. However, this leads to further strengthening of the b-process and the necessity to increase the amount of drug that is needed to remove the b-process. Masking of the a-process results in what has been termed "apparent tolerance" (Colpaert, 1996; Laulin et al., 1999). This resulting tolerance produces more drug taking to remove the b-process and thus engages the addictive cycle (Solomon and Corbit, 1974). 
Indeed, data indicate that if the dedvelopment of the bprocess is blocked, then tolerance does not develop.

Under this framework, development of the b-process reflects the development of hyperkatifeia (or a constellation of negative emotional withdrawal symptoms), masked at least initially by the hedonic properties of the drug. As the opponent b-process grows, such symptoms as dysphoria, anxiety, alexithymia, irritability, sleep disturbances, physical and emotional pain, subjective feelings of unease, and simply not feeling hedonically normal become manifest. This hypernegative emotional state, termed hyperkatifeia, is hypothesized to sensitize with repeated drug exposure and withdrawal. Hyperkatifeia can be considered an emotional parallel to hyperalgesia (i.e., greater sensitivity to physical pain) that is observed with repeated administration of chronic opioids and alcohol (Shurman et al., 2010; Koob, 2019). In terms of the motivation for drug seeking, a new source of acquired motivation is generated, termed negative reinforcement (Ahmed and Koob, 2005). As a result, a greater amount and more frequent use of the previously rewarding drug is needed to maintain or approach euthymia (i.e., tolerance).

\section{Validation of the Hyperkatifeia Construct in Humans}

Several lines of evidence, ranging from a factor analysis of responses on self-report measures and neuropsychological tests in humans with AUD to a connectome imaging study in mice, have validated the importance of the hyperkatifeia construct as a key stage in the development and maintenance of AUD and other substance use disorders. In an attempt to translate the research domain framework to a clinical framework, a study was performed with the goal of translating and reverse-translating knowledge that has been derived from animal models of AUD and substance use disorders to the human condition via measures of neurobiological processes that are orthologous in animals and humans and that are shared in AUD and substance use disorders (Kwako et al., 2016). Thus, the hypothesis was that measures of three neuroscience-based functional domains (incentive salience, negative emotionality, and executive function) could capture many of the effects of heritability and early exposure that lead to trait vulnerability that is shared across different addictive disorders. A further hypothesis was that measures of these domains in a general framework of an Addictions Neuroclinical Assessment have the possibility to transform the assessment and nosology of addictive disorders and can be informative for staging disease progression. A subhypothesis was that a focus on negative emotionality and stress may serve as a bridge to a reformulation of the addiction nosology to better capture individual differences in patients for whom the withdrawal/negative affect stage drives compulsive drug taking (Kwako and Koob, 2017). Using the Addictions Neuroclinical
Assessment, five subdomains of negative emotional states that can be operationally measured in human laboratory settings and paralleled by animal models were outlined (Kwako et al., 2016). In a subsequent study, the three neurofunctional domains that were proposed to be critical for the addiction cycle (incentive salience, negative emotionality, and executive function) were validated using a factor analysis of a deeply phenotyped clinical sample (Kwako et al., 2019; Fig. 3). Clinical, behavioral, and self-report measures of addiction, personality, cognition, behavior, and exposure to early life stress were collected as part of a screening and natural history study of AUD in 454 individuals who represented the spectrum of alcohol use and AUD. A three-factor model generally demonstrated a good fit with the assessment measures, and the factors closely aligned with the Addictions Neuroclinical Assessment domains of incentive salience, negative emotionality, and executive function.

Note that a similar theoretical framework has been proposed for compulsive eating, in which habitual overeating, overeating to relieve a negative emotional state, and overeating despite aversive consequences reflect the three functional domains that are outlined in drug addiction (Moore et al., 2017, 2019). Such a framework has generated significant evidence to suggest that powerful nondrug reinforcers, such as food, can also dysregulate the same motivational constructs and circuits that are outlined herein.

\section{Validation of the Hyperkatifeia Construct in a Molecular-Neurocircuitry Study in an Animal Model}

To delineate the neurocircuits that are involved in the role of $\mu$-opioid receptor tone in controlling aversion/ pain, key symptoms of hyperkatifeia, a connectome imaging study that used a hypothesis-free analysis of combined resting-state functional magnetic resonance imaging diffusion tractography was conducted. The authors showed that $\mu$-opioid receptor gene (Oprm1) inactivation produced dramatic changes in aversion/ pain-related connectivity and less so in reward connectivity (Mechling et al., 2016). Direct statistical intergroup comparisons and an analysis of changes in hub status indicated a reshaping of networks that are known to process information of negative valence. The negative valence network that evolved included such structures as the periaqueductal gray, hippocampus, amygdala, cingulate cortex, median raphe, and habenula (Mechling et al., 2016). Behavioral differences in Oprm1 mutant mice compared with wild-type mice showed that pain and emotional-like and rewardrelated behaviors correlated predominantly with alterations within reward/aversion pathways (Kieffer and Gaveriaux-Ruff, 2002). The authors hypothesized that under resting-state conditions, the results may reflect stronger inhibitory $\mu$-opioid receptor tone or a developmental influence on negative affect neurocircuits. 


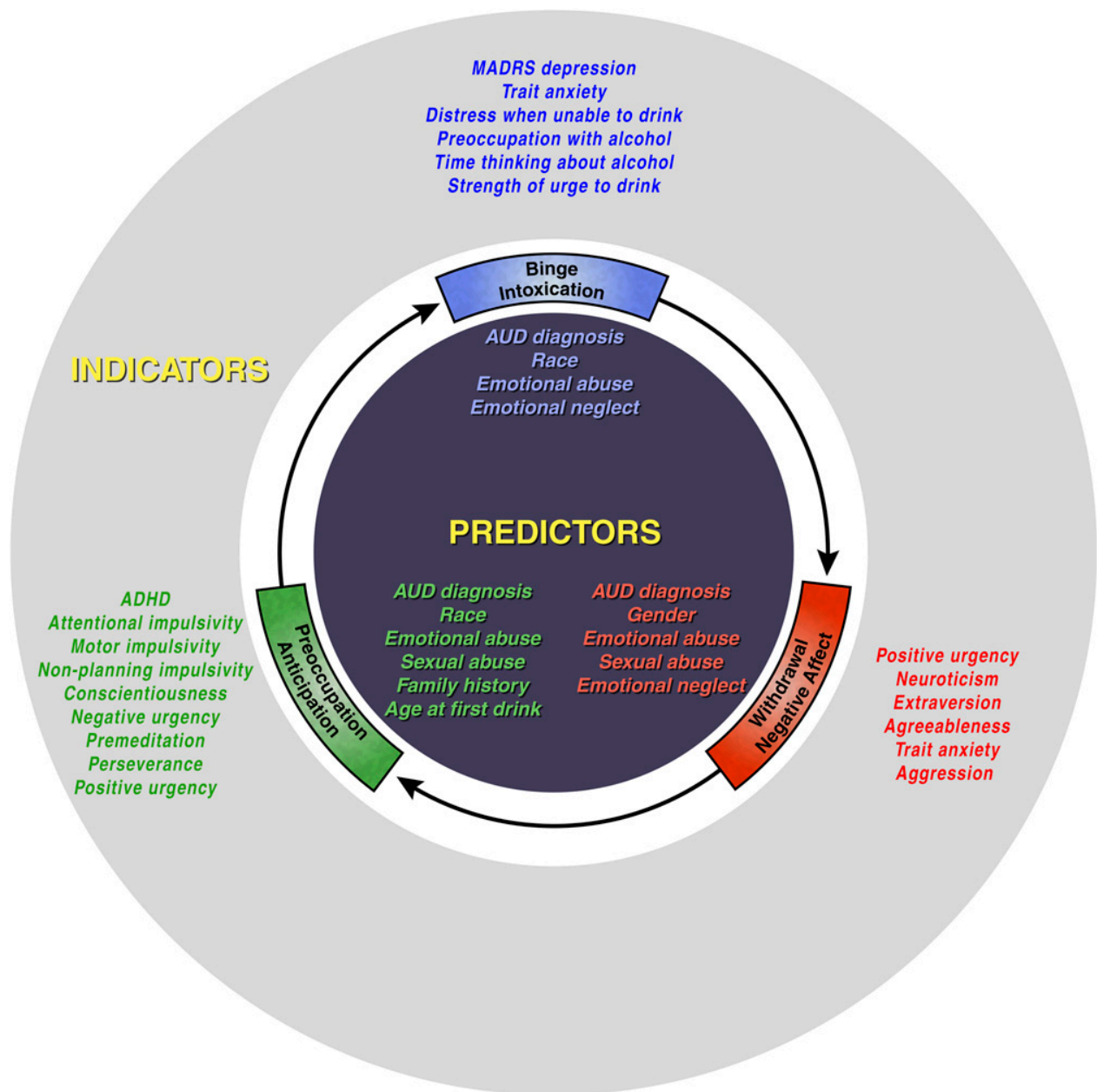

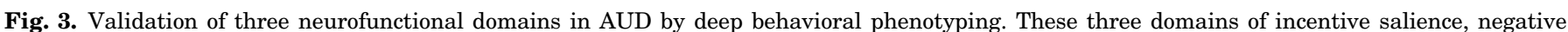

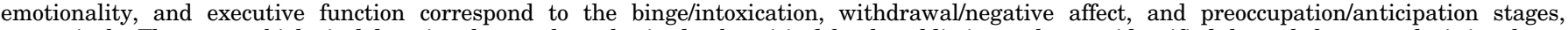

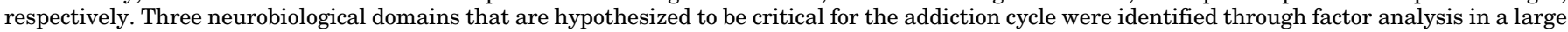

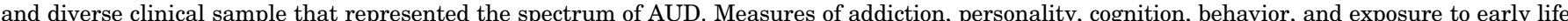

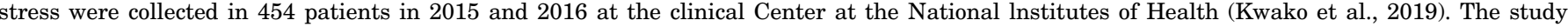

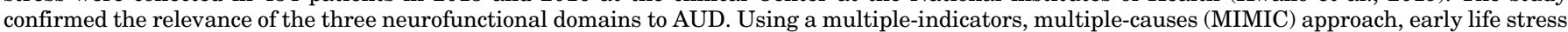

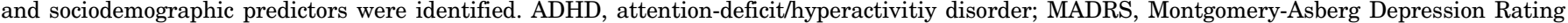
Scale. [Figure based on results of Kwako et al. (2019)].

\section{Within-System/Between-System Neurobiological Substrates for Hyperkatifeia Associated with Opioid and Alcohol Withdrawal}

\section{A. Within-System Neurocircuits}

From the perspective of self-regulation theory, opponent process-driven hyperkatifeia sets up misregulation in which subjects take more drug to alleviate hyperkatifeia, which paradoxically drives more hyperkatifeia. Under this framework, substance use is compulsively escalated or renewed (in relapse) via negative-reinforcement mechanisms because it transiently prevents or relieves negative emotional symptoms or hyperkatifeia (Koob and Le Moal, 1997).

Little work has explored the neurobiological basis of opponent processes. Solomon (1980) hypothesized possible roles for endogenous opioid peptides and the hypothalamic-pituitary-adrenal (HPA) axis. What follows is what we know about the neurobiology of the b-process, taken from the neurobiology of motivational aspects of drug withdrawal, and how these neurocircuits form a rich substrate for pharmaceutical treatment of a neglected but key component of addiction. Thus, the argument in this review is that there are elements of drug withdrawal and repeated, chronic drug intake that are expressed in common elements across different drugs of abuse.

Key components of hyperkatifeia are dysphoria and malaise, reflected by a decrease in brain reward function and an increase in brain and hormonal stress responses. Rapid acute tolerance and opponent process-like actions against the hedonic effects of psychostimulants have been reported in humans (Breiter et al., 1997). Indeed, in opponent process theory, tolerance and dependence are inextricably linked, in which the hedonic effects of the drug subside, and the b-process gets progressively larger over time, in effect contributing to or producing more 


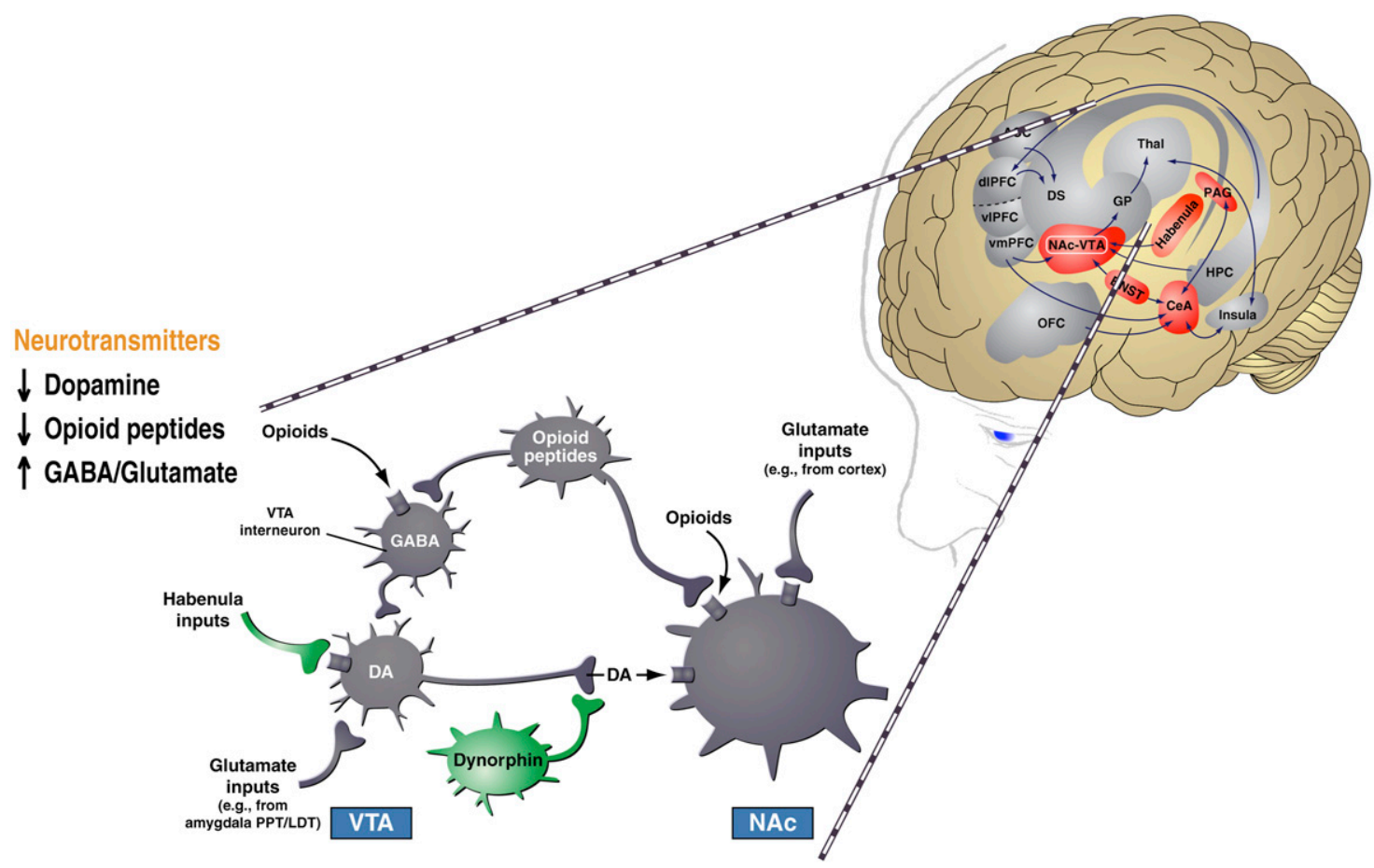

Fig. 4. Within-system neurocircuitry associated with hyperkatifeia in the withdrawal/negative affect stage. Note the loss of dopamine and opioid peptide function in ventral tegmental area-nucleus accumbens circuitry, with a hypothesized contribution of the habenula that suppresses neuron activity in the ventral tegmental area and dynorphin that suppresses dopamine release in the nucleus accumbens. The extended amygdala is composed of several basal forebrain structures, including the bed nucleus of the stria terminalis, the central nucleus of the amygdala, and possibly a transition area in the medial portion (shell) of the nucleus accumbens. ACC, anterior cingulate cortex; DA, dopamine; dlPFC, dorsolateral prefrontal cortex; DS, dorsal striatum; GP, globus pallidus; HPC, hippocampus; LDT, laterodorsal tegmentum; OFC, orbitofrontal cortex; PAG, periaqueductal gray; PPT, pedunculopontine tegmentum; Thal, thalamus; vlPFC, ventrolateral prefrontal cortex; vmPFC, ventromedial prefrontal cortex; VTA, ventral tegmental area. [Adapted with permission from Koob (2008); George and Koob (2013)].

complete tolerance to the initial euphoric effects of the drug.

Brain reward systems that involve connections between the medial forebrain bundle and such structures as the ventral tegmental area (VTA) and ventral striatum are compromised during withdrawal from drugs of abuse (Koob and Le Moal, 2005). All major drugs of abuse produce elevations of reward thresholds (measured by intracranial self-stimulation) during withdrawal from either chronic drug administration or in animal models of drug self-administration with extended access. Such elevations have been observed in studies of alcoholdependent animals (Schulteis et al., 1995), extended access to cocaine self-administration (Ahmed et al., 2002), methamphetamine self-administration (Jang et al., 2013a), heroin self-administration (Kenny et al., 2006), and nicotine self-administration (Harris et al., 2011).

A conceptual framework that was adopted to explain the neural systems that mediate the long-hypothesized opponent process adaptation to excessive reward system engagement and drive negative reinforcement involved the within-system downregulation of brain reward circuitry and the between-system recruitment of brain stress circuitry (Koob and Bloom, 1988). Within-system neuroadaptations were defined as the process by which the primary cellular response to the drug within a given neurochemical circuit itself adapts to neutralize the effects of the drug. Much of the work on within-system neuroadaptations has focused on the mesolimbic dopamine system that projects from the VTA to the nucleus accumbens (NAc; Fig. 4). Significant evidence has also emerged for a role for the lateral habenula-VTA circuit in driving aversive responses to the loss of reward and mediating and encoding aversive states (Hikosaka, 2010). The lateral habenula may play a role in modulating motivated behavior and addiction by modulating dopamine neurotransmission via actions on dopamine neurons in the VTA (Hikosaka, 2010; Velasquez et al., 2014; Boulos et al., 2017). Neurons in the lateral habenula fire in response to the presentation of unexpected aversive events (Matsumoto and Hikosaka, 2007). The unexpected delivery of rewards caused inhibition of the lateral habenula, consistent with an aversive role for activation of the habenula (Matsumoto and Hikosaka, 2007). Consistent with these observations, electrical stimulation of the lateral habenula output caused conditioned place aversions (Stamatakis and Stuber, 2012). Finally, a local dynorphin circuit in the NAc has been hypothesized to be activated and ultimately contribute to the hypodopaminergic state of opioid and alcohol withdrawal (Carlezon et al., 2000).

\section{B. Between-System Neurocircuits}

In contrast, between-system neuroadaptations were defined as circuitry changes in which other circuits 


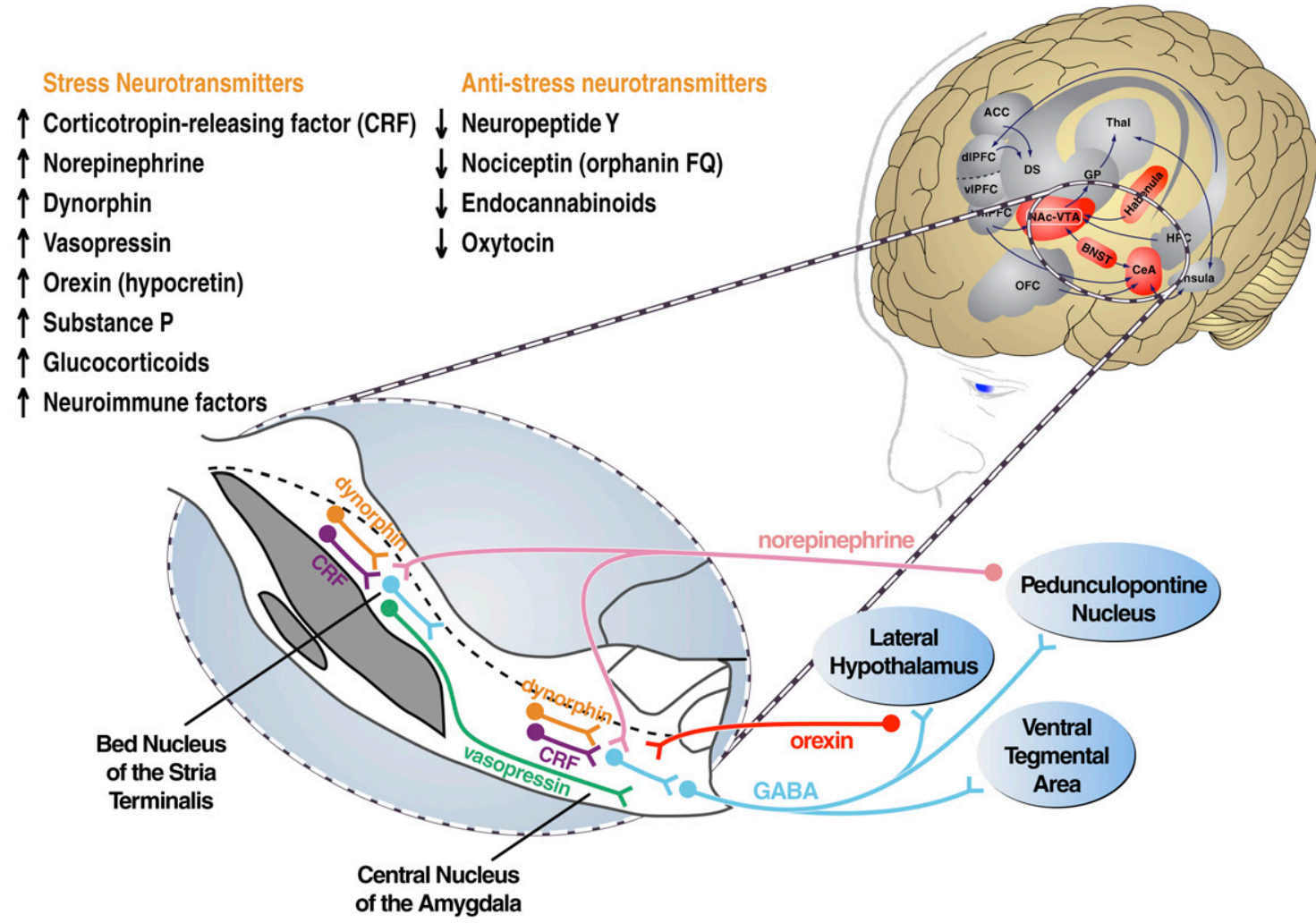

Fig. 5. Between-system extended amygdala circuitry associated with hyperkatifeia in the withdrawal/negative affect stage. Note the gain of stress neurotransmitter and neuromodulator function and the loss of antistress neurotransmitter and neuromodulator function throughout the neurocircuitry of the extended amygdala. The extended amygdala is composed of several basal forebrain structures, including the bed nucleus of the stria terminalis, the central nucleus of the amygdala, and possibly a transition area in the medial portion (shell) of the nucleus accumbens. ACC, anterior cingulate cortex; dIPFC, dorsolateral prefrontal cortex; DS, dorsal striatum; GP, globus pallidus; HPC, hippocampus; OFC, orbitofrontal cortex; Thal, thalamus; vlPFC, ventrolateral prefrontal cortex; vmPFC, ventromedial prefrontal cortex; VTA, ventral tegmental area. [Taken with permission from George and Koob (2013)].

(i.e., stress or antireward circuits) are activated to oppose overactivity in reward circuits. Subsequently, the focus of between-system neuroadaptations fell on understanding neurocircuitry within the extended amygdala and its role in opponent process, more specifically hyperkatifeia (Koob and Bloom, 1988; Koob and Le Moal, 2008; Koob, 2019).

The extended amygdala comprises several basal forebrain structures, including the bed nucleus of the stria terminalis (BNST), central nucleus of the amygdala (CeA), sublenticular substantia innominata, and a transition zone in the shell of the NAc (Heimer and Alheid, 1991). The regions that comprise the extended amygdala have cytoarchitectural and circuitry similarities with each other (Heimer and Alheid, 1991). Afferents to the extended amygdala come from brain structures that are involved in emotion, such as the basolateral amygdala and hippocampus, and the extended amygdala sends efferents to the medial part of the ventral pallidum and a large projection to the lateral hypothalamus (Alheid et al., 1995; Fig. 5). The extended amygdala has long been hypothesized to play a key role in fear, anxiety, and stress (Le Doux, 2000; Shackman and Fox, 2016) and also in the emotional component of pain processing (Neugebauer et al., 2004). The extended amygdala has been hypothesized to be a key link that defines specific brain areas that interface classic structures that are involved in emotion with classic structures that are involved in motor action and motivation, such as the extrapyramidal motor system (Alheid et al., 1995).

\section{Within-System Neurobiological Substrates for Hyperkatifeia Associated with Opioid and Alcohol Withdrawal}

\section{A. Within-System Neuroadaptations: Dopamine}

The mesolimbic dopamine system has historically been hypothesized to mediate the reinforcing effects of drugs of abuse. As more studies evolved, however, it became clear that although the mesolimbic dopamine system is critical for the reinforcing actions of drugs, such as cocaine and amphetamines, other drugs of abuse, such as opioids and alcohol, can activate the mesolimbic dopamine system and exert actions on reward circuits independent of dopamine release (Wise and Koob, 2014). Nevertheless, what is also evident is that the mesolimbic dopamine system becomes compromised after the chronic administration of virtually all drugs of abuse, including opioids and alcohol (Koob and Volkow, 2010; Diana, 2011). Such within-system neuroadaptations 
can take on many forms, including changes in receptors, transduction mechanisms, local circuits, and modulatory circuits, such as the habenula-VTA aversion circuit.

For opioids at the neurocircuitry level, a prominent neuroadaptation is the loss of dopaminergic function in the mesolimbic dopamine pathway, which is hypothesized to contribute to hedonic tolerance and the hypohedonia that is associated with opioid withdrawal (see Fig. 4). In animal models, early studies showed that precipitated opioid withdrawal decreases extracellular dopamine levels in the NAc and mesolimbic dopamine system (Pothos et al., 1991; Rossetti et al., 1992) and decreases dopamine neuron firing in the VTA (Diana, 2011). In humans, positron emission tomography imaging studies reported lower baseline dopamine $\mathrm{D}_{2}$ receptor availability in the dorsal striatum in psychostimulant abusers and opioid-dependent subjects compared with control subjects (Wang et al., 1997; Ashok et al., 2017). In another study, the decrease in $\mathrm{D}_{2}$ receptor availability in the striatum was negatively correlated with years of opioid use (Zijlstra et al., 2008).

For alcohol, both the mesocorticolimbic dopamine system and endogenous opioid system have been hypothesized to contribute to the mechanisms that mediate acute alcohol reinforcement (Lewis, 1996). In humans, consistent with animal studies, oral doses of alcohol increased extracellular dopamine concentrations during intoxication in healthy volunteers, based on positron emission tomography measures (Boileau et al., 2003; Urban et al., 2010).

Dopaminergic function is also compromised during acute alcohol withdrawal in animal models of chronic administration or compulsive-like drinking (Diana et al., 1993; Weiss et al., 1996). Animals that were subjected to alcohol withdrawal after the intragastric delivery of a dose of $2-5 \mathrm{~g} / \mathrm{kg}$ every 6 hours for six consecutive days, based on the method of Majchrowicz (1975), exhibited a dramatic decrease in extracellular dopamine, measured by microdialysis, that correlated with withdrawal scores (Diana et al., 1993). In a study in which animals were sustained on an alcohol liquid diet that was sufficient to produce dependence, a decrease in extracellular dopamine levels was observed in the NAc during withdrawal (Weiss et al., 1996). When the animals were allowed to self-administer alcohol during acute withdrawal, they self-administered just enough alcohol to return extracellular dopamine levels in the NAc back to predependence baseline levels (Weiss et al., 1996). Substantial electrophysiological data suggest profound neuroadaptations in both the origins and terminals of the mesocorticolimbic dopamine system with chronic alcohol that drive these changes (Diana et al., 1993, 2003; Bailey et al., 2001).

In humans, dopamine dysfunction has also been repeatedly observed in detoxified alcohol-dependent subjects using brain imaging (Volkow et al., 1996, 2002, 2007; Kuikka et al., 2000). Similar to other drugs of abuse, studies that employed positron emission tomography and single-photon emission computed tomography using $\mathrm{D}_{2}$ or $\mathrm{D}_{2} / \mathrm{D}_{3}$ receptor ligands showed that $\mathrm{D}_{2}$ receptor expression was lower in the temporal cortex and striatum in subjects with AUD (Volkow et al., 1996; Kuikka et al., 2000). When detoxified individuals with AUD were tested using positron emission tomography combined with $\left[{ }^{11} \mathrm{C}\right]$ raclopride, a $\mathrm{D}_{2} / \mathrm{D}_{3}$ receptor ligand with binding that is sensitive to endogenous dopamine in the basal ganglia, challenges with the stimulant drug methylphenidate failed to produce the increases in endogenous dopamine levels that were associated with the stimulant effects of methylphenidate (Volkow et al., 2007).

Another mechanism to explain the hypodopaminergic state is that opioids, psychostimulants, and alcohol activate dynorphin, particularly in the shell of the NAc, triggered by a cascade of molecular events that involve cAMP-to-dynorphin activation (Carlezon et al., 2000; Chavkin and Koob, 2016).

\section{B. Within-System Neuroadaptations: Enkephalin/ Endorphin Opioid Peptides}

For the acute effects of opioid drugs, G proteins are activated through the $\mu$-opioid receptor and modulate the activity of several second messengers and cellular effectors that generate both short-term and long-term neuroadaptations that are relevant to a blunted hedonic response to the drug (i.e., tolerance; Cahill et al., 2016). Other molecular/cellular events, in addition to $\mathrm{G}$ protein signaling cascades, contribute to decreases in $\mu$-opioid receptor signaling, including receptor desensitization, receptor internalization, transcriptional changes, and structural changes, such as dendritic spine remodeling (Sugiura et al., 2009; Al-Hasani and Bruchas, 2011; Williams et al., 2013). Within-system neuroadaptations that produce both hyperkatifeia and consequently apparent tolerance at the cellular level may be the sum of these multiple events (Cahill et al., 2016).

From a medication development perspective, accumulating evidence suggested that different effects of $\mu$-opioid receptor agonists may be mediated by different transduction pathways that are linked to the $\mu$-opioid receptor (Raehal and Bohn, 2014). Mutant mice that lacked arrestin 3 ( $\beta$-arrestin 2 ) exhibited greater analgesia but significantly less antinociceptive tolerance, physical dependence, constipation, and respiratory suppression in response to morphine (Raehal and Bohn, 2014). These observations led to the hypothesis that drugs could be developed that activate $\mu$-opioid receptors without activating the arrestin 3 signal transduction cascade and by extrapolation result in less receptor internalization and desensitization, higher analgesic potential, and lower respiratory depression (Raehal and Bohn, 2014). Moreover, the effects on fentanyl tolerance 
and dependence, a high receptor-internalizing agonist, were unaltered in mice that lacked arrestin 3 ( $\beta$-arrestin 2; Raehal and Bohn, 2014). Non-arrestinactivating drugs produced more potent analgesia and less tolerance, but they produced more gastrointestinal side effects (e.g., constipation; Altarifi et al., 2017). Thus, data to date suggest that such non-arrestin 3signaling drugs retain undesirable constipating and abuse-related effects with repeated exposure, despite their bias for $\mathrm{G}$ protein signaling (Altarifi et al., 2017).

For alcohol, endogenous enkephalin/endorphin opioid peptide systems have long been hypothesized to play a role in their reinforcing effects (Nutt, 2014), but there is some evidence of a direct role for within-system changes in $\mu$-opioid receptor transduction mechanisms. Indeed, molecular changes in the cAMP system are classically opposite to changes that are associated with opioids but nevertheless provide an example of withinsystem changes of motivational significance, albeit in other structures, such as the extended amygdala. Acute alcohol potentiates receptor-activated cAMP production, but chronic exposure to alcohol decreases cAMPprotein kinase $\mathrm{A}$ activity and a decrease in cAMP response element binding protein (CREB) phosphorylation (Gordon et al., 1986). Lower phosphorylated CREB in the CeA and medial nucleus of the amygdala is associated with anxiety-like responses during withdrawal and an increase in alcohol self-administration. Alcohol-preferring Indiana $\mathrm{P}$ rats have lower levels of phosphorylated CREB in the CeA and medial nucleus of the amygdala (Pandey et al., 2003, 2004; Pandey, 2004). These decreases in CREB activity have been associated with a decrease in neuropeptide Y (NPY; see below), linking within-system molecular changes with betweensystem neurotransmitter circuit changes.

\section{Within-System Neuroadaptations: GABA and Glutamate}

GABA and glutamate are ubiquitous neurotransmitter systems throughout the neuraxis that have long been associated with neuroadaptations that are associated with the chronic use of opioids and alcohol (Hwa et al., 2017; Roberto and Varodayan, 2017). For opioids, a transient increase in GABA neuronal activity in the VTA may explain the loss of dopaminergic function with chronic opioids. A prominent observation is a chronic opioid-induced cAMP-dependent increase in the probability of GABA release in the VTA, which would inhibit dopamine neurons (Bonci and Williams, 1997). Notably, however, GABA tone returns during protracted abstinence (Bonci and Williams, 1996). Consistent with these preclinical results is a human positron emission tomography imaging study that showed that in recently abstinent male opioid-dependent subjects, a decrease in $\mathrm{D}_{2}$ receptor binding and anhedonia were observed, but higher dopamine release was found in the striatum after cue exposure (Zijlstra et al., 2008), suggesting that craving that is produced by hypohedonia and craving that is produced by cues can coexist, albeit at different time points of opioid addiction.

For opioids, the noncompetitive glutamate receptor antagonist MK-801 blocked the expression of withdrawal signs that were precipitated by naloxone in opioid-dependent animals (Tanganelli et al., 1991; Tokuyama et al., 1996), suggesting a hyperglutamatergic contribution to opioid withdrawal. In an animal model of long-lasting hyperalgesia after exposure to heroin, a noncompetitive glutamate receptor antagonist reversed hyperalgesia (Laulin et al., 1998). A noncompetitive glutamate receptor antagonist also prevented the long-lasting heroin-induced enhancement of pain sensitivity and naloxone-precipitated hyperalgesia in humans (Koppert et al., 2003).

For alcohol, both GABA and glutamate modulate its acute intoxicating effects, with GABA function being enhanced and glutamatergic function being suppressed (Roberto and Varodayan, 2017). However, chronic alcohol decreases GABA receptor function, with multiple effects on GABA receptor subunits, including downregulation of the $\alpha 1$ subunit and upregulation of the $\alpha 4$ subunit (Mhatre et al., 1993; Devaud et al., 1997). Nevertheless, subsequent work on the action of alcohol on GABA in local circuits demonstrated that alcoholexposed neurons in the VTA showed electrophysiological evidence of a higher probability of action potentialindependent GABA release after alcohol exposure, consistent with actions that would drive a hypodopaminergic state, similar to opioids (Melis et al., 2002). Similarly, in the extended amygdala, chronic alcohol exposure increased GABAergic tone in dependent animals, which was hypothesized to drive compulsive-like drinking (Roberto et al., 2008).

In contrast, alcohol withdrawal is characterized by a hyperglutamatergic state that is opposite to the acute effects of alcohol (Hwa et al., 2017). Chronic alcohol is well known to upregulate $N$-methyl-D-aspartate (NMDA) receptor function in the brain (Chandler et al., 1993; Snell et al., 1993; Roberto et al., 2004), including the upregulation of different NMDA receptor subunits with chronic alcohol and withdrawal in some brain regions (Trevisan et al., 1994; Follesa and Ticku, 1995). Competitive glutamate receptor antagonists can partially reverse the anxiogenic-like effects of alcohol withdrawal (Gatch et al., 1999).

One hypothesis is that glutamate plays a key role in sensitization or hyperexcitability that is elicited by repeated alcohol withdrawal (McCown and Breese, 1990; Stephens, 1995). Chronic acamprosate, a glutamate modulator and Food and Drug Administrationapproved treatment of AUD, blocked the alcohol deprivation effect-induced increase in drinking in rodents (Heyser et al., 1998) and blocked increases in glutamate in the brain in rats (Dahchour et al., 1998) and humans (Umhau et al., 2010; Hermann et al., 2012). 


\section{Between-System Neurobiological Substrates for Hyperkatifeia Associated with Opioid and Alcohol Withdrawal}

In addition to the above within-system neuroadaptations, other neurocircuits appear to be activated by excessive drug intake that act in hedonic opposition to reward neurotransmitter circuits [corticotropinreleasing factor $(\mathrm{CRF})$, norepinephrine, glucocorticoids, dynorphin, hypocretin, and neuroimmune factors] or act to protect against the development of hyperkatifeia (NPY, nociceptin, endocannabinoids, and oxytocin; Koob and Bloom, 1988; Koob and Le Moal, 1997; Koob, 2008). The location of the circuits that mediate hyperkatifeia to a large extent involves elements of the extended amygdala or its connections (see above and Fig. 5).

Consistent with the connectome study described above, a substantial number of neurochemical/neurocircuitry studies implicate brain stress systems in between-system neuroadaptations that contribute to hyperkatifeia, with the extended amygdala as a focal point. Much of the data show the recruitment of brain stress systems, including CRF, norepinephrine, hypocretin, dynorphin, and glucocorticoids, as major key substrates that are responsible for hyperkatifeia that is associated with drug withdrawal and thus compulsivelike drug seeking via negative reinforcement (Koob and Bloom, 1988; Koob, 2019).

\section{A. Between-System Neuroadaptations: Corticotropin- Releasing Factor}

Corticotropin-releasing factor has long been known to mediate behavioral responses to stress in addition to its role in driving the sympathetic nervous system response to stress (Koob, 1999). Corticotropin-releasing factor is a 41-amino-acid neuropeptide that mediates neuroendocrine and behavioral responses to stress (Bale and Vale, 2004). It interacts with two $\mathrm{G}_{\mathrm{s}}$ proteincoupled receptors: $\mathrm{CRF}_{1}$ and $\mathrm{CRF}_{2}$ (Bale and Vale, 2004). Corticotropin-releasing factor neurons are highly expressed in the extended amygdala and project throughout the midbrain and pons (Swanson et al., 1983).

For opioids, CRF has been implicated in hyperkatifeia that is associated with opioid withdrawal in animal models. Precipitated opioid withdrawal increases the release of CRF in the CeA (Weiss et al., 2001). The antagonism of CRF receptors in the extended amygdala blocked the aversive stimulus effects of drug withdrawal (Koob, 2015). Systemic CRF receptor antagonist and functional noradrenergic receptor antagonist administration blocked naloxone-precipitated conditioned place aversion in opioid-dependent rats (Schulteis et al., 1998; Stinus et al., 2005). Excitotoxic lesions of the basolateral amygdala abolished the robust conditioned suppression of response rates in an operant task after the presentation of a withdrawal-associated conditioned stimulus that was observed in sham-operated rats (Schulteis et al., 2000). Excitotoxic lesions of the CeA blocked the development of morphine withdrawalinduced conditioned place aversion but had less of an effect on somatic signs of withdrawal (Watanabe et al., 2002). CRF is aversive to animals and produces place aversions and elevations of reward thresholds, both of which are reversed by intracerebroventricular administration of a $\mathrm{CRF}_{1} / \mathrm{CRF}_{2}$ peptide receptor antagonist (Cador et al., 1992; Macey et al., 2000). Conditioned place aversion that was produced by precipitated opioid withdrawal was also blocked by the administration of a $\mathrm{CRF}_{1} / \mathrm{CRF}_{2}$ peptide receptor antagonist in the $\mathrm{CeA}$ (Heinrichs et al., 1995). $\mathrm{CRF}_{1}$ receptor antagonists selectively decreased heroin self-administration in long-access but not short-access rats in an animal model of extended access (Greenwell et al., 2009a). Chronic systemic administration of a CRF receptor antagonist also attenuated the escalation of heroin self-administration that was associated with extended access (Park et al., 2015).

For alcohol, early work reported that CRF was involved in hyperkatifeia that was associated with alcohol withdrawal. Alcohol withdrawal is associated with increases in the release of CRF in the CeA (Merlo-Pich et al., 1995) and BNST (Olive et al., 2002). Systemic $\mathrm{CRF}_{1}$ receptor antagonist administration blocked anxiety-like responses to alcohol withdrawal (Knapp et al., 2004; Overstreet et al., 2004b; Breese et al., 2005). Microinjections of a peptide $\mathrm{CRF}_{1} / \mathrm{CRF}_{2}$ antagonist in the CeA blocked the anxiogenic-like effects of alcohol withdrawal in rats (Rassnick et al., 1993). Intracerebroventricular or systemic CRF receptor antagonist administration also blocked the potentiation of anxiety-like responses to stressors that were observed during protracted abstinence from chronic alcohol (Valdez et al., 2003; Breese et al., 2005; Sommer et al., 2008). A CRF 1 receptor antagonist prevented the sensitization of withdrawal-induced anxiety, supporting a between-system neuroadaptation (Overstreet et al., 2004a). Additionally, systemic $\mathrm{CRF}_{1}$ receptor antagonist administration blunted the hyperalgesic response to alcohol withdrawal (Edwards et al., 2012b).

Rats drink alcohol excessively during acute and protracted abstinence from intermittent, high, sustained alcohol via a liquid diet or vapor exposure. Systemic injections of small-molecule $\mathrm{CRF}_{1}$ receptor antagonists blocked the increase in alcohol intake that was associated with acute withdrawal (Knapp et al., 2004; Overstreet et al., 2004a; Funk et al., 2007) and protracted abstinence (Gehlert et al., 2007). Corticotropin-releasing factor receptor antagonists also reduced binge-like, excessive drinking and stress-induced increases in alcohol intake (Lowery et al., 2008; Cippitelli et al., 2012; Lowery-Gionta et al., 2012; Simms et al., 2014).

The increase in alcohol self-administration that was observed in alcohol-dependent rats was also blocked by a peptide $\mathrm{CRF}_{1} / \mathrm{CRF}_{2}$ receptor antagonist that was 
directly administered in the CeA (Funk et al., 2006). Cellular studies have identified the actions of CRF on GABAergic interneurons in the CeA (Roberto et al., 2010) and CRF projections from the BNST to midbrain and hypothalamus (Vranjkovic et al., 2017; Pati et al., 2020). An optogenetic study showed that activation of CRF neurons in the CeA during alcohol withdrawal that projected to the BNST may mediate dependenceinduced excessive alcohol intake (de Guglielmo et al., 2016, 2019).

\section{B. Between-System Neuroadaptations: Norepinephrine}

Norepinephrine is a key member of the sympathetic nervous system. Ascending noradrenergic projections from the brainstem have long been implicated in stress responsivity (Koob, 2008). Norepinephrine binds to three receptor families, $\alpha_{1^{-}}, \alpha_{2^{-}}$, and $\beta$-adrenergic, and each of these has three receptor subtypes (Rohrer and Kobilka, 1998). Norepinephrine activation has long been hypothesized to be involved in opioid withdrawal in animals, based on neurobiological measures and the pharmacology of withdrawal (Maldonado, 1997), and in humans, based largely on pharmacological studies of opioid withdrawal (Gold et al., 1978; Harris and Gewirtz, 2005). Noradrenergic function is well documented to be activated during alcohol withdrawal in humans (Hawley et al., 1981). Signs and symptoms of alcohol withdrawal in humans are blocked by postsynaptic $\beta$-adrenergic receptor blockade (Romach and Sellers, 1991).

For opioids, norepinephrine has also been implicated in hyperkatifeia that is associated with opioid withdrawal in animal models. Norepinephrine inhibition with an $\alpha_{2}$-adrenergic receptor agonist blocked naloxone-precipitated conditioned place aversion in opioid-dependent rats (Kosten, 1994; Nader and Van der Kooy, 1996). An in vivo microdialysis study reported an elevation of norepinephrine release in the CeA during naloxone-precipitated morphine withdrawal (Watanabe et al., 2003). Opioid withdrawalinduced conditioned place aversion was blocked by the inhibition of noradrenergic function with an $\alpha_{2}$-adrenergic receptor agonist or $\beta$-adrenergic receptor antagonist in the BNST (Delfs et al., 2000) and by the administration of $\beta_{1}$ - and $\beta_{2}$-adrenergic receptor antagonists in the $\mathrm{CeA}$ (Watanabe et al., 2003). The $\alpha_{1}$-adrenergic receptor antagonist prazosin dose-dependently reduced intravenous heroin self-administration in long-access rats but not in short-access rats in an animal model of extended access to opioid self-administration that produces dependence (Greenwell et al., 2009b).

For alcohol, the norepinephrine metabolite 3-Methoxy4-hydroxyphenylglycol was elevated during acute withdrawal in alcohol-dependent rats (Karoum et al., 1976), and alcohol withdrawal signs were blocked in animals by $\alpha_{1}$-adrenergic receptor antagonists and $\beta$-adrenergic receptor antagonists and the selective blockade of norepinephrine synthesis (Trzaskowska and Kostowski, 1983). In dependent rats, the $\alpha_{1}$-adrenergic receptor antagonist prazosin selectively blocked the increase in drinking that was associated with acute withdrawal (Walker et al., 2008), and the $\beta$-adrenergic receptor antagonist propranolol blocked the increase in drinking that was associated with acute withdrawal in dependent rats at doses that did not block nondependent drinking (Gilpin and Koob, 2010).

Consistent with these results, a subsensitivity of $\alpha_{2^{-}}$ adrenergic receptors by $\alpha_{2}$-adrenergic receptor agonists has also been shown to be effective in blocking somatic alcohol withdrawal signs, reducing anxiogenic-like withdrawal responses and reducing alcohol intake in alcohol-preferring rodents. In an early rat study in which alcohol dependence was induced by repeated intragastric alcohol administration, clonidine suppressed withdrawal signs, whereas yohimbine, which increases norepinephrine levels, exacerbated withdrawal (Trzaskowska and Kostowski, 1983). Subsequent studies have shown that $\alpha_{2}$-adrenergic agonists decrease somatic signs of alcohol withdrawal in animal models (Parale and Kulkarni, 1986; Riihioja et al., 1997), including responses that are associated with hyperkatifeia, such as the clonidine-induced blockade of anxiogenic-like effects of alcohol withdrawal in mice (Arora and Vohora, 2016). The $\alpha_{2}$-adrenergic agonists decreased alcohol intake in Finnish Alko alcohol rats that had free-choice access to $10 \%$ alcohol and drinking water (Opitz, 1990). Clonidine also decreased voluntary alcohol drinking in Indiana alcohol-preferring $(\mathrm{P})$ rats, but it also affected saccharin intake (Rasmussen et al., 2014).

Additionally, the subsensitivity of $\alpha_{2}$-adrenergic receptors has been hypothesized to be a marker of alcohol dependence in humans (Balldin et al., 1992; Berggren et al., 2000). For example, postsynaptic $\alpha_{2^{-}}$ adrenergic receptor function was downregulated in patients not only during acute withdrawal but also during late withdrawal after heavy alcohol intake, measured by the growth hormone response to clonidine (Berggren et al., 2000). In an animal study, prolonged treatment with alcohol ( $5 \mathrm{~g} / \mathrm{kg}$ per day, orally) produced subsensitivity to clonidine's actions on protein kinase activity as measured by the inhibition of an endogenous inhibitor of protein kinase in the hippocampus, NAc, and hypothalamus in rats (Szmigielski et al., 1977, 1989).

Altogether, converging data from studies of CRF and norepinephrine suggest that both $\mathrm{CRF}$ and noradrenergic neurotransmission are enhanced during opioid and alcohol withdrawal, and CRF and noradrenergic functional receptor antagonists can block motivational aspects of opioid and alcohol withdrawal. A feedforward system of CRF-norepinephrine interactions at 
multiple levels of the pons and basal forebrain has been conceptualized in which CRF activates norepinephrine, and norepinephrine in turn activates CRF (Koob, 1999). Such an interaction may play a key role in the vulnerability and maintenance of hyperkatifeia.

\section{Between-System Neuroadaptations: Glucocorticoids}

Given that opioid withdrawal is a severely dysphoric and emotionally painful state, there is significant activation of the HPA axis stress response during opioid withdrawal (Koob and Kreek, 2007). Whereas, acutely, opioid receptor agonists inhibit the HPA axis, opioid withdrawal potently activates it (Culpepper-Morgan and Kreek, 1997; Bearn et al., 2001). Upon activation, the paraventricular nucleus of the hypothalamus (PVN) releases $\mathrm{CRF}$ that in turn stimulates the release of adrenocorticotropic hormone (ACTH) in the anterior pituitary. Adrenocorticotropic hormone stimulates the cortex of the adrenal gland to synthesize the release of corticosteroids (corticosterone in rats). Corticosteroids bind to both mineralocorticoid receptors and glucocorticoid receptors, but given that glucocorticoid receptors are low-affinity receptors for corticosteroids, they are activated only at high circulating levels of corticosteroid, such as those that are produced by intense stress. Negative feedback mechanisms inhibit HPA axis activity to terminate the acute stress response and maintain homeostasis, but intense and repeated activation of the HPA axis produces cumulative corticosteroiddependent changes in brain stress circuits (Koob and Schulkin, 2019; McEwen and Akil, 2020).

One hypothesis is that although activation of the HPA axis can feed back and shut off the HPA axis, this same activation of the HPA axis can drive neuroadaptive changes in extrahypothalamic CRF systems in the extended amygdala (Makino et al., 1994a,b; Richardson et al., 2008; Koob and Schulkin, 2019). High corticosterone decreases CRF mRNA in the PVN but increases CRF mRNA in the CeA and lateral BNST (Makino et al., 1994a,b; Albeck et al., 1997; Schulkin et al., 1998; Shepard et al., 2000).

For opioids, individuals with OUD, when subjected to acute withdrawal from heroin and methadone, exhibited persistent elevations of cortisol levels (Culpepper-Morgan and Kreek, 1997; Bearn et al., 2001), and cortisol levels correlated with withdrawal severity (Bearn et al., 2001). However, subjects with OUD while under methadone maintenance therapy exhibited lower levels of craving, withdrawal, anxiety, ACTH, and cortisol, suggesting a return of the HPA axis to homeostasis (Walter et al., 2013). In parallel and linked directly to HPA axis overactivity, opioid withdrawal activates central extrahypothalamic CRF signaling, even long into protracted abstinence, which contributes to negative emotional symptoms that are associated with opioid withdrawal, such as dysphoria and pain. Altogether, these results suggest that HPA axis activity is central to the persistence of negative emotional states during abstinence (Koob and Schulkin, 2019).

The chronic or acute blockade of glucocorticoid receptor with mifepristone prevented or reversed the escalation of heroin intake that was associated with extended access in rats, similar to the effect of a CRF receptor antagonist (see above; Carmack et al., unpublished results). The glucocorticoid receptor antagonist also blocked the opioid-induced enhancement of $\mathrm{CRF}$ neurotransmission in the amygdala (Carmack et al., unpublished results), consistent with the hypothesis that high glucocorticoids drive CRF circuitry in the CeA.

For alcohol, high comorbidity is seen between AUD and stress-associated disorders, reflected by dysregulation of the HPA axis (Boden and Fergusson, 2011; Haass-Koffler et al., 2014; Lijffijt et al., 2014). Indeed, a blunted cortisol response is commonly reported in individuals with AUD. A condition known as pseudoCushing's syndrome, manifested by high levels of corticosterone, can be observed in individuals with AUD (Kirkman and Nelson, 1988; Besemer et al., 2011).

Similar effects have been observed in animal models in which rats that are made dependent using the chronic intermittent alcohol vapor model exhibit a blunted corticosterone response (Richardson et al., 2008). In the same paradigm, these animals exhibit an increase in CRF mRNA in the CeA (Roberto et al., 2010). Consistent with the hypothesis of blunted glucocorticoids in the HPA and sensitized CRF in the CeA, chronic glucocorticoid receptor blockade with mifepristone, when administered systemically during the course of alcohol vapor exposure, prevented the escalation of alcohol intake and blocked the increase in progressive-ratio responding for alcohol in dependent animals (Vendruscolo et al., 2012). Chronic, systemic glucocorticoid receptor antagonist treatment blocked escalated and compulsive alcohol drinking during protracted abstinence in rats with a history of alcohol dependence, suggesting the persistence of such stress axis dysregulation in animals with a history of alcohol dependence.

One hypothesis for the differential control of CRF transcription by corticosteroids in the PVN versus CeA is that tissue-specific differences in steroid receptor coactivators, such as SRC-1, might play a role in the neuron-specific action of glucocorticoids on CRF transcription (Kovacs, 2013). The SRC1 $\alpha$ isoform is highly expressed in the PVN, whereas the SRC1ع isoform is enriched in the CeA, and the expression of both was shown to correlate with the differential effect of corticosterone in these areas (Meijer et al., 2000).

\section{Between-System Neuroadaptations: Dynorphin/к-Opioid Receptors}

Dynorphin is an opioid peptide that binds $\kappa$-opioid receptors. It has long been known to be activated by chronic psychostimulant and opioid administration and 
self-administration (Nestler, 2004; Koob, 2008) and alcohol self-administration (Karkhanis and Al-Hasani, 2020). $\kappa$-Opioid receptor agonists (administered systemically) and dynorphins (administered intracerebrally) produce aversive-like effects in both animals and humans (Shippenberg et al., 2007) and have been hypothesized to mediate negative emotional states that are associated with drug withdrawal (Chavkin and Koob, 2016), pain, and more specifically pain that is associated with acute withdrawal (see also the Pain, Hyperkatifeia, and Addiction section).

For opioids, animal studies have demonstrated region-specific increases in the levels of dynorphin after the passive administration of morphine (Nylander et al., 1995) and heroin (Weissman and Zamir, 1987). Expression of the dynorphin precursor prodynorphin is also increased during the anticipation of heroin (Cappendijk et al., 1999) and after heroin self-administration (Solecki et al., 2009). The selective blockade of $\kappa$-opioid receptor by $20 \mathrm{mg} / \mathrm{kg}$ nor-binaltorphimine (nor-BNI) administration (i.p.) 5 hours before naltrexone-precipitated withdrawal in morphine-dependent rats decreased some signs of opioid withdrawal during a 30-minute withdrawal session and, more relevant for the present thesis, decreased the subsequent conditioned place aversion for the withdrawal chamber 2 days later (Kelsey et al., 2015).

One hypothesized mechanism by which dynorphin alters the aversive/rewarding aspects of drug intake is through a decrease in dopamine release in the NAc shell (Carlezon et al., 2000). The $\kappa$-opioid receptor agonist $\mathrm{U} 50,488 \mathrm{H}$ suppressed dopamine release in the NAc in rats that self-administered heroin, resulting in an increase in immediate heroin intake (Xi et al., 1998). $\kappa$-Opioid receptor antagonists do not block the acute rewarding ("euphoric-like") effects of opioids but block the stress-induced potentiation of opioid reward, the stress-induced reinstatement of opioid-seeking behavior, and the escalation of drug consumption in longaccess models (Schlosburg et al., 2013; Zhou et al., 2013b).

For alcohol, an increase in prodynorphin mRNA expression is observed in the CeA during acute withdrawal (Kissler et al., 2014) and in the NAc during withdrawal after 1 month of voluntary alcohol consumption (Przewłocka et al., 1997). There is also an increase in the expression of dynorphin mRNA in the CeA and hypothalamus in alcohol-preferring rats compared with nonpreferring rats after voluntary consumption (Zhou et al., 2013a). Acute withdrawal and extended withdrawal (72 hours) from exposure to chronic intermittent exposure to alcohol in mice increased anxiety-like responses, which were reversed by a $\kappa$-opioid receptor antagonist (Rose et al., 2016). In this study, the $\kappa$-opioid receptor activation-induced inhibition of dopamine release, measured by fast-scan voltammetry, was produced by a $\kappa$-opioid receptor agonist, and these effects were exacerbated in mice that were exposed to chronic intermittent alcohol (Rose et al., 2016). In mice that were exposed to chronic intermitted alcohol, an acute alcohol challenge decreased extracellular dopamine levels in the NAc, measured by microdialysis, which was reversed by the blockade of $\kappa$-opioid receptors, suggesting that an increase in dynorphin/ $\kappa$-opioid receptor system activity drives the reduction of stimulated (by electrical stimulation and alcohol) dopamine release in the NAc (Karkhanis et al., 2016; Karkhanis and Al-Hasani, 2020).

Both systemic and intracerebral $\kappa$-opioid receptor antagonist administration blocked high compulsivelike drug intake that was associated with extended access to and dependence on alcohol (Hölter et al., 2000; Walker and Koob, 2008). The stress-induced escalation of intake in mice that were exposed to chronic intermittent alcohol (Anderson et al., 2016a) was blocked by a $\kappa$-opioid receptor antagonist (Anderson et al., 2016b). These effects may be mediated by the extended amygdala, including the CeA and shell of the NAc (Nealey et al., 2011). The CeA may mediate the effects of $\kappa$-opioid receptor blockade on binge-like drinking in mice (Anderson et al., 2019).

\section{E. Between-System Neuroadaptations: Vasopressin}

Vasopressin is a neurohormone that is synthesized in the hypothalamus and transported to the posterior pituitary (Brownstein et al., 1980), where it is released into the bloodstream during dehydration to act via vasopressin $\mathrm{V}_{2}$ receptors on the kidneys to produce water retention (Kaufmann et al., 2000). Arginine vasopressin also exerts synergistic effects with CRF to release ACTH (Antoni, 1993). Vasopressin has a neurotropic action by being centrally localized and originating in the PVN, BNST, medial amygdala, and suprachiasmatic nucleus and projecting extensively throughout the basal forebrain (Veinante and Freund-Mercier, 1997; De Vries and Buijs, 1983). Early studies hypothesized a role for central vasopressin in aversive learning and memory mechanisms (de Wied and Versteeg, 1979; Le Moal et al., 1984; Engelmann et al., 1996).

For opioids, vasopressin has some parallels to CRF in its role in opioid addiction. Brattleboro rats, which are genetically vasopressin-deficient, exhibited attenuation of the increase in ACTH and corticosterone during spontaneous withdrawal from chronic morphine (Domokos et al., 2008). Vasopressin mRNA levels increased selectively in the amygdala only during early spontaneous withdrawal from chronic heroin exposure and not during late withdrawal (Zhou et al., 2008). The vasopressin $\mathrm{V}_{1 \mathrm{~B}}$ receptor antagonist SSR149415 blocked the heroin- and foot shock-induced reinstatement of heroin-seeking behavior, suggesting that vasopressin systems in the amygdala may be a key component of the aversive emotional consequences of opioid withdrawal (Zhou et al., 2008). 
For alcohol, vasopressin administration in animals potentiated the long-term maintenance of tolerance to the hypothermic and sedative effects of alcohol (Hoffman et al., 1978, 1990; Lê et al., 1982), and this effect was linked to a central vasopressin $\mathrm{V}_{1}$ receptor subtype (Szabó et al., 1988). Later studies implicated vasopressin more in regulating various affective-like behaviors (Caldwell et al., 2008). A small-molecule $V_{1 b}$ receptor antagonist exerted anxiolytic- and antidepressantlike effects (Griebel et al., 2002), with a focus on sites of action in the basolateral amygdala, CeA, medial amygdala (Salomé et al., 2006), lateral septum (Stemmelin et al., 2005), and dorsal hippocampus (Engin and Treit, 2008). The $\mathrm{V}_{1 \mathrm{~b}}$ receptor antagonist SSR149415 dose-dependently reduced the higher levels of alcohol self-administration that were observed in dependent animals, without affecting alcohol drinking in nondependent animals (Edwards et al., 2012a). The $V_{1 b}$ receptor antagonist also significantly reduced alcohol intake in Sardinian alcohol-preferring rats (Zhou et al., 2011).

In a 12 -week, multisite, randomized clinical trial in 150 alcohol-dependent individuals, the selective $V_{1 b}$ receptor antagonist ABT-436 significantly increased the percentage of days abstinent compared with placebo (Ryan et al., 2017). Altogether, these results suggest that elevations of vasopressin release during withdrawal can promote a negative emotional state that in turn facilitates the escalation of drinking to alleviate that aversive state. Indeed, individuals who reported higher baseline levels of stress responded better to ABT436 treatment than to placebo on drinking outcomes in an analysis of moderators (Ryan et al., 2017).

\section{F. Between-System Neuroadaptations: Hypocretin}

The neuropeptides hypocretin (Hcrt)-1 (also called orexin A) and Hcrt-2 (also called orexin B) have been associated with sleep-wake regulation, arousal, stress, and drug-seeking behavior (Sutcliffe and de Lecea, 2002; Johnson et al., 2012; Mahler et al., 2012). Hypocretin-containing neurons are found in restricted regions of the dorsal hypothalamus, including the lateral hypothalamus proper, adjacent perifornical area, and dorsomedial hypothalamus (de Lecea et al., 1998; Sakurai et al., 1998), and project widely throughout the brain (Peyron et al., 1998). Hypocretin neurons target two G protein-coupled receptors: Hcrt-1 and Hcrt-2. Hypocretin neuron projections also include reciprocal connections to the extended amygdala and other basal forebrain regions (Peyron et al., 1998; Baldo et al., 2003), thus providing a neuroanatomical basis for the hypothesis that hypocretin neurotransmission plays an important role in negative reinforcement that is thought to contribute to the motivation for compulsive-like intake during dependence (for review, see Koob, 2008; Koob et al., 2014).

Consistent with this hypothesis, immunohistochemical studies indicate the stress-induced activation of
Hcrt neurons through $\mathrm{CRF}_{1}$ receptor activation (Winsky-Sommerer et al., 2004, 2005). Additional studies demonstrate that intraventricular Hcrt-1 elevates intracranial self-stimulation thresholds, suggesting an aversive effect of excessive activation of the Hcrt system (Boutrel et al., 2005). Intra-VTA infusions of Hcrt-1 also elevated reward thresholds via the activation of CRF in the CeA (Hata et al., 2011). Altogether, these results support the hypothesis that Hcrt may have antireward/ brain stress actions possibly via the CRF system in the extended amygdala.

For opioids, the negative affective state that is associated with opioid withdrawal is also associated with greater Hcrt neuron activation. Using a chronicmorphine, intermittent, escalating-dose procedure, Hcrt mRNA levels in the lateral hypothalamus increased during the aversive state of acute morphine withdrawal (Zhou et al., 2010). Naloxone-precipitated morphine withdrawal in rats that were chronically treated with morphine increased Hcrt-1 gene expression and Hcrt neuron activation in the lateral hypothalamus, and an Hcrt-1 receptor antagonist attenuated the somatic expression of naloxone-precipitated morphine withdrawal (Laorden et al., 2012). The Hcrt-1 receptor antagonist also partially reduced withdrawal-induced Fos expression in the extended amygdala in morphinewithdrawn rats (Laorden et al., 2012). Others have observed a decrease in opioid withdrawal in Hcrt knockout mice (Georgescu et al., 2003). An Hcrt-1 receptor antagonist blocked naloxone-precipitated withdrawal in morphine-dependent mice (Sharf et al., 2008). The systemic administration of an Hcrt-2 receptor antagonist dose-dependently decreased heroin self-administration in long-access but not in shortaccess animals in an extended-access procedure (Schmeichel et al., 2015). Additionally, an increase in Hcrt-2 receptor mRNA levels in the CeA in longaccess rats was observed by quantitative polymerase chain reaction.

For alcohol, prepro-Hcrt mRNA increased in the lateral hypothalamus in inbred alcohol-preferring rats after chronic alcohol consumption (Lawrence et al., 2006) but decreased in the perifornical area in Sprague-Dawley rats (Morganstern et al., 2010). Both Hcrt-1 and Hcrt-2 receptor blockade decreased alcohol self-administration in alcohol-preferring rats (Lawrence et al., 2006; Brown et al., 2013). Another study tested the effect of an Hcrt-1 receptor-specific antagonist on responding for alcohol in dependent mice that were exposed to chronic intermittent alcohol vapor compared with mice that were nondependent. The Hcrt-1 receptor antagonist dosedependently decreased alcohol intake, particularly in alcohol-dependent mice (Lopez et al., 2016). An Hcrt-1 receptor antagonist also blocked the stress (yohimbine)induced reinstatement of alcohol seeking (Richards et al., 2008). Altogether, Hcrt likely exerts both direct and indirect modulatory actions on brain stress systems to 
contribute to opioid and alcohol withdrawal-induced hyperkatifeia.

\section{G. Between-System Neuroadaptations: Neuroimmune Systems}

Neuroinflammatory signaling pathways in the central nervous system are also hypothesized to contribute to neuroadaptive processes that mediate the dysregulation of hyperkatifeia that is associated with the withdrawal/negative affect stage of the addiction cycle (Koob and Volkow, 2010; Crews and Vetreno, 2016). Repeated cycles of withdrawal have a particularly pronounced effect on neuroimmune function. Here, withdrawal from chronic drug exposure amplifies neuroimmune gene expression, impacting stress and fear circuits, and as a result is hypothesized to contribute to hyperkatifeia.

Interactions between the immune system and stress system that are associated with the withdrawal/negative affect stage involve both microglia and astrocytes (Crews et al., 2017). Microglia are the primary neuroimmune cells in the brain and act as resident macrophages of the brain. Microglia normally exist in a "resting" state but can become activated in response to insults (Kettenmann et al., 2013). Astrocytes are also an important component of the brain immune system but are also involved in the metabolic support of neurons and modulation of synaptic transmission (Farina et al., 2007; Khakh and Sofroniew, 2015). In response to insults, astrocytes undergo a process of activation; like microglia, they are capable of adopting proinflammatory and anti-inflammatory states (Jang et al., 2013b). Repeated cycles of stress and excessive drug use are hypothesized to result in increasingly sensitized/activated microglia, contributing to signs and symptoms that are associated with the withdrawal/negative affect stage of the addiction cycle (Crews et al., 2017). With repeated episodes of drug administration or stress, as observed with hyperkatifeia, immune danger signals and glial activation are amplified within glia and across other brain cells. Such activation persists for long periods of time. Both stress and chronic pain activate microglia, increase Toll-like receptor 4 (TLR4) danger signals, increase the expression of nuclear factor $\kappa \mathrm{B}$ target genes, and increase tumor necrosis factor $\alpha$ (TNF $\alpha$; Watkins et al., 2007; Graeber, 2010).

For opioids, glia and proinflammatory cytokines may also play a role in the development of opioid-induced hyperalgesia during withdrawal (DeLeo et al., 2004) and other physical and motivational measures of opioid withdrawal (Wieseler-Frank et al., 2005; Hao et al., 2011; Taylor et al., 2016). The acute administration of opioids exerts anti-inflammatory effects (Eisenstein, 2019), whereas chronic opioid exposure activates microglia and astrocytes in the spinal cord (Watkins et al., 2009; Cahill et al., 2016) and central nervous system, including the VTA, NAc, frontal cortex, and periaqueductal gray (Hao et al., 2011; Taylor et al., 2016).

Glial activation may also contribute to hyperkatifeialike responses that are observed during opioid withdrawal. The blockade of glial cell activation restored mesolimbic dopamine function using minocycline (Taylor et al., 2016), prevented withdrawal using various inhibitors of glial cell activation (Watkins et al., 2009), prevented the relapse of morphine-seeking behavior via the epigenetic reprogramming of interleukin-10 overexpression (Schwarz et al., 2011), and prevented incubation-induced heroin seeking in rats after prolonged abstinence using the TLR4 antagonist (+)-naltrexone (Theberge et al., 2013). For example, chronic opioid treatment caused the dysregulation of transmembrane $\mathrm{Cl}^{-}$homeostasis in GABAergic neurons in the VTA, driven by brain-derived neurotrophic factor (BDNF) and activated microglia (Taylor et al., 2016). Here, microglia via a BDNF-potassium-chloride transporter member 5 mechanism are hypothesized to be activated during opioid withdrawal and increase VTA GABAergic tone, which inhibits dopaminergic neurons (Cahill et al., 2016). The resulting blunting of VTA-dependent reward suggests opponent process-like changes that are driven by nonneuronal modulators (Cahill et al., 2016).

In parallel, neuroimmune activation contributes to opioid withdrawal and tolerance. Intra-periaqueductal gray microinjections of a herpes simplex virus vector that expressed the soluble TNF receptor, which downregulates the expression of glial fibrillary acidic protein and $\mathrm{TNF} \alpha$ in astrocytes, significantly attenuated behavioral manifestations of naloxone-precipitated withdrawal (Hao et al., 2011). Microinjections of the soluble TNF receptor-expressing herpes simplex virus vector in the periaqueductal gray also significantly reduced the phosphorylation of both extracellular signal-regulated kinase 1/2 and CREB and reduced Fos immunoreactivity in periaqueductal gray neurons after naloxoneprecipitated withdrawal. These findings support the hypothesis that proinflammatory cytokines that are expressed in astrocytes in the periaqueductal gray may play an important role in the pathogenesis of the morphine withdrawal response (Hao et al., 2011). An alternate hypothesis to explain proinflammatory actions of opioids after administration and withdrawal is that lipopolysaccharide may be released into the circulation from the escape of Gram negative flora from the gastrointestinal tract, which would be proinflammatory (Eisenstein, 2019). The inhibition of glial activation and inhibition of many of the resulting downstream signaling components (e.g., chemokines, cytokines, fractalkine, nitric oxide, and connexin 43) can reverse analgesic tolerance after chronic morphine administration (Song and Zhao, 2001; DeLeo et al., 2004; Johnston et al., 2004; Watkins et al., 2009; Horvath et al., 2010; Muscoli et al., 2010; Wen et al., 2011; Shen et al., 2014; Hua et al., 2016). 
For alcohol, chronic alcohol treatment in mice induced proinflammatory gene expression in the brain that persisted for at least 1 week of abstinence (Qin et al., 2007). Mice that lacked TLR4 were protected from alcohol-induced glial activation, anxiety-like behavior, and cognitive impairments (Pascual et al., 2011). Similarly, mice that lacked CD14, a key TLR4 accessory signaling protein, drank significantly less alcohol than normal mice (Blednov et al., 2012). The amygdala may be one site for the action of neuroimmune cytokines. Mice that lacked CD14 had significantly lower GABA interneuron firing in the $\mathrm{CeA}$ in response to alcohol (Bajo et al., 2014). Injections of $\mathrm{TNF} \alpha$ in the amygdala in rats increased anxiety-like behavior and mimicked the amplification of anxiety-like behavior that was observed with repeated cycles of alcohol drinking (Breese et al., 2008). Injections of cytokines in the amygdala increased withdrawal-induced hyperkatifeialike responses, similar to exposure to stress or alcohol (Knapp et al., 2011). Furthermore, TLR4 knockdown in the amygdala reduced responding for alcohol in alcoholdependent rats (Liu et al., 2011), consistent with the hypothesis that the activation of innate immune danger signals within the amygdala may contribute to hyperkatifeia that drives dependence-induced alcohol drinking. Phosphodiesterase- 4 inhibitors, which hydrolyze cAMP within immune cells and have anti-inflammatory actions, reduced alcohol drinking and relapse in alcohol-preferring $P$ rats, high-alcohol drinking (HAD1) rats, and mice that were made dependent on alcohol by repeated cycles of alcohol vapor exposure, with no effect in nondependent mice (Bell et al., 2015; Franklin et al., 2015).

Additionally, CRF receptor antagonists that blocked alcohol dependence-induced excessive drinking also blocked the induction of withdrawal/negative affect and anxiety by cytokines (Knapp et al., 2011). These studies support the hypothesis that the amplification of danger signals and glial activation in the amygdala and other components of brain fear/anxiety/stress neurocircuitry contribute to the progression and persistence of the withdrawal/negative affect stage, possibly by interacting with brain stress systems.

Another link between alcohol abuse and innate immunity is hypothesized to involve the gut. Alcoholic liver disease involves inflammation, in part through an alcohol-induced increase in the permeability of the gut to endotoxins, such as lipopolysaccharide, that activate innate immune cells in the liver (Szabo et al., 2011). Lipopolysaccharide is a large molecule that does not cross the blood-brain barrier, but cytokines that are induced by lipopolysaccharide may be transported into the brain and result in neuroinflammation and microglial activation (Qin et al., 2007; Banks and Erickson, 2010). Indeed, high levels of lipopolysaccharide cause a "sickness-like" response, characterized by decreases in food and water intake, loss of weight, lethargy, and hypohedonia (Dantzer et al., 2008). Thus, the hypothesis is that repeated cycles of binge/withdrawal sensitize neuroimmune systems that interact with brain stress systems to facilitate negative emotional states during withdrawal and drive compulsive-like drinking under a negative-reinforcement framework.

\section{Antistress Neurotransmitters/ Neuromodulators and Hyperkatifeia}

The vulnerability to hyperkatifeia in driving AUD and substance use disorders may derive not only from the activation of prostress neurotransmitter systems but also from antistress neurotransmitter systems (see Fig. 5). Antistress neurotransmitter systems can be defined as neuroadaptive buffers to prostress actions that are described above, in which neurotransmitter systems are hypothesized to act either in opposition to stress neurotransmitters (Heilig, 2004; Pleil et al., 2015) or in response to the excess activation of prostress neural systems or even in anticipation of the activation of stress (Heilig and Koob, 2007). Neurotransmitter/ neuromodulatory systems that are implicated in antistress actions include NPY, nociceptin, endocannabinoids, and oxytocin.

\section{A. Neuropeptide $Y$}

Neuropeptide $\mathrm{Y}$ has powerful orexigenic and anxiolytic-like effects in animal models and has been hypothesized to act in opposition to the actions of CRF in AUD and substance use disorders (Heilig and Koob, 2007).

For opioids, NPY can potentiate their acute rewarding effects (Robinson and Thiele, 2017). For example, one study showed that in nondependent rats (3 hours of access per day), intracerebroventricular NPY injections increased ongoing heroin self-administration and induced the reinstatement of extinguished heroin-seeking behavior (Maric et al., 2008). However, NPY administration attenuated somatic withdrawal symptoms that were produced during naloxone-precipitated withdrawal from chronic opioids (Woldbye et al., 1998; Clausen et al., 2001). Npy gene expression decreased in rats at both 1 and 14 days of withdrawal from 3 hours of heroin self-administration, with an increase in the $\mathrm{Y}_{5}$ receptor (Kuntz-Melcavage et al., 2009). Little work has been done on the effects of NPY on opioid selfadministration in dependent animals. These studies suggest that NPY may facilitate the initial rewarding effects of opioids but may also play a role in withdrawal, although little research has been done in the domain of hyperkatifeia.

For alcohol, NPY administration directly in the brain blocked the increase in self-administration in alcoholpreferring rats and in alcohol dependence, blocked the transition to excessive drinking with the development of dependence, and blocked the increase in GABA release in the CeA that was produced by alcohol 
(Gilpin et al., 2003, 2008, 2011; Thorsell et al., 2005a,b, 2007). Similar effects on dependenceinduced drinking in rats and binge-like drinking in mice were observed with injections of NPY in the amygdala, BNST, and NAc shell but not in the hypothalamus, suggesting a focus of the effects of NPY on alcohol drinking on the extended amygdala (Kelley et al., 2001; Gilpin et al., 2008; Pleil et al., 2015). Viral vector-induced NPY overexpression in the amygdala reversed the increase in alcohol intake that was caused by repeated deprivations in Wistar rats (Thorsell et al., 2007). Given that the activation of NPY in the CeA has opposite effects to CRF, one hypothesis is that NPY may act as a buffer to the stress-driving effects of CRF; by extrapolation, low functional activity of NPY may contribute to the etiology and vulnerability to hyperkatifeia.

\section{B. Nociceptin}

Nociceptin has antistress-like effects in animals (Ciccocioppo et al., 2003; Martin-Fardon et al., 2010). High numbers of nociceptin-containing neurons are found in the extended amygdala, cortex, and midbrain (Mollereau and Mouledous, 2000). Nociceptin can block both opioid and alcohol withdrawal and attenuate the increase in alcohol and opioid self-administration in dependent animals.

For opioids, intraventricular injections of nociceptin inhibited naloxone-precipitated withdrawal signs in morphine-dependent rats (Kotlinska et al., 2000, Kotlińska et al., 2004), and conditioned withdrawal (measured by place aversion) increased nociceptin levels (measured by a radioimmunoassay) in the frontal cortex (Walker et al., 2002). Intracerebroventricular nociceptin administration did not block heroin selfadministration in nondependent rats, but a nociceptin receptor agonist decreased intravenous remifentanil self-administration in rats and rhesus monkeys (Podlesnik et al., 2011; Sukhtankar et al., 2014). Perhaps more compelling for the present thesis, direct injections of nociceptin in the $\mathrm{CeA}$ attenuated the escalation of intravenous oxycodone self-administration in a high addiction index subset of outbred rats (Kallupi et al., 2020). The same high-addiction subgroup had lower levels of nociceptin in the CeA, and nociceptin normalized GABAergic transmission in the CeA, suggesting that the downregulation of nociceptin levels in the CeA may be responsible for the hyper-GABAergic tone in the $\mathrm{CeA}$ that is observed in individuals who develop addiction-like behaviors.

For alcohol, intracerebroventricular nociceptin administration significantly reduced the expression of somatic withdrawal signs and reversed anxiety-like behaviors that were associated with both chronic and acute alcohol intoxication in Wistar rats (Economidou et al., 2011). Synthetic nociceptin receptor agonists blocked high alcohol consumption in Marchigian Sardinian alcohol-preferring
$(\mathrm{msP})$ rats, a genetically selected line of rats that is known to be hypersensitive to stressors (Economidou et al., 2008). Nociceptin receptor agonists exerted effects on GABA synaptic activity in the CeA that were similar to NPY (Economidou et al., 2008). msP rats exhibited increases in nociceptin and nociceptin receptor mRNA expression in most of the brain but a decrease in nociceptin signaling, which was measured by $\left.{ }^{35} \mathrm{~S}\right] \mathrm{GTP} \gamma \mathrm{S}$ binding in the CeA (Economidou et al., 2008). Intra-amygdala administration of nociceptin also blunted alcohol self-administration in msP rats (Economidou et al., 2008). In postmortem brains of humans with AUD, nociceptin mRNA decreased in the amygdala (Kuzmin et al., 2009). Altogether, one hypothesis is that repeated alcohol intake may downregulate the endogenous nociceptin system, resulting in the activation of alcohol consumption through the release of stress modulation.

Notably, however, nociceptin receptor antagonists also decreased high levels of drinking in $\mathrm{msP}$ rats (Rorick-Kehn et al., 2016), leading to the hypothesis by these authors that the previously reported agonist effects that are mentioned above may reflect receptor desensitization with agonist administration, in effect producing the antagonist-like functional blockade of subchronic agonist dosing (Rorick-Kehn et al., 2016; Toll et al., 2016). Another hypothesis to explain the efficacy of both nociceptin agonists and antagonists in animal models of high alcohol consumption is that such agonists and antagonists of nociceptin receptors may produce different patterns of activation or inhibition in different brain areas that are relevant to reward and addiction (Rorick-Kehn et al., 2016). Future studies are needed to elucidate the exact nature of the neuromodulatory role of nociceptin.

\section{Endocannabinoids}

Endocannabinoids are hypothesized to have stressbuffering actions that may be involved not only in the response to repeated withdrawal from alcohol but also in the vulnerability to negative emotional dysregulation that drives excessive drinking. Reductions of endocannabinoid signaling produce anxiogenic-like behavioral effects. Increasing endogenous endocannabinoid levels through the inhibition of endocannabinoid clearance mechanisms produces anxiolytic-like effects in various animal models of anxiety, particularly under stressful or aversive conditions (Serrano and Parsons, 2011).

Opioids and cannabinoids have a long history of interactions, including crosstolerance and crosswithdrawal precipitation with antagonists (Scavone et al., 2013). These interactions may involve alterations in the level of endogenous opioids or their receptors or via changes in $\mathrm{G}$ protein-mediated signaling through opioid receptors or $\mu$-opioid receptor-cannabinoid $\mathrm{CB}_{1}$ receptor complexes (Scavone et al., 2013). The administration of an opioid or cannabinoid $\mathrm{CB}_{1}$ receptor 
antagonist in morphine-dependent individuals precipitated withdrawal symptoms with somatic and affective components (Navarro et al., 1998; Kosten and George, 2002). Less work has explored the role of endocannabinoids in opioid withdrawal and withdrawal-induced self-administration (Scavone et al., 2013).

With regard to the hyperkatifeia-buffering role of endogenous cannabinoids, the administration of 2arachidonoylglycerol (2-AG) and anandamide blunted physical symptoms of morphine withdrawal (Vela et al., 1995; Yamaguchi et al., 2001). The blockade of fatty acid amide hydrolase (FAAH) blocked somatic signs of precipitated opioid withdrawal and facilitated the extinction of naloxone-precipitated withdrawal-induced place aversion in rats (Manwell et al., 2009), and systemic pretreatment with the monoacylglycerol lipase (MAGL) inhibitor MJN110 blocked place aversion that was produced by naloxone-precipitated acute withdrawal after a single large dose of morphine through a cannabinoid $\mathrm{CB}_{1}$ receptor-dependent mechanism in rats (Wills et al., 2016). Neutral $\mathrm{CB}_{1}$ receptor antagonists also blocked place aversion that was produced by naloxone-precipitated acute withdrawal after a single large dose of morphine in rats (Wills et al., 2014). Additionally, intracerebral administration of the MAGL inhibitor directly in the basolateral amygdala blocked acute withdrawal-induced place aversion in rats, and $\mathrm{CB}_{1}$ receptor antagonist administration in the CeA blocked acute withdrawal-induced place aversion in rats (Wills et al., 2016). These authors suggested that $\mathrm{CB}_{1}$ receptor antagonists decrease the inhibition of GABA release in the basolateral amygdala, and MAGL inhibitors inhibit GABA release in the CeA, returning the amygdala to normal levels of function in both cases (Wills et al., 2016). Intraperitoneal administration of a dual FAAH/MAGL inhibitor also decreased heroin seeking in mice, which was measured as a decrease in nose poking for heroin during the escalation of intake and a decrease in progressive-ratio responding after escalation (Wilkerson et al., 2017). This same dual FAAH/MAGL inhibitor dose-dependently reversed mechanical allodynia in a sciatic nerve constriction injury model of neuropathic pain and in a model of carrageenan-induced inflammatory pain (Wilkerson et al., 2017). However, in mice, an FAAH inhibitor and an MAGL inhibitor blocked somatic signs of precipitated opioid withdrawal in mice (Gamage et al., 2015), but they failed to block naloxone-precipitated withdrawal-induced place aversion. Altogether, the data suggest that, at least in rats, the modulation of endogenous endocannabinoids can reverse hyperkatifeia that is associated with opioid withdrawal, but the nature of such modulation may be circuitspecific.

For alcohol, chronic alcohol exposure increases brain 2-AG (Caillé et al., 2007; Alvarez-Jaimes et al., 2009) and $\mathrm{N}$-arachidonoylethanolamine (AEA), particularly in basal forebrain areas, in rodents (González et al., 2004; Vinod et al., 2006), but decreases in both 2-AG and AEA were observed in the CeA during withdrawal (Serrano et al., 2018). Both FAAH inhibitors and MAGL inhibitors, which functionally increase endocannabinoids, decreased withdrawal-induced anxiety-like behavior and decreased alcohol consumption in alcoholdependent rats (Serrano et al., 2018). Alcohol-preferring rats that exhibited high alcohol drinking and preference showed high anxiety-like responses, with higher FAAH activity in the CeA and lower AEA levels in the CeA, measured by in vivo microdialysis (Natividad et al., 2017). Consistent with these results, microinjections of the selective FAAH inhibitor URB597 in the CeA in alcohol-preferring rats significantly reduced alcohol selfadministration (Stopponi et al., 2018).

\section{Oxytocin}

Oxytocin has been hypothesized to play a role in such diverse functions as memory, learning, social behavior, fear, and anxiety (Stoop, 2012). It has also been hypothesized to normalize stress function and attenuate hyperkatifeia in the context of addiction (Lee and Weerts, 2016). Oxytocin has been detected in the brain after both intraperitoneal and intranasal administration in mice, rats, and rhesus monkeys (Neumann et al., 2013; Bustion et al., 2016; Lee et al., 2018, 2020; Tanaka et al., 2018).

For opioids, early studies showed that systemic, intracerebroventricular, and intracerebral injections of oxytocin and oxytocin analogs in the dorsal hippocampus and NAc attenuated morphine tolerance and dependence (Kovacs et al., 1984). Both systemic and central routes of administration have been used in preclinical studies to evaluate the effects of oxytocin on drug self-administration. Systemic injections of oxytocin and oxytocin analogs blocked intravenous heroin selfadministration in heroin-tolerant rats (Kovács and Van Ree, 1985; Kovács et al., 1985). Naloxone-precipitated morphine withdrawal after chronic exposure to morphine produced the hyperexcitation of oxytocin neurons and gene expression and increased Fos expression in the rat supraoptic nucleus (Murphy et al., 1997; Johnstone et al., 2000). Increases in oxytocin content in the PVN and median eminence were observed during naloxoneprecipitated morphine withdrawal (Laorden et al., 1998). These effects on central oxytocin neurons led some authors to suggest that hypothalamic oxytocin neurons develop morphine dependence, and despite the requirement of afferent inputs for the expression of morphine withdrawal-induced excitation, "the underlying mechanisms appear to reside within the oxytocin neurons themselves and probably involve changes in the intrinsic membrane properties of these neurons" (Brown and Russell, 2004; Brown et al., 2005). Systemic injections of an oxytocin analog also blunted anxiety-like responses that were associated with opioid withdrawal 
in mice and prevented opioid-induced reinstatement in the place preference test (Zanos et al., 2014). Particularly interesting from a translational perspective, in human clinical studies of individuals with opioid addiction, higher withdrawal-related levels of stress were associated with higher plasma oxytocin levels and early treatment discharge (Nikolaou et al., 2017). In heroin users during abstinence in a double-blind placebocontrolled study, acute intranasal oxytocin administration reduced craving and withdrawal scores and decreased cortisol levels but did not significantly change anxiety (Moeini et al., 2019).

For alcohol, early studies showed that oxytocin or oxytocin analogs inhibited the development of tolerance to its hypnotic and hypothermic effects (Puciłowski et al., 1985; Szabó et al., 1987; Jodogne et al., 1991). Systemic oxytocin administration suppressed the opposite compensatory response that was conditioned to alcohol-paired cues that were hypothesized to cause tolerance (Tirelli et al., 1992). Oxytocin significantly decreased withdrawal signs in alcohol-dependent mice (Szabó et al., 1987; Kovacs et al., 1998).

Oxytocin receptors are found in many brain regions that are relevant to alcohol dependence, such as the frontal cortex and extended amygdala, in rats and humans (Knobloch et al., 2012; Boccia et al., 2013). Oxytocin and oxytocin analogs can blunt alcohol reward (Bahi, 2015) and decrease alcohol drinking (MacFadyen et al., 2016; King et al., 2017). Oxytocin also attenuated the increase in drinking that was associated with dependence in animal models after both systemic and central administration. Oxytocin administration intranasally or directly in the brain blocked the increase in drinking in alcohol-dependent rats (Tunstall et al., 2019). Oxytocin blocked this increase in alcohol drinking at doses that did not alter non-alcohol-related behaviors or alcohol drinking in nondependent rats, suggesting that the effect was specific to alcohol drinking in dependence. These effects were hypothesized to be centrally rather than peripherally mediated. Ex vivo electrophysiological recordings in the CeA indicated that oxytocin blocked the facilitatory effects of alcohol on GABA release in the CeA in dependent rats but not in nondependent rats (Tunstall et al., 2019). Intraperitoneal oxytocin administration also blocked the stressinduced reinstatement of alcohol seeking in mice (King and Becker, 2019). Oxytocin also reduced cue-induced reinstatement in dependent rats but not in nondependent rats (Hansson et al., 2018).

In a postmortem study of males with AUD, oxytocin peptide mRNA was significantly elevated in the prefrontal cortex in subjects with AUD compared with controls (Lee et al., 2017). A small study showed that intranasal oxytocin blocked alcohol withdrawal in humans, based on such measures as the Alcohol Withdrawal Symptom Checklist of the Clinical Institute Withdrawal Assessment for Alcohol, and reduced the amount of benzodiazepines that were required for treatment (Pedersen et al., 2013). Another study failed to observe such a reduction of the amount of benzodiazepines that were required for alcohol withdrawal treatment (Melby et al., 2019). In a double-blind crossover study of non-treatment-seeking individuals with alcohol abuse, oxytocin did not produce an overall decrease in craving, but further analysis revealed that the effects on craving were moderated by attachment anxiety, with oxytocin reducing craving in more anxiously attached individuals and increasing craving in less anxiously attached individuals (Mitchell et al., 2016).

\section{Hyperkatifeia and Sex Differences}

More men use and are addicted to opioids and alcohol (National Survey on Drug Use and Health, Substance Abuse and Mental Health Services Administration, 2007). However, for alcohol, the gaps between women and men are narrowing with regard to the prevalence, frequency, and intensity of drinking, early onset drinking, having AUD, drunk driving, and self-reported consequences (White et al., 2015; Slade et al., 2016).

For opioids, clinical reports indicate that women who become addicted to opioids progress through the stages of addiction, from initial use to dependence, at a faster rate than men (Brady and Randall, 1999). In animal models, female rodents generally acquire morphine and heroin self-administration faster than males and exhibit higher motivation to self-administer opioids (Lynch and Carroll, 1999; Cicero et al., 2003; Becker and Koob, 2016). Female rodents are also less sensitive to the analgesic effects of $\mu$-opioid receptor agonists (Barrett et al., 2002; Negus et al., 2002), and some physical signs of opioid withdrawal are more pronounced in male mice than in female mice (Diaz et al., 2005).

To date, little work has focused on preclinical studies of gender differences in animal models of hyperkatifeia and negative reinforcement with opioids (Becker and Koob, 2016).

For alcohol, women are more likely to experience blackouts, liver inflammation, brain atrophy, cognitive deficits, certain cancers, negative affect during withdrawal, and stress- or anxiety-induced relapse (Becker and Koob, 2016). Female rodents also drink more alcohol than males (Eriksson and Pikkarainen, 1968; Becker and Koob, 2016). Selectively bred lines exhibited the faster acquisition of self-administration ( $\mathrm{Li}$ and Lumeng, 1984; Moore and Lynch, 2015).

For alcohol, males generally exhibit a greater withdrawal response and slower recovery from acute alcohol withdrawal (Becker and Koob, 2016). Male rats also exhibit greater physical signs of withdrawal, such as greater seizure susceptibility, compared with female rats (Devaud and Chadda, 2001). However, male rats 
also exhibit greater motivational signs of withdrawal, such as anxiety-like responses in the social interaction test (Varlinskaya and Spear, 2004) and elevated plus maze after one cycle of exposure to an alcohol liquid diet (Overstreet et al., 2004a), and greater increases in acoustic startle responses than female rats (Reilly et al., 2009). Male rats also exhibit greater hangoverlike anxiety-like responses (acute alcohol withdrawal; Varlinskaya and Spear, 2004). Chronic alcohol exposure and withdrawal result in modest elevations of alcohol intake in male High Alcohol Preferring 2 mice. In contrast, female High Alcohol Preferring 2 mice did not show changes in alcohol intake (Lopez et al., 2011).

\section{Pain, Hyperkatifeia, and Addiction}

\section{A. Opioids and Pain}

Opioids are recognized as the most powerful and effective drugs for the relief of acute pain in humans, and a unifying common theme is their relief of pain and suffering, including negative emotional states (Lutz and Kieffer, 2013). Particularly important for the present thesis, opioids also relieve emotional pain, which is a key component of hyperkatifeia, as noted above, and the driving force for the withdrawal/negative affect stage of the addiction cycle. Individuals who experienced or expressed physical abuse and violent behavior described the ways in which opioids helped them feel normal, calm, mellow, soothed, and relaxed (Khantzian, 1985).

However, opioids are significantly less effective against chronic pain, such as neuropathic pain, fibromyalgia, and low-back pain, and tolerance develops to the analgesic effects of opioids, thus necessitating the need for increasingly higher doses to sustain analgesia (McQuay, 1988; Dowell et al., 2016). Interwoven into this framework is that chronic opioids lose their effectiveness for chronic emotional pain. One could argue that chronic opioids actually drive chronic emotional pain via withdrawal.

In humans and animal models, withdrawal from chronic opioid self-administration produces hyperalgesia (i.e., lower pain thresholds; Tilson et al., 1973; Angst and Clark, 2006). In humans, heightened pain perception has long been observed in individuals with a history of opioid addiction (Ho and Dole, 1979; Ren et al., 2009). Methadone-maintained patients have low pain tolerance (Doverty et al., 2001). In these individuals, pain is one of the main triggers of relapse to addiction (Compton et al., 2001). Particularly important is an interaction between negative emotional states and withdrawal-related hyperalgesia. Individuals who were in acute withdrawal (24-72 hours) from opioids or protracted abstinence (average of 30 months) exhibited lower pain thresholds and pain tolerance, measured by the ischemic pain submaximal tourniquet procedure, and these decreases in pain thresholds were exacerbated by negative emotional states (Carcoba et al., 2011). Non-opioid-dependent individuals who underwent an acute opioid physical dependence challenge with naloxone exhibited the presence of hyperalgesia in response to experimental cold-pressor pain, thus showing that even acute opioid administration can produce hyperalgesia (Compton et al., 2003).

In animal models, repeated opioid administration (e.g., once daily for 2 weeks) produces a gradual and dose-dependent decrease in nociceptive thresholds that lasts for several weeks after drug administration (Célèrier et al., 2001; Simonnet and Rivat, 2003). Such hyperalgesia has also been observed with a single injection of heroin in rats (Laulin et al., 1998). Some have argued that a neuronal memory of pain sensitization may remain long after complete washout of the drug and when apparent equilibrium near the predrug state has been reestablished (Laulin et al., 1998).

Neurobiological mechanisms for opioid-induced hyperalgesia have long been hypothesized to be mediated by glutamatergic mechanisms and involve alterations of the function of NMDA glutamate receptors. Behavioral studies in rodents have shown that the activation of NMDA pronociceptive processes by opioids may be involved in the development of hyperalgesia that is classically observed after chronic opioid treatment (Célèrier et al., 1999; Laulin et al., 2002; see the Within-System Neuroadaptations section above). Given that protein kinase $\mathrm{C}$ (PKC) regulates NMDA receptors, opioid-induced hyperalgesia was also reduced in $\mathrm{PKC} \gamma$ gene knockout mice (Célèrier et al., 2004). NMDA receptor antagonists, such as ketamine, blocked hyperalgesia in animal models (Célèrier et al., 2000).

Opioid withdrawal-induced hyperalgesia also includes the activation of the same brain stress systems (e.g., CRF and dynorphin) that are implicated in hyperkatifeia in general. Hyperalgesia in the tail flick test that was associated with morphine withdrawal was blocked by microinjections of a $\mathrm{CRF}_{1} / \mathrm{CRF}_{2}$ peptide receptor antagonist in the $\mathrm{CeA}$, without affecting plasma corticosterone responses (McNally and Akil, 2002). Consistent with this observation, hyperalgesia during withdrawal in animals that developed compulsive-like responding with extended access to heroin was blocked by the systemic administration of a $\mathrm{CRF}_{1}$ receptor antagonist (Edwards et al., 2012b; Park et al., 2015). Dynorphin knockout mice exhibited a facilitated return to normal nociceptive baselines after a peripheral nerve lesion (Wang et al., 2001), suggesting a pronociceptive role for dynorphin in chronic pain, in contrast to the antinociceptive effects of acute $\kappa$-opioid receptor agonist administration.

The dynorphin/ $/$-opioid receptor system may also be engaged in negative emotional states that are associated with chronic pain (Cahill et al., 2014; Massaly et al., 2016, 2019). Evidence that supports this hypothesis includes studies of the neuropharmacological 
blockade of $\kappa$-opioid receptors and neurocircuitryspecific engagement of dynorphin neurons. Increases in the GTP $\gamma \mathrm{S}$ binding of $\kappa$-opioid receptor-specific ligands in the amygdala were associated with anxiety that was produced by Complete Freund's Adjuvantinduced chronic pain or sciatic nerve ligation-induced neuropathic pain (Narita et al., 2006). The pain-induced attenuation of conditioned place preference can be reversed by the systemic or local NAc blockade of $\kappa$-opioid receptors using nor-BNI (Narita et al., 2005), and nor-BNI significantly prevented loss of the diffuse noxious inhibitory control response (i.e., a pain-inhibiting pain response) in the rat hindpaw after morphine-primed stress (Nation et al., 2018).

At the microcircuitry level, the stimulation of specifically dynorphin-containing neurons in the ventral NAc shell by selectively expressing channelrhodopsin- 2 in dynorphin-Cre+ mice decreased the motivation to selfadminister sucrose. The local infusion of microgram amounts of the $\kappa$-opioid receptor antagonist nor-BNI into the ventral NAc shell blocked conditioned place aversion and the lower motivation to self-administer sucrose that was produced by inflammation (Massaly et al., 2019). These authors hypothesized that the in vivo recruitment of NAc shell dynorphin neurons that act through $\kappa$-opioid receptors can drive paininduced negative affect (Massaly et al., 2016, 2019). Much evidence shows that the activation of $\kappa$-opioid receptor agonists elevates intracranial self-stimulation reward thresholds and decreases the function of the mesolimbic dopamine system (Todtenkopf et al., 2004; Chefer et al., 2013). However, systemic doses of the $\kappa$-opioid receptor antagonist (3R)-7-hydroxy-N-\{(2S)-1[(3R,4R)-4-(3-hydroxyphenyl)-3,4-dimethylpiperidin-1yl]-3-methylbutan-2-yl\}-1,2,3,4-tetrahydroisoquinoline3 -carboxamide (JDtic) failed to block conditioned place aversion that was produced by visceral and acid-induced pain in mice (Bagdas et al., 2016). Moreover, the $\kappa$-opioid receptor antagonist nor-BNI failed to block lactic acidinduced elevations of brain reward thresholds and the decrease in NAc dopamine in rats (Leitl et al., 2014). The type of pain is likely important, as well as the dependent variable that is used to measure negative affective effects of pain, the time course of dynorphin mediation, and the opposing actions of dynorphin neuron subcircuits (Cahill et al., 2014; Massaly et al., 2016). Furthermore, burgeoning interest in animal models of the affective/ motivational component of pain will help elucidate specific interactions with pain and hyperkatifeia in addiction (Edwards et al., 2020). Nevertheless, a role for the dynorphin/ $\kappa$-opioid receptor system in negative affective effects of chronic pain remains "an engaging hypothesis" (Cahill et al., 2014).

Melanocortin receptors also modulate nociceptin, opioid-induced analgesia, the development of tolerance to this effect, and opioid withdrawal-induced hyperalgesia (Kalange et al., 2007). Thus, there appears to be some role for glutamate, CRF, the dynorphin/ $\kappa$-opioid receptor system, and the melanocortin system in modulating the interplay between pain, stress, and reward processing. The high comorbidity between chronic pain, addiction, depression, and suicide provides a compelling rationale for further studies in this domain.

\section{B. Alcohol and Pain}

An association between pain and alcohol use and misuse is supported by clinical studies and metaanalyses. A meta-analysis of 18 controlled studies that compared pain in people who were given alcohol versus no alcohol provided support for the analgesic effects of alcohol (Thompson et al., 2017). The threshold appeared to be a mean BAL of $\sim 0.08 \%$ (i.e., the legal driving limit) for producing a small elevation of pain thresholds, and a significant reduction of pain intensity with a higher BAL was associated with greater pain insensitivity. Additionally, individuals with chronic pain had significantly greater odds of also meeting DSM-IV criteria for alcohol abuse/dependence (Demyttenaere et al., 2007). Indeed, there is a positive association between pain severity and a higher risk for AUD (Lawton and Simpson, 2009; Edlund et al., 2013). Perhaps more compelling, physical pain appears to be a significant predictor of alcohol use and heavy alcohol use and relapse to drinking after a period of abstinence (Larson et al., 2007; Caldeiro et al., 2008; Witkiewitz et al., 2015).

Theorists have long hypothesized that a negativereinforcement model of drug use assumes that individuals frequently consume alcohol (or opioids) to alleviate aversive physical or emotional states (Cappell and Herman, 1972; Sher and Levenson, 1982; Khantzian, 1985; Koob and Bloom, 1988; Baker et al., 2004; Ahmed and Koob, 2005). One model hypothesizes that there are effects of alcohol on pain and effects of pain on alcohol use (Zale et al., 2015). Here, pain serves as a situational motivator of alcohol consumption, partly as a function of pain-induced negative affect (Zale et al., 2015). Moderate alcohol use was associated with positive painrelated outcomes (e.g., greater quality of life), but excessive drinking and AUD were associated with deleterious pain-related outcomes (e.g., greater pain severity; Zale et al., 2015). As noted above, alcohol produces analgesic effects (Thompson et al., 2017). Individuals often report consuming alcohol to selfmedicate physical and emotional pain (Holahan et al., 2001; Brennan et al., 2005; Aira et al., 2008; Riley and King, 2009; Zale et al., 2015). Indeed, negative affect, measured by the Beck Depression Inventory, increased thermal and electrical sensation pain sensitivity in alcohol withdrawal, and depressed mood in patients was associated with lower pain tolerance (Jochum et al., 2010). In a secondary analysis of two large clinical trials of AUD, negative affect significantly mediated the association between pain and drinking 
outcomes (Witkiewitz et al., 2010). In a study that tested the effects of experimentally induced pain on proximal antecedents of alcohol consumption as proxies for ad libitum alcohol consumption and investigated pain-induced negative affect as a mechanism of action, participants in the pain condition subsequently endorsed a greater urge and intention to drink, and these effects were mediated by paininduced negative affect (Moskal et al., 2018). Thus, individuals with comorbid pain and AUD may drink to alleviate pain-related negative affect, and behavioral treatments that improve pain-coping skills may enhance pain-management abilities, subsequently reducing coping-motivated drinking (Moskal et al., 2018). These effects could explain alcohol misuse in individuals with persistent pain despite high-dose alcohol having significant potential negative consequences for long-term health. These findings also suggest that medications that address both physical and emotional pain may be useful for treating alcohol and drug addiction.

As with opioids, although acute alcohol administration in animal studies may confer analgesic effects, abstinence from chronic alcohol consumption produces hyperalgesia (Gatch et al., 1999; Gatch, 2009; Egli et al., 2012). For example, rodent models of alcohol withdrawal have reliably observed hyperalgesia in multiple pain assays (Gatch et al., 1999; Gatch, 2009; Egli et al., 2012). The neurobiological substrates for alcohol withdrawal-induced hyperalgesia have to date focused on a hyperkatifeia neurocircuitry interaction. Corticotropinreleasing factor in the amygdala, particularly in the CeA, is hypothesized to play an important role in affect-like responses that are associated with pain and pain modulation (Ji et al., 2013). In a model of arthritic pain, the blockade of $\mathrm{CRF}_{1}$ receptors in the CeA inhibited both pain- and anxiety-like behaviors (Ji et al., 2007; Fu and Neugebauer, 2008). Hyperalgesia that is associated with alcohol withdrawal can be blunted by the blockade of $\mathrm{CRF}_{1}$ receptors (Edwards et al., 2012b), and CRF receptor antagonists can blunt nociceptive hypersensitivity in a wide variety of pain assays in animals (Hummel et al., 2010).

Intraventricular and intranasal administration of melanocortin-4 receptor antagonists reduced thermal hyperalgesia in alcohol-dependent rats during withdrawal (Roltsch Hellard et al., 2017), and this effect appeared to be mediated by melanocortin- 4 receptor signaling in the CeA (Avegno et al., 2018). Other molecular targets include $\mathrm{PKC} \varepsilon$, in which the administration of an antisense oligodeoxynucleotide to $\mathrm{PKC} \varepsilon$ blocked alcohol withdrawal-induced hyperalgesia (Shumilla et al., 2005; Dina et al., 2006). Alcohol withdrawal-induced hyperalgesia was also attenuated by a histone deacetylase inhibitor, suggesting possible epigenetic mechanisms (Pradhan et al., 2019).

Another structure that impacts the mesolimbic dopamine circuit and is implicated in alcohol withdrawal- induced hyperalgesia is the habenula (Zuo et al., 2019; see the Within-System Neuroadaptations section above). The lateral habenula projects to the VTA, and its activation is known to decrease activity in VTA dopamine neurons (Hikosaka, 2010; see the WithinSystem Neuroadaptations section above). Alcohol withdrawal-induced hyperalgesia and relapse-like alcohol consumption were reversed by the chemogenetic inhibition of lateral habenula neurons, the pharmacological activation of M-channels, and the overexpression of the M-channel subunit potassium voltage-gated channel subfamily KQT member 3 (Kang et al., 2019). Intralateral habenula infusion of serotonin 5-hydroxytryptamine- 2 receptor antagonists or a serotonin reuptake blocker decreased nociceptive sensitivity and alcohol intake in alcohol-withdrawn rats (Zuo et al., 2019).

\section{Pain and Animal Models of Addiction}

Given the widespread use of drug self-administration techniques to assess the neurobiological substrates of addiction, some have argued that drug self-administration could be used in combination with chronic pain models as a tool to develop novel therapies with less abuse liability and potential for producing physical dependence (Martin and Ewan, 2008). However, although a few mouse studies have shown some increase in drinking with chronic pain in a neuropathic model of pain (González-Sepúlveda et al., 2016) and osteoarthritis model of pain (Butler et al., 2017), the data to date that show increases in the rewarding effects of opioids or increases in opioid self-administration after chronic pain have been limited (Ozaki et al., 2002; Narita et al., 2005; Martin et al., 2007; Hipólito et al., 2015). One possibility is that rodents must learn the association between the removal of withdrawal and drug taking, as has been demonstrated in studies of alcohol selfadministration during withdrawal using chronic intermittent exposure to alcohol vapor (Roberts et al., 1996). This may be particularly difficult in an animal model, although clonidine was shown to maintain selfadministration intrathecally in spinal nerve-ligated rats only over a range of doses that reversed tactile hypersensitivity in these animals (Martin et al., 2006).

Future studies of drug self-administration in laboratory animals in the presence of chronic pain may need to focus more on chronic emotional-like pain rather than physical pain (Edwards et al., 2020). Indeed, in a study of chronic inflammatory pain that was induced by a hindpaw injection of Complete Freund's Adjuvant, dynorphin expression increased in dynorphin-containing neurons in a discrete subregion of the NAc shell through a disinhibition mechanism, and pain increased $\kappa$-opioid receptor function (Massaly et al., 2019). Even more compelling, using a series of pharmacological, optogenetic, and chemogenetic approaches, the authors showed that both dynorphin-containing neurons and $\kappa$-opioid receptor 


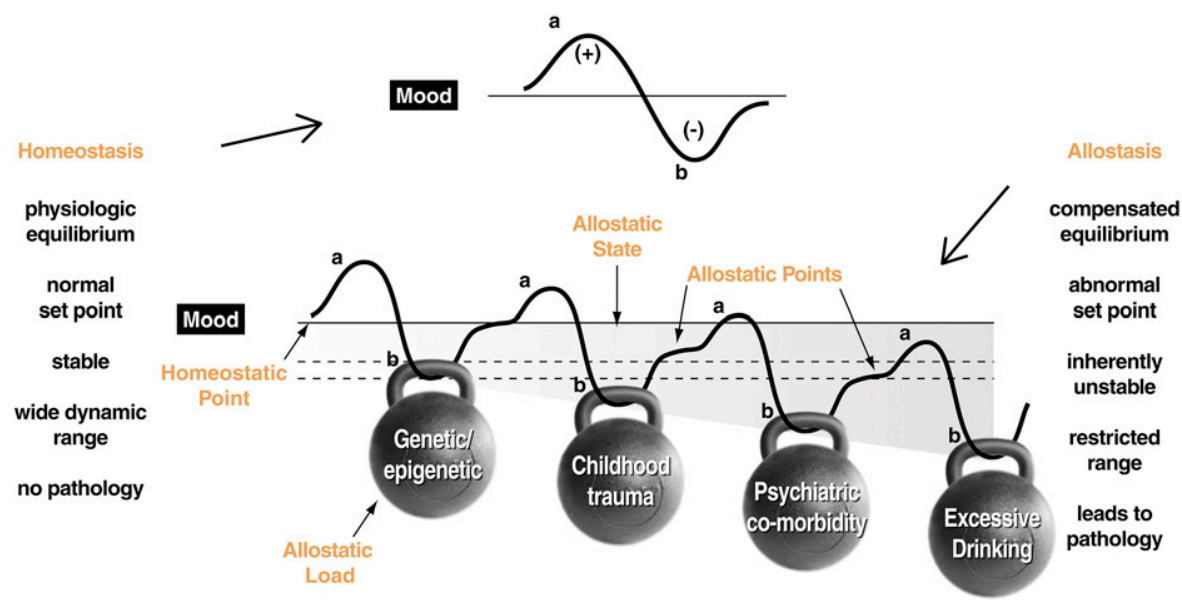

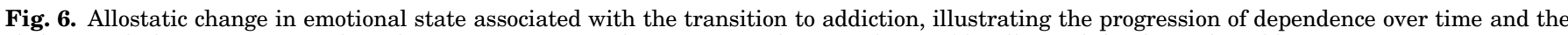

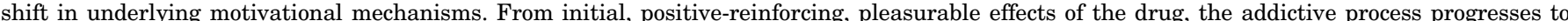

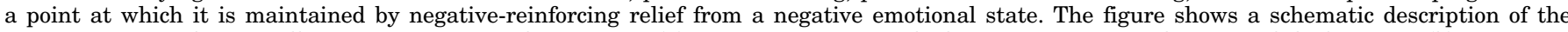

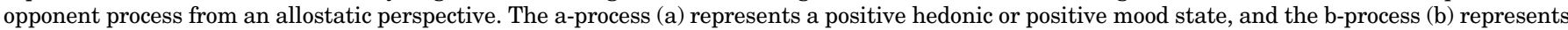

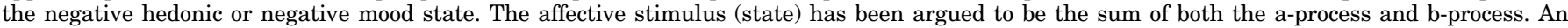

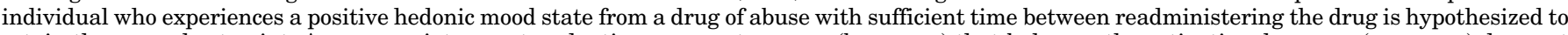

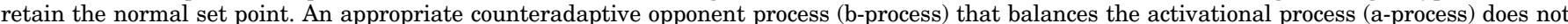

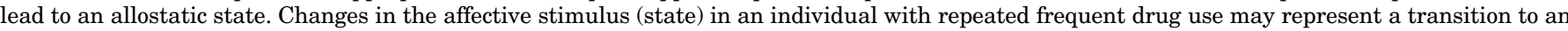

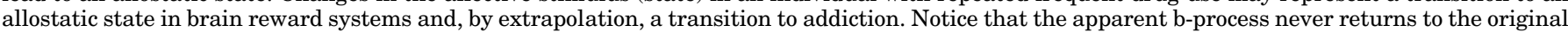

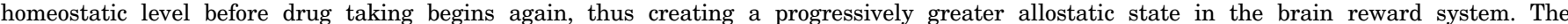

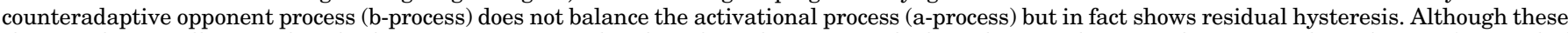

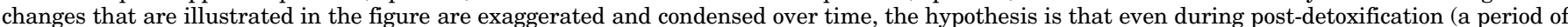

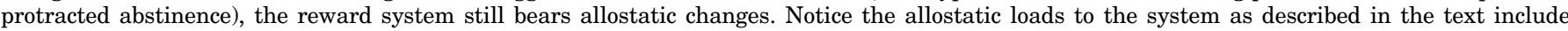

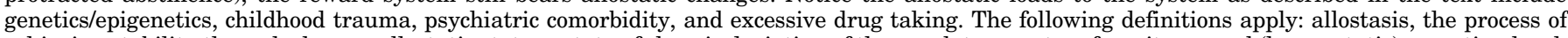

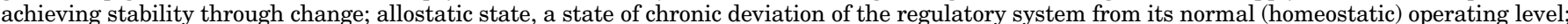

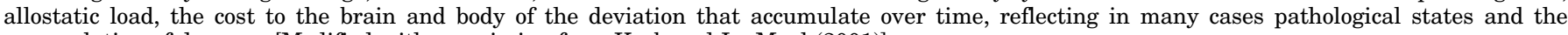
accumulation of damage. [Modified with permission from Koob and Le Moal (2001)].

activity in the NAc shell were necessary and sufficient to drive pain-induced negative affective states (Massaly et al., 2019).

\section{Individual Differences in Hyperkatifeia}

\section{A. Genetics}

Finally, individual differences beg the question of selective vulnerability in individuals who enter the addiction cycle via the withdrawal/negative affect stage (Fig. 6). From a nosology perspective, the Addictions Neuroclinical Assessment framework allows the identification of individuals with phenotypes that signal dysregulation in this domain (Kwako et al., 2016). Genetic association studies that have focused on neurobiological substrates for hyperkatifeia (CRF and other brain stress system) are limited, but some are listed below.

An association was found between binge drinking and single-nucleotide polymorphisms (SNPs) of the $\mathrm{CRF}_{1}$ receptor gene in adolescents and alcohol-dependent adults (Treutlein et al., 2006), one of which, rs1876831, is located on an intron that could potentially influence $\mathrm{CRF}_{1}$ receptor gene transcription. In adolescents who were homozygous for the $\mathrm{C}$ allele of the rs1876831 SNP of the $\mathrm{CRF}_{1}$ receptor gene, a history of stress was associated with greater increases in future alcohol intake (Blomeyer et al., 2008; Schmid et al., 2010) and an earlier onset of drinking (Schmid et al., 2010). In individuals who were already dependent, $\mathrm{CRF}_{1} \mathrm{SNP}$ s also predicted greater alcohol consumption (Treutlein et al., 2006). Polymorphisms of the CRF binding protein (CRHBP) gene have also been associated with the risk of both heroin addiction in African Americans (Levran et al., 2014) and a higher risk of drinking and/or anxiety in subjects with AUD (Haass-Koffler et al., 2016). Polymorphisms of the genes that encode the human $\kappa$-opioid receptor (Yuferov et al., 2004; Gerra et al., 2007) and prodynorphin (Clarke et al., 2012) have also been associated with a higher risk for opioid addiction.

Studies have also linked NPY or NPY receptor polymorphisms to addiction. Associations were found between SNPs of the NPY Y2 receptor (NPY2R) gene and alcohol dependence, alcohol withdrawal symptoms, tobacco addiction, comorbid alcohol and cocaine dependence, and cocaine dependence (Wetherill et al., 2008; Okahisa et al., 2009; Mutschler et al., 2012; Bhaskar et al., 2013). A polymorphism of the oxytocin gene, rs6133010, was associated with alcohol dependence in a northern Chinese Han population (Yang et al., 2017). For further details of these polymorphisms and their associations with hyperkatifeia, see Koob and Mason (2016) and Spierling and Zorrilla (2017).

\section{B. Development, Comorbidities, Epigenetics, and Hyperkatifeia}

Adult AUD and substance use disorders are linked not only to genetics but also to life experiences, such as 
adverse childhood events (Khoury et al., 2010; Mingione et al., 2012). For example, there is a cumulative effect of childhood trauma on the risk of substance dependence, in which for every unit increase in the number of types of violent crime/abuse experiences, the odds of a person developing dependence on alcohol, cocaine, and/or opioids almost doubled (Douglas et al., 2010; Fig. 6). Exposure to childhood trauma is a major risk factor for the development and maintenance of AUD (De Bellis, 2002) and predicts an earlier onset of heavy drinking (Waldrop et al., 2007; Enoch, 2011). Thus, adverse childhood events are associated with an increase in alcohol and substance misuse, and repeated adverse events may potentiate such effects. Early-onset adolescent exposure to alcohol, tobacco, and drugs of abuse also predicts later AUD and substance use disorder and alcohol- and drug-related problems (Grant et al., 2001; Englund et al., 2008; Enoch, 2011). When the prevalence of lifetime illicit or nonmedical drug use and dependence was estimated for each year of onset of drug use from the ages of 13 and $<21$ years, the early onset of drug use was a significant predictor of the subsequent development of drug abuse (Hingson et al., 2003). The lifetime prevalence of DSM-IV substance dependence among people who began using drugs under the age of 14 was $34 \%$ and dropped to $14 \%$ for those who began using at age 21 or older (Grant and Dawson, 1998).

There is also substantial comorbidity between substance use and other psychiatric disorders. A recent epidemiological study showed particularly high comorbidity between AUD and major depressive disorder and bipolar disorder and comorbidity with personality disorders and anxiety disorders (Grant et al., 2015). Alcohol misuse correlates with poor mental health and often precedes diagnoses of mental health conditions. Alcohol is commonly used in an effort to cope with symptoms, but in the end, it makes the prognosis worse, and comorbid mental health conditions complicate treatments for AUD (Mäkelä et al., 2015). Such comorbidity has been particularly linked to the neural substrates of the extended amygdala that mediate common elements of negative affect and hyperkatifeia (Centanni et al., 2019).

The role of environmental factors begs the question of mechanism and inevitably leads to epigeneticsnamely, the way in which environmental factors or other mechanisms of the expression of heritable traits are modified without a change in the DNA sequence. One example of epigenetic modifications in the extended amygdala provides a molecular basis of how hyperkatifeia that is engaged by repeated alcohol use, genetic vulnerability, and alcohol exposure during crucial developmental periods interact. Acute alcohol exposure in rodents produces an anxiolytic-like response that is mediated at least partially by the inhibition of histone deacetylase, an increase in histone acetylation, and an increase in the opening of chromatin (Pandey et al., 2008a). Such an opening of chromatin results in an increase in synaptic plasticity-related genes, such as BDNF, and an increase in activityrelated cytoskeleton-associated protein and NPY in the CeA (Pandey et al., 2008a,b). However, with chronic alcohol exposure and subsequent withdrawal, all of these epigenetic activities are reversed, with decreases in histone acetylation through an increase in histone deacetylase activity and decreases in the expression of BDNF, activity-related cytoskeleton-associated protein, and NPY in CeA circuitry that produce anxiety-like responses (Pandey et al., 2008a,b). Adolescent exposure to alcohol also leads to a deficit in global and genespecific histone acetylation in the amygdala that is associated with a decrease in the expression of several synaptic plasticity-associated genes and contributes to heightened anxiety-like responses and excessive alcohol intake (Pandey et al., 2015). Thus, one can envision that ongoing and future epigenetic studies may help us understand risk factors for addiction that are biologically embedded and identify windows of vulnerability, such as childhood adverse events, adolescent exposure, and genetics. Ultimately, such approaches will capitalize on existing neurocircuitry of addiction for prevention or intervention, the identification of epigenetic biomarkers of addiction risk, and the development of personalized approaches to treatment (Cecil et al., 2016).

\section{The Case for Hyperkatifeia as a Target for Medications Development}

\section{A. Reward Dysregulation, Stress Surfeit, Pain, and Negative Reinforcement}

The thesis outlined herein is that the knowledge of neuroadaptations that occur within the framework of the hyperkatifeia construct of the addiction cycle withdrawal/negative affect stage provides fertile ground for developing new treatments for AUD and OUD and, by extrapolation, other drugs of addiction. Significant hyperkatifeia is also associated with psychostimulant, tobacco, and cannabinoid addiction from the perspectives of phenotypes and neurocircuitry/neurotransmitter systems (Baker et al., 1987, 2004; Diana, 2011; Cook et al., 2015; Koob, 2015; Ashok et al., 2017). Acute withdrawal-induced hyperkatifeia that results from chronic and excessive opioid and alcohol administration has numerous effects on neuropharmacological systems that interface with the extended amygdala, a key pathway that is associated with the withdrawal/negative affect stage of the addiction cycle. Alcohol and opioids act directly on neurotransmitter systems that are associated with incentive salience and reward pathways and indirectly via GABA and glutamate systems to activate reward pathways. With excessive use, these systems undergo neuroadaptations with 
chronic drug exposure that lower reward function, increase stress function, and increase the negative affect component of pain, all of which contribute to the construct of hyperkatifeia. The argument is that these specific neurocircuitry dysregulations contribute to the links that have been hypothesized to exist between the neural mechanisms that are responsible for hyperkatifeia and hyperalgesia (Shurman et al., 2010; Koob, 2019).

From a negative-reinforcement perspective, in a study cited above, rats showed avoidance of the cues that were paired with a hypothesized negative emotional state of precipitated opioid withdrawal, and this conditioned avoidance was blocked by a direct intracerebral injection of a peptide CRF antagonist in the CeA (Heinrichs et al., 1995). More recently, also as noted above, optogenetically shutting off CRF neurons in the CeA selectively suppressed alcohol-dependent drinking, but only in dependent animals (de Guglielmo et al., 2019). Thus, CRF in the extended amygdala may play an important role in the development of hyperkatifeia that drives compulsive-like drug seeking that is associated with opioids and alcohol via a negative-reinforcement process (Koob, 2019). Medications that have been developed to reverse the neurochemical changes outlined above would be hypothesized to be effective subjects when hyperkatifeia motivates drug seeking.

\section{B. Negative Results}

Despite the overwhelming evidence that $\mathrm{CRF}_{1}$ receptor antagonists block hyperkatifeia-like responses in rodents, there are limited data on the effects of $\mathrm{CRF}_{1}$ receptor antagonists on addiction in humans. One study reported negative results with one dose of a $\mathrm{CRF}_{1}$ receptor small-molecule antagonist in a human laboratory study in reversing stress-induced craving but some efficacy in reversing HPA axis dysregulation (Schwandt et al., 2016). This study had a small sample size, was limited to only female subjects, and explored only one dose (Schwandt et al., 2016). However, the data on HPA axis endpoints confirmed target engagement by the tested dose and imply a dissociation between observation of the predicted endocrine effect without the predicted behavioral effect. Additionally, no clinical studies to date have found efficacy of $\mathrm{CRF}_{1}$ receptor antagonists for the treatment of other stress-related psychiatric disorders, such as major depression, generalized anxiety disorder, social anxiety, or posttraumatic stress disorder (Griebel and Holsboer, 2012; Dunlop et al., 2017). No double-blind treatment study of alcohol or opioid addiction has been conducted. The reason for such treatment failures is largely unknown, but several possibilities include issues about the brain penetrance and receptor occupancy of small nonpeptide $\mathrm{CRF}_{1}$ receptor antagonists and the need for circumstances in which prostress-like CRF-CRF 1 circuits are dynamically activated, which would mean evaluating the efficacy of $\mathrm{CRF}_{1}$ receptor antagonists with regard to particular symptoms of psychiatric disorders, specific patient subgroups, or specific genetic vulnerabilities (Griebel and Holsboer, 2012; Spierling and Zorrilla, 2017).

Other negative results for the hyperkatifeia hypothesis have been reported based on behavioral procedures that reflect elements of compulsive-like responding for drugs. Studies did show that changes in choice responding in rhesus monkeys during extended opioid exposure and subsequent opioid withdrawal reflected an increase in the reinforcing strength of heroin in a manner that supports the hypothesis that negative reinforcement is a source of motivation (Negus and Banks, 2018). However, using this choice model, a study in rhesus monkeys failed to show positive effects with a $\mathrm{CRF}_{1}$ receptor antagonist (although one of three monkeys did respond) and a $\kappa$-opioid receptor antagonist, but it did show positive results with opioid substitution drugs (Negus and Rice, 2009). Obviously, species differences may be an important factor. In rodent studies, choice procedures are notoriously resistant to disruption, and a large proportion of rats continue to select a sweet solution (e.g., saccharin) rather than the drug even after the clear establishment of dependence (Lenoir et al., 2013; Ahmed, 2018). Altogether, these observations suggest that some measures of hyperkatifeia, such as the expression of stress-like responses in specific contexts and the escalation of drug taking in rodents, are sensitive to treatment with anti-hyperkatifeia agents, whereas other measures, such as choice procedures, may not be sensitive. Given that no single animal model is predictive of all aspects of the human condition, future studies might engage human laboratory studies that capture the phenotype that is exhibited by the activation of negative-reinforcement circuits, and any positive results could be back-translated to animal models.

\section{Construct Validity}

Construct validity refers to the explanatory power of a model but can also be defined in terms of the construct of functional equivalence, defined as "assessing how controlling variables influence outcome in the model and the target disorders" (Katz and Higgins, 2003). A validation of the present thesis may be derived not only from such observations as a compromised dopamine system or sensitized HPA system in animal models and humans but also from construct validity, in which the observations that treatments for hyperkatifeia in animal models are effective in OUD and AUD in the clinical setting. For OUD, all medically assisted treatments that interact with the $\mu$-opioid receptor system (e.g., methadone and buprenorphine) reverse opioid withdrawal-induced hyperkatifeia in animal models and have established efficacy in treating opioid addiction (Mello and Mendelson, 1980). The opioid 
substitution drug methadone transiently blocks opioid self-administration in rats and dogs but not in monkeys (Jones and Prada, 1977; Mello et al., 1983; Leri et al., 2004; Alizadeh et al., 2018), and buprenorphine decreases opioid self-administration in dependent rats and monkeys (Mello et al., 1983; Chen et al., 2006). However, one would expect a full agonist treatment to be transient because each subsequent treatment would contribute to future hyperkatifeia, which would consequently drive further tolerance and drug seeking (Masten et al., 1978). Methadone, buprenorphine, and other opioids are, however, substitution treatments, so they only transiently prevent hyperkatifeia while the drug in on board, but they do not reverse it. Several studies have shown that methadone and levo- $\alpha$-acetylmethadol substitute for morphine self-administration (Jones and Prada, 1977; Moreton et al., 1976; Young et al., 1978). Clearly, the opioid medication-assisted treatment of opioid addiction blocks hyperkatifeia in humans, but only while the drug is on board. Moreover, in the domain of stress dysregulation, the pioneering work of Kreek and colleagues showed that methadonemaintained individuals reestablish a homeostatic-like level of HPA activity (Kreek, 1973; Kreek and Koob, 1998).

For alcohol in animal models, alcohol self-administration in dependent rats prevented the manifestation of a withdrawal syndrome (Roberts et al., 1996) and reversed the hypodopaminergic effects of alcohol withdrawal (Weiss et al., 1996). With regard to non-alcohol-like drugs, acamprosate is one of three Food and Drug Administration-approved medications for the treatment of AUD that is widely prescribed worldwide, and it has an effect size (Mason, 2003; Maisel et al., 2013; Jonas et al., 2014) that is similar to selective serotonin reuptake inhibitors for depression (Schalkwijk et al., 2014). Acamprosate was developed from animal models of dependence-induced drinking (Le Magnen et al., 1987) and also blocked hyperkatifeia that was associated with alcohol withdrawal in rodent models (Cole et al., 2000). Acamprosate also blocked sleep disturbances that were associated with protracted abstinence in humans (Perney et al., 2012), again linking its therapeutic actions to the reversal of hyperkatifeia.

Gabapentin is an anticonvulsant $\mathrm{Ca}^{2+}$ channel blocker that increases GABAergic neurotransmission in the brain. Gabapentin decreased GABA inhibitory postsynaptic current amplitudes in the CeA in alcoholdependent rats, suggesting the "normalization" of dependence-induced GABA dysregulation in the CeA. It also blocked hyperkatifeia-like responses in alcoholdependent rats and blocked dependence-induced drinking in rodents (Roberto et al., 2008). In human studies, gabapentin blocked craving in a human laboratory study in non-treatment-seeking AUD subjects (Mason et al., 2009) and was shown to be an effective treatment of AUD in a double-blind placebo-controlled clinical trial (Mason et al., 2014). Notably, gabapentin reversed sleep disturbances in AUD (Mason et al., 2014). A recent overall-negative study with a gabapentin prodrug has been reported, but the consensus was that the dose was low, and secondary analyses showed some efficacy in some subgroups of subjects in the study (Falk et al., 2019; Laska et al., 2020). Gabapentin is a widely used off-label drug for AUD and is currently on the Veterans Administration formulary for the treatment of AUD (https://www. veteranshealthlibrary.va.gov/Encyclopedia/142,41564_VA; accessed August 10, 2020).

Similarly, the chronic administration of mifepristone, a glucocorticoid and progesterone receptor antagonist, when administered systemically in rats during the course of alcohol vapor exposure, blocked the escalation of drinking during withdrawal that developed during dependence induction (Vendruscolo et al., 2012). In a human laboratory study of non-treatment-seeking subjects with AUD, mifepristone decreased alcoholcued craving in the laboratory and reduced alcohol consumption during the 1-week treatment phase and 1-week post-treatment phase (Vendruscolo et al., 2015).

Additionally, $\alpha_{2}$-adrenergic receptor agonists block both somatic signs of withdrawal and anxiogenic-like responses to withdrawal in rodents. In humans, the $\alpha_{2^{-}}$ adrenergic receptor agonists clonidine and dexmedetomidine have been used extensively to treat acute alcohol withdrawal. It has been argued that $\alpha_{2}$-adrenergic receptor agonists safely and effectively reduce symptoms of sympathetic overdrive and concomitant medication use during the treatment of alcohol withdrawal (Muzyk et al., 2011).

\section{Conditioning in Withdrawal and Protracted Abstinence}

As discussed above, AUD and OUD are hypothesized to move to compulsive drug seeking via negativereinforcement mechanisms because the use of these drugs transiently prevents or relieves negative emotional symptoms or hyperkatifeia. This compulsive drug seeking defends a hedonic set point that gradually gains allostatic load and shifts from a homeostatic hedonic state to an allostatic hedonic state (Koob and Le Moal, 2001; Fig. 6). Negative affect networks have been hypothesized to be activated not only during withdrawal but also by conditioned predictors of withdrawal (e.g., drug cues) and unappetitive consequences (e.g., punishment and frustrative nonreward) or their conditioned cues (Baker et al., 1987). Here, as hypothesized by opponent process and allostatic theories, escape from and the avoidance of negative affect are powerful motives for compulsive drug use (Solomon, 1980; Koob and Le Moal, 2001; Baker et al., 2004; Evans and Cahill, 2016). Indeed, opioid addiction has been hypothesized to be sustained by a learned association between opioids 
TABLE 2

Molecular and neurocircuitry targets for medications development to reverse hyperkatifeia of the withdrawal/negative affect stage for OUD and AUD

\begin{tabular}{|c|c|c|c|}
\hline Target & Manipulation & Opioids & Alcohol \\
\hline \multicolumn{4}{|l|}{ Within-system } \\
\hline Dopamine & Dopamine receptor partial agonists & $\boldsymbol{\nu}$ & $\boldsymbol{\nu}$ \\
\hline \multirow{4}{*}{ Opioid peptides } & G protein modulators & $\boldsymbol{\nu}$ & - \\
\hline & CREB & $\boldsymbol{\nu}$ & - \\
\hline & cAMP/PKA modulators & - & レ \\
\hline & CREB & - & $\boldsymbol{\nu}$ \\
\hline \multirow[t]{2}{*}{ GABA/glutamate } & GABA subunit receptor agonists & $\boldsymbol{\nu}$ & $\boldsymbol{\nu}$ \\
\hline & Glutamate receptor antagonists & $\boldsymbol{\nu}$ & $\nu$ \\
\hline \multicolumn{4}{|l|}{ Between-system } \\
\hline CRF & $\mathrm{CRF}_{1}$ receptor antagonists & $\boldsymbol{\nu}$ & $\boldsymbol{\nu}$ \\
\hline Dynorphin & $\kappa$-Opioid receptor antagonists & $\nu$ & $\nu$ \\
\hline Vasopressin & $\mathrm{V}_{1 \mathrm{~b}}$ receptor antagonists & $\boldsymbol{\nu}$ & $\boldsymbol{\nu}$ \\
\hline \multirow{3}{*}{ Norepinephrine } & $\alpha_{1}$-Adrenergic receptor antagonists & $\boldsymbol{\nu}$ & $\boldsymbol{\nu}$ \\
\hline & $\alpha_{2}$-Adrenergic receptor agonists & $\nu$ & $\nu$ \\
\hline & $\beta$-Adrenergic receptor antagonists & $\boldsymbol{\nu}$ & $\boldsymbol{\nu}$ \\
\hline \multirow[t]{2}{*}{ Hypocretin } & Hcrt-1 receptor antagonists & $\boldsymbol{\nu}$ & $\boldsymbol{\nu}$ \\
\hline & Hcrt-2 receptor antagonists & $\nu$ & $\nu$ \\
\hline \multirow[t]{3}{*}{ Neuroimmune system } & Neuroimmune modulators & & \\
\hline & Tumor necrosis factor & $\boldsymbol{\nu}$ & $\boldsymbol{\nu}$ \\
\hline & Phosphodiesterase inhibitors & - & $\nu$ \\
\hline \multicolumn{4}{|l|}{ Antistress modulators } \\
\hline \multirow[t]{2}{*}{ NPY } & $Y_{1}$ receptor agonists & $\boldsymbol{\nu}$ & $\boldsymbol{\nu}$ \\
\hline & $\mathrm{Y}_{2}$ receptor antagonists & $\boldsymbol{\nu}$ & レ \\
\hline Nociceptin & Nociceptin receptor agonists & $\boldsymbol{\nu}$ & $\boldsymbol{\nu}$ \\
\hline \multirow{2}{*}{ Endocannabinoids } & FAAH inhibitors & $\boldsymbol{\nu}$ & $\boldsymbol{\nu}$ \\
\hline & MAGL inhibitors & $\nu$ & $\nu$ \\
\hline Oxytocin & Oxytocin receptor agonists & $\boldsymbol{\nu}$ & $\boldsymbol{\nu}$ \\
\hline \multicolumn{4}{|l|}{ Hyperalgesia/pain } \\
\hline Glutamate & NMDA receptor antagonists & $\boldsymbol{\nu}$ & $\boldsymbol{\nu}$ \\
\hline $\mathrm{CRF}$ & $\mathrm{CRF}_{1}$ receptor antagonists & $\boldsymbol{\nu}$ & $\boldsymbol{\nu}$ \\
\hline Dynorphin & $\kappa$-Opioid receptor antagonists & $\boldsymbol{\nu}$ & - \\
\hline Melanocortin & Melanocortin receptor 4 antagonists & $\boldsymbol{\nu}$ & $\boldsymbol{\nu}$ \\
\hline \multirow{2}{*}{ PKC } & $\mathrm{PKC} \varepsilon$ inhibitor & - & $\boldsymbol{\nu}$ \\
\hline & PKC $\gamma$ inhibitor & $\boldsymbol{\nu}$ & - \\
\hline Serotonin & $5-\mathrm{HT}_{2 \mathrm{~A}}$ receptor antagonist & - & レ \\
\hline
\end{tabular}

PKA, protein kinase A; -, no data available; 5-HT2A, 5-hydroxytryptamine-2A.

and relief from an existing dysphoric state, and this learned association is formed through negative reinforcement (Evans and Cahill, 2016). As noted above, the neurocircuitry that is activated during conditioned withdrawal shows a remarkable similarity to neurocircuitry that is associated with acute withdrawal (Carmack et al., 2019), consistent with the argument that stressful events during protracted abstinence can generalize to such a dysphoric state and produce recall that opioid drugs can relieve such a negative state (Koob, 2008; Evans and Cahill, 2016).

A neglected area in the domain of the development of medications and behavioral strategies is the identification of specific targets of the hyperkatifeia component of protracted abstinence. Studies have reported hypersensitivity to pain and discomfort with opioids that can last for over 1 year post-detoxification, and hypersensitivity to pain is linked to the misregulation of alcohol consumption as a coping response. Based on preclinical studies, medications and behavioral therapies that reset the HPA axis/CRF brain system and return other brain stress neurotransmitters and neuromodulators to homeostasis may be promising new targets for medication development. Table 2 outlines neurotransmitter and molecular targets for hyperkatifeia based on the neuropharmacological/neurocircuitry framework that is outlined above. Although not exhaustive, this list may serve as a starting point to explore a relatively unexplored domain of treatment. Much of the clinical world recognizes the role of hyperkatifeia in driving addiction (Marlatt and Gordon, 1980; Khantzian, 1997, 2012 , 2013), but most preclinical medication development efforts to date have focused on blocking or modulating drug reward. Medication development for the treatment of addiction must consider the dysregulation of pain and stress systems during acute withdrawal and long into recovery.

\section{Acknowledgments}

The author thanks Dr. Aaron White for gathering the epidemiological data and Michael Arends for his assistance with manuscript preparation and proofreading.

\section{Authorship Contributions \\ Wrote or contributed to the writing of the manuscript: Koob.}

\section{References}

Ahmed SH (2018) Individual decision-making in the causal pathway to addiction: contributions and limitations of rodent models. Pharmacol Biochem Behav 164 $22-31$.

Ahmed SH, Kenny PJ, Koob GF, and Markou A (2002) Neurobiological evidence for hedonic allostasis associated with escalating cocaine use. Nat Neurosci 5:625-626. Ahmed SH and Koob GF (2005) Transition to drug addiction: a negative reinforcement model based on an allostatic decrease in reward function. Psychopharmacology (Berl) 180:473-490. 
Aira M, Hartikainen S, and Sulkava R (2008) Drinking alcohol for medicinal purposes by people aged over 75: a community-based interview study. Fam Pract 25: $445-449$.

Albeck DS, McKittrick CR, Blanchard DC, Blanchard RJ, Nikulina J, McEwen BS, and Sakai RR (1997) Chronic social stress alters levels of corticotropin-releasing factor and arginine vasopressin mRNA in rat brain. $J$ Neurosci 17:4895-4903.

Al-Hasani R and Bruchas MR (2011) Molecular mechanisms of opioid receptordependent signaling and behavior. Anesthesiology 115:1363-1381.

Alheid GF, De Olmos JS, and Beltramino CA (1995) Amygdala and extended amygdala, in The Rat Nervous System, 2nd ed (Paxinos G ed) pp 495-578, Academic Press, San Diego, CA.

Alizadeh M, Zahedi-Khorasani M, and Miladi-Gorji H (2018) Treadmill exercise attenuates the severity of physical dependence, anxiety, depressive-like behavior and voluntary morphine consumption in morphine withdrawn rats receiving methadone maintenance treatment. Neurosci Lett 681:73-77.

Altarifi AA, David B, Muchhala KH, Blough BE, Akbarali H, and Negus SS (2017) Effects of acute and repeated treatment with the biased mu opioid receptor agonist TRV130 (oliceridine) on measures of antinociception, gastrointestinal function, and abuse liability in rodents. $J$ Psychopharmacol 31:730-739.

Alvarez-Jaimes L, Polis I, and Parsons LH (2009) Regional influence of cannabinoid $\mathrm{CB}_{1}$ receptors in the regulation of ethanol self-administration by wistar rats. Open Neuropsychopharmacol J 2:77-85.

American Psychiatric Association (1994) Diagnostic and Statistical Manual of Mental Disorders, 4th ed, American Psychiatric Press, Washington, DC

American Psychiatric Association (2013) Diagnostic and Statistical Manual of Mental Disorders, 5th ed, American Psychiatric Publishing, Washington, DC

Anderson RI, Lopez MF, and Becker HC (2016a) Forced swim stress increases ethanol consumption in C57BL/6J mice with a history of chronic intermittent ethanol exposure. Psychopharmacology (Berl) 233:2035-2043.

Anderson RI, Lopez MF, and Becker HC (2016b) Stress-induced enhancement of ethanol intake in C57BL/6J mice with a history of chronic ethanol exposure: involvement of kappa opioid receptors. Front Cell Neurosci 10:45

Anderson RI, Lopez MF, Griffin WC, Haun HL, Bloodgood DW, Pati D, Boyt KM, Kash TL, and Becker HC (2019) Dynorphin-kappa opioid receptor activity in the central amygdala modulates binge-like alcohol drinking in mice. Neuropsychopharmacology 44:1084-1092.

Angst MS and Clark JD (2006) Opioid-induced hyperalgesia: a qualitative systematic review. Anesthesiology 104:570-587.

Antoni FA (1993) Vasopressinergic control of pituitary adrenocorticotropin secretion comes of age. Front Neuroendocrinol 14:76-122.

Arora S and Vohora D (2016) Comparative evaluation of partial $\alpha 2$-adrenoceptor aonist and pure $\alpha 2$-adrenoceptor antagonist on the behavioural symptoms of withdrawal after chronic alcohol administration in mice. Basic Clin Pharmacol Toxicol 119:202-209.

Ashok AH, Mizuno Y, Volkow ND, and Howes OD (2017) Association of stimulant use with dopaminergic alterations in users of cocaine, amphetamine, or methamphetamine: a systematic review and meta-nalysis. JAMA Psychiatry 74:511-519.

Avegno EM, Lobell TD, Itoga CA, Baynes BB, Whitaker AM, Weera MM, Edwards S, Middleton JW, and Gilpin NW (2018) Central amygdala circuits mediate hyperalgesia in alcohol-dependent rats. J Neurosci 38:7761-7773.

Bagdas D, Muldoon PP, AlSharari S, Carroll FI, Negus SS, and Damaj MI (2016) Expression and pharmacological modulation of visceral pain-induced conditioned place aversion in mice. Neuropharmacology 102:236-243.

Bahi A (2015) The oxytocin receptor impairs ethanol reward in mice. Physiol Behav 139:321-327.

Bailey CP, O'Callaghan MJ, Croft AP, Manley SJ, and Little HJ (2001) Alterations in mesolimbic dopamine function during the abstinence period following chronic ethanol consumption. Neuropharmacology 41:989-999.

Bajo M, Madamba SG, Roberto M, Blednov YA, Sagi VN, Roberts E, Rice KC, Harris RA, and Siggins GR (2014) Innate immune factors modulate ethanol interaction with GABAergic transmission in mouse central amygdala. Brain Behav Immun 40: 191-202.

Baker TB, Morse E, and Sherman JE (1987) The motivation to use drugs: a psychobiological analysis of urges, in Alcohol and Addictive BehaviorRiver PC ed) pp 257-323, University of Nebraska Press, Lincoln, NE.

Baker TB, Piper ME, McCarthy DE, Majeskie MR, and Fiore MC (2004) Addiction motivation reformulated: an affective processing model of negative reinforcement. Psychol Rev 111:33-51.

Baldo BA, Daniel RA, Berridge CW, and Kelley AE (2003) Overlapping distributions of orexin/hypocretin- and dopamine-beta-hydroxylase immunoreactive fibers in rat brain regions mediating arousal, motivation, and stress. J Comp Neurol 464: $220-237$.

Bale TL and Vale WW (2004) CRF and CRF receptors: role in stress responsivity and other behaviors. Annu Rev Pharmacol Toxicol 44:525-557.

Ballantyne JC, Sullivan MD, and Koob GF (2019) Refractory dependence on opioid analgesics. Pain 160:2655-2660.

Balldin J, Berggren U, Engel J, Lindstedt G, Sundkler A, and Wålinder J (1992) Alpha-2-adrenoceptor sensitivity in early alcohol withdrawal. Biol Psychiatry 31: $712-719$.

Banks WA and Erickson MA (2010) The blood-brain barrier and immune function and dysfunction. Neurobiol Dis 37:26-32.

Barrett AC, Smith ES, and Picker MJ (2002) Sex-related differences in mechanical nociception and antinociception produced by $\mu$ - and $\kappa$-opioid receptor agonists in rats. Eur $J$ Pharmacol 452:163-173.

Bearn J, Buntwal N, Papadopoulos A, and Checkley S (2001) Salivary cortisol during opiate dependence and withdrawal. Addict Biol 6:157-162.

Becker JB and Koob GF (2016) Sex differences in animal models: focus on addiction. Pharmacol Rev 68:242-263.

Bell RL, Lopez MF, Cui C, Egli M, Johnson KW, Franklin KM, and Becker HC (2015) Ibudilast reduces alcohol drinking in multiple animal models of alcohol dependence. Addict Biol 20:38-42.
Berggren U, Fahlke C, Norrby A, Zachrisson O, and Balldin J (2000) Subsensitive alpha-2-adrenoceptor function in male alcohol-dependent individuals during 6 months of abstinence. Drug Alcohol Depend 57:255-260.

Besemer F, Pereira AM, and Smit JW (2011) Alcohol-induced cushing syndrome. Hypercortisolism caused by alcohol abuse. Neth J Med 69:318-323.

Bhaskar LV, Thangaraj K, Kumar KP, Pardhasaradhi G, Singh L, and Rao VR (2013) Association between neuropeptide $\mathrm{Y}$ gene polymorphisms and alcohol dependence: a case-control study in two independent populations. Eur Addict Res 19:307-313.

Blednov YA, Ponomarev I, Geil C, Bergeson S, Koob GF, and Harris RA (2012) Neuroimmune regulation of alcohol consumption: behavioral validation of genes obtained from genomic studies. Addict Biol 17:108-120.

Blomeyer D, Treutlein J, Esser G, Schmidt MH, Schumann G, and Laucht M (2008) Interaction between CRHR1 gene and stressful life events predicts adolescent heavy alcohol use. Biol Psychiatry 63:146-151.

Boccia ML, Petrusz P, Suzuki K, Marson L, and Pedersen CA (2013) Immunohistochemical localization of oxytocin receptors in human brain. Neuroscience 253: 155-164.

Boden JM and Fergusson DM (2011) Alcohol and depression. Addiction 106:906-914 Boileau I, Assaad JM, Pihl RO, Benkelfat C, Leyton M, Diksic M, Tremblay RE, and Dagher A (2003) Alcohol promotes dopamine release in the human nucleus accumbens. Synapse 49:226-231.

Bonci A and Williams JT (1996) A common mechanism mediates long-term changes in synaptic transmission after chronic cocaine and morphine. Neuron 16:631-639.

Bonci A and Williams JT (1997) Increased probability of GABA release during withdrawal from morphine. $J$ Neurosci 17:796-803.

Boulos LJ, Darcq E, and Kieffer BL (2017) Translating the habenula-from rodents to humans. Biol Psychiatry 81:296-305.

Boutrel B, Kenny PJ, Specio SE, Martin-Fardon R, Markou A, Koob GF, and de Lecea L (2005) Role for hypocretin in mediating stress-induced reinstatement of cocaineseeking behavior. Proc Natl Acad Sci USA 102:19168-19173.

Brady KT and Randall CL (1999) Gender differences in substance use disorders. Psychiatr Clin North Am 22:241-252.

Breese GR, Knapp DJ, Overstreet DH, Navarro M, Wills TA, and Angel RA (2008) Repeated lipopolysaccharide (LPS) or cytokine treatments sensitize ethanol withdrawal-induced anxiety-like behavior [published correction appears in $\mathrm{Neu}$ ropsychopharmacology (2008) 33:1777]. Neuropsychopharmacology 33:867-876.

Breese GR, Overstreet DH, Knapp DJ, and Navarro M (2005) Prior multiple ethanol withdrawals enhance stress-induced anxiety-like behavior: inhibition by CRF1and benzodiazepine-receptor antagonists and a 5-HT1a-receptor agonist. Neuropsychopharmacology 30:1662-1669.

Breiter HC, Gollub RL, Weisskoff RM, Kennedy DN, Makris N, Berke JD, Goodman JM, Kantor HL, Gastfriend DR, Riorden JP, et al. (1997) Acute effects of cocaine on human brain activity and emotion. Neuron 19:591-611.

Brennan PL, Schutte KK, and Moos RH (2005) Pain and use of alcohol to manage pain: prevalence and 3-year outcomes among older problem and non-problem drinkers. Addiction 100:777-786.

Brown CH and Russell JA (2004) Cellular mechanisms underlying neuronal excitability during morphine withdrawal in physical dependence: lessons from the magnocellular oxytocin system. Stress 7:97-107.

Brown CH, Stern JE, Jackson KL, Bull PM, Leng G, and Russell JA (2005) Morphine withdrawal increases intrinsic excitability of oxytocin neurons in morphinedependent rats. Eur J Neurosci 21:501-512.

Brown RM, Khoo SY, and Lawrence AJ (2013) Central orexin (hypocretin) 2 receptor antagonism reduces ethanol self-administration, but not cue-conditioned ethanolseeking, in ethanol-preferring rats. Int J Neuropsychopharmacol 16:2067-2079.

Brownstein MJ, Russell JT, and Gainer H (1980) Synthesis, transport, and release of posterior pituitary hormones. Science 207:373-378.

Bustion A, Chiu A, Brunelle A, Ray S, Hite M, and Hoekman J (2016) Nose-to-brain transport of oxytocin following intranasal delivery with Precision Olfactory Delivery (POD) technology, in The 46th annual meeting of the Society for Neuroscience (SFN); 2016 November 12-16; San Diego, CA

Butler RK, Knapp DJ, Ulici V, Longobardi L, Loeser RF, and Breese GR (2017) A mouse model for chronic pain-induced increase in ethanol consumption. Pain 158: 457-462.

Cador M, Ahmed SH, Koob GF, Le Moal M, and Stinus L (1992) Corticotropinreleasing factor induces a place aversion independent of its neuroendocrine role. Brain Res 597:304-309.

Cahill CM, Taylor AM, Cook C, Ong E, Morón JA, and Evans CJ (2014) Does the kappa opioid receptor system contribute to pain aversion? Front Pharmacol 5 253.

Cahill CM, Walwyn W, Taylor AMW, Pradhan AAA, and Evans CJ (2016) Allostatic mechanisms of opioid tolerance beyond desensitization and downregulation. Trends Pharmacol Sci 37:963-976.

Caillé S, Alvarez-Jaimes L, Polis I, Stouffer DG, and Parsons LH (2007) Specific alterations of extracellular endocannabinoid levels in the nucleus accumbens by ethanol, heroin, and cocaine self-administration. J Neurosci 27:3695-3702.

Caldeiro RM, Malte CA, Calsyn DA, Baer JS, Nichol P, Kivlahan DR, and Saxon AJ (2008) The association of persistent pain with out-patient addiction treatment outcomes and service utilization. Addiction 103:1996-2005.

Caldwell HK, Wersinger SR, and Young WS III (2008) The role of the vasopressin 1b receptor in aggression and other social behaviours. Prog Brain Res 170:65-72.

Cappell $\mathrm{H}$ and Herman CP (1972) Alcohol and tension reduction. A review. Q J Stud Alcohol 33:33-64.

Cappendijk SL, Hurd YL, Nylander I, van Ree JM, and Terenius L (1999) A heroin-, but not a cocaine-expecting, self-administration state preferentially alters endogenous brain peptides. Eur J Pharmacol 365:175-182.

Carcoba LM, Contreras AE, Cepeda-Benito A, and Meagher MW (2011) Negative affect heightens opiate withdrawal-induced hyperalgesia in heroin dependent individuals. $J$ Addict Dis 30:258-270.

Carlezon WA Jr, Nestler EJ, and Neve RL (2000) Herpes simplex virus-mediated gene transfer as a tool for neuropsychiatric research. Crit Rev Neurobiol 14:47-67. 
Carmack SA, Keeley RJ, Vendruscolo JCM, Lowery-Gionta EG, Lu H, Koob GF, Stein EA, and Vendruscolo LF (2019) Heroin addiction engages negative emotional learning brain circuits in rats. J Clin Invest 129:2480-2484.

Case A and Deaton A (2015) Rising morbidity and mortality in midlife among white non-Hispanic Americans in the 21st century. Proc Natl Acad Sci USA 112 15078-15083.

Cecil CA, Walton E, and Viding E (2016) Epigenetics of addiction: current knowledge, challenges, and future directions. J Stud Alcohol Drugs 77:688-691.

Célèrier E, Laulin J, Larcher A, Le Moal M, and Simonnet G (1999) Evidence for opiate-activated NMDA processes masking opiate analgesia in rats. Brain Res $\mathbf{8 4 7}$ $18-25$

Célèrier E, Laulin JP, Corcuff JB, Le Moal M, and Simonnet G (2001) Progressive enhancement of delayed hyperalgesia induced by repeated heroin administration: a sensitization process. $J$ Neurosci 21:4074-4080

Célèrier E, Rivat C, Jun Y, Laulin JP, Larcher A, Reynier P, and Simonnet G (2000) Long-lasting hyperalgesia induced by fentanyl in rats: preventive effect of ketamine. Anesthesiology 92:465-472.

Célérier E, Simonnet G, and Maldonado R (2004) Prevention of fentanyl-induced delayed pronociceptive effects in mice lacking the protein kinase Cgamma gene. Neuropharmacology 46:264-272.

Centanni SW, Bedse G, Patel S, and Winder DG (2019) Driving the downward spiral alcohol-induced dysregulation of extended amygdala circuits and negative affect. Alcohol Clin Exp Res 43:2000-2013.

Chandler LJ, Newsom H, Sumners C, and Crews F (1993) Chronic ethanol exposure potentiates NMDA excitotoxicity in cerebral cortical neurons. J Neurochem 60 1578-1581.

Chavkin C and Koob GF (2016) Dynorphin, dysphoria and dependence: the stress of addiction. Neuropsychopharmacology 41:373-374.

Chefer VI, Bäckman CM, Gigante ED, and Shippenberg TS (2013) Kappa opioid receptors on dopaminergic neurons are necessary for kappa-mediated place aversion. Neuropsychopharmacology 38:2623-2631.

Chen SA, O’Dell LE, Hoefer ME, Greenwell TN, Zorrilla EP, and Koob GF (2006) Unlimited access to heroin self-administration: independent motivational markers of opiate dependence [published correction appears in Neuropsychopharmacology (2006) 31:2802]. Neuropsychopharmacology 31:2692-2707.

Ciccocioppo R, Economidou D, Fedeli A, and Massi M (2003) The nociceptin/orphanin $\mathrm{FQ} / \mathrm{NOP}$ receptor system as a target for treatment of alcohol abuse: a review of recent work in alcohol-preferring rats. Physiol Behav 79:121-128.

Cicero TJ, Aylward SC, and Meyer ER (2003) Gender differences in the intravenous self-administration of mu opiate agonists. Pharmacol Biochem Behav 74:541-549. Cippitelli A, Damadzic R, Singley E, Thorsell A, Ciccocioppo R, Eskay RL, and Heilig M (2012) Pharmacological blockade of corticotropin-releasing hormone receptor 1 (CRH1R) reduces voluntary consumption of high alcohol concentrations in nondependent Wistar rats. Pharmacol Biochem Behav 100:522-529.

Clarke TK, Ambrose-Lanci L, Ferraro TN, Berrettini WH, Kampman KM, Dackis CA Pettinati HM, O'Brien CP, Oslin DW, and Lohoff FW (2012) Genetic association analyses of PDYN polymorphisms with heroin and cocaine addiction. Genes Brain Behav 11:415-423.

Clausen TR, Møller M, and Woldbye DP (2001) Inhibitory effect of neuropeptide Y on morphine withdrawal is accompanied by reduced c-fos expression in specific brain regions. J Neurosci Res 64:410-417.

Cole JC, Littleton JM, and Little HJ (2000) Acamprosate, but not naltrexone, inhibits conditioned abstinence behaviour associated with repeated ethanol administration and exposure to a plus-maze. Psychopharmacology (Berl) 147:403-411.

Colpaert FC (1996) System theory of pain and of opiate analgesia: no tolerance to opiates. Pharmacol Rev 48:355-402.

Compton P, Athanasos P, and Elashoff D (2003) Withdrawal hyperalgesia after acute opioid physical dependence in nonaddicted humans: a preliminary study. J Pain 4: 511-519.

Compton P, Charuvastra VC, and Ling W (2001) Pain intolerance in opioidmaintained former opiate addicts: effect of long-acting maintenance agent. Drug Alcohol Depend 63:139-146.

Cook JW, Piper ME, Leventhal AM, Schlam TR, Fiore MC, and Baker TB (2015) Anhedonia as a component of the tobacco withdrawal syndrome. J Abnorm Psychol 124:215-225.

Crews FT, Lawrimore CJ, Walter TJ, and Coleman LG Jr (2017) The role of neuroimmune signaling in alcoholism. Neuropharmacology 122:56-73.

Crews FT and Vetreno RP (2016) Mechanisms of neuroimmune gene induction in alcoholism. Psychopharmacology (Berl) 233:1543-1557.

Culpepper-Morgan JA and Kreek MJ (1997) Hypothalamic-pituitary-adrenal axis hypersensitivity to naloxone in opioid dependence: a case of naloxone-induced withdrawal. Metabolism 46:130-134

Dahchour A, De Witte P, Bolo N, Nédélec JF, Muzet M, Durbin P, and Macher JP (1998) Central effects of acamprosate: part 1. Acamprosate blocks the glutamate increase in the nucleus accumbens microdialysate in ethanol withdrawn rats. Psychiatry Res 82:107-114.

D'Amato MR (1974) Derived motives. Annu Rev Psychol 25:83-106.

Dantzer R, O'Connor JC, Freund GG, Johnson RW, and Kelley KW (2008) From inflammation to sickness and depression: when the immune system subjugates the brain. Nat Rev Neurosci 9:46-56.

De Bellis MD (2002) Developmental traumatology: a contributory mechanism for alcohol and substance use disorders. Psychoneuroendocrinology 27: $155-170$.

de Guglielmo G, Crawford E, Kim S, Vendruscolo LF, Hope BT, Brennan M, Cole M, Koob GF, and George O (2016) Recruitment of a neuronal ensemble in the central nucleus of the amygdala is required for alcohol dependence. J Neurosci $\mathbf{3 6}$ 9446-9453.

de Guglielmo G, Kallupi M, Pomrenze MB, Crawford E, Simpson S, Schweitzer P, Koob GF, Messing RO, and George O (2019) Inactivation of a CRF-dependent amygdalofugal pathway reverses addiction-like behaviors in alcohol-dependent rats. Nat Commun 10:1238. de Lecea L, Kilduff TS, Peyron C, Gao X, Foye PE, Danielson PE, Fukuhara C, Battenberg EL, Gautvik VT, Bartlett FS II, et al. (1998) The hypocretins: hypothalamus-specific peptides with neuroexcitatory activity. Proc Natl Acad Sci USA 95:322-327.

DeLeo JA, Tanga FY, and Tawfik VL (2004) Neuroimmune activation and neuroinflammation in chronic pain and opioid tolerance/hyperalgesia. Neuroscientist 10: $40-52$.

Delfs JM, Zhu Y, Druhan JP, and Aston-Jones G (2000) Noradrenaline in the ventral forebrain is critical for opiate withdrawal-induced aversion. Nature 403:430-434. Demyttenaere K, Bruffaerts R, Lee S, Posada-Villa J, Kovess V, Angermeyer MC, Levinson D, de Girolamo G, Nakane H, Mneimneh Z, et al. (2007) Mental disorders among persons with chronic back or neck pain: results from the World Mental Health Surveys. Pain 129:332-342.

Devaud LL and Chadda R (2001) Sex differences in rats in the development of and recovery from ethanol dependence assessed by changes in seizure susceptibility. Alcohol Clin Exp Res 25:1689-1696.

Devaud LL, Fritschy JM, Sieghart W, and Morrow AL (1997) Bidirectional alterations of $\mathrm{GABA}(\mathrm{A})$ receptor subunit peptide levels in rat cortex during chronic ethanol consumption and withdrawal. J Neurochem 69:126-130.

De Vries GJ and Buijs RM (1983) The origin of the vasopressinergic and oxytocinergic innervation of the rat brain with special reference to the lateral septum. Brain Res 273:307-317.

de Wied D and Versteeg DH (1979) Neurohypophyseal principles and memory. Fed Proc 38:2348-2354.

Diana M (2011) The dopamine hypothesis of drug addiction and its potential therapeutic value. Front Psychiatry 2:64

Diana M, Brodie M, Muntoni A, Puddu MC, Pillolla G, Steffensen S, Spiga S, and Little HJ (2003) Enduring effects of chronic ethanol in the CNS: basis for alcoholism. Alcohol Clin Exp Res 27:354-361.

Diana M, Pistis M, Carboni S, Gessa GL, and Rossetti ZL (1993) Profound decrement of mesolimbic dopaminergic neuronal activity during ethanol withdrawal syndrome in rats: electrophysiological and biochemical evidence. Proc Natl Acad Sci USA 90:7966-7969.

Diaz SL, Kemmling AK, Rubio MC, and Balerio GN (2005) Morphine withdrawal syndrome: involvement of the dopaminergic system in prepubertal male and female mice. Pharmacol Biochem Behav 82:601-607.

Dina OA, Messing RO, and Levine JD (2006) Ethanol withdrawal induces hyperalgesia mediated by PKCepsilon. Eur J Neurosci 24:197-204.

Domokos A, Mergl Z, Barna I, Makara GB, and Zelena D (2008) Congenital vasopressin deficiency and acute and chronic opiate effects on hypothalamopituitary-adrenal axis activity in Brattleboro rats. $J$ Endocrinol 196 113-121.

Douglas KR, Chan G, Gelernter J, Arias AJ, Anton RF, Weiss RD, Brady K, Poling J, Farrer L, and Kranzler HR (2010) Adverse childhood events as risk factors for substance dependence: partial mediation by mood and anxiety disorders. Addict Behav 35:7-13.

Doverty M, White JM, Somogyi AA, Bochner F, Ali R, and Ling W (2001) Hyperalgesic responses in methadone maintenance patients. Pain 90:91-96.

Dowell D, Haegerich TM, and Chou R (2016) CDC guideline for prescribing opioids for chronic pain--United States, 2016. JAMA 315:1624-1645.

Dunlop BW, Binder EB, Iosifescu D, Mathew SJ, Neylan TC, Pape JC, Carrillo-Roa T, Green C, Kinkead B, Grigoriadis D, et al. (2017) Corticotropin-releasing factor receptor 1 antagonism is ineffective for women with posttraumatic stress disorder. Biol Psychiatry 82:866-874

Economidou D, Cippitelli A, Stopponi S, Braconi S, Clementi S, Ubaldi M, MartinFardon R, Weiss F, Massi M, and Ciccocioppo R (2011) Activation of brain NOP receptors attenuates acute and protracted alcohol withdrawal symptoms in the rat. Alcohol Clin Exp Res 35:747-755.

Economidou D, Hansson AC, Weiss F, Terasmaa A, Sommer WH, Cippitelli A, Fedel A, Martin-Fardon R, Massi M, Ciccocioppo R, et al. (2008) Dysregulation of nociceptin/orphanin FQ activity in the amygdala is linked to excessive alcohol drinking in the rat. Biol Psychiatry 64:211-218.

Eddy NB, Halbach H, Isbell H, and Seevers MH (1965) Drug dependence: its significance and characteristics. Bull World Health Organ 32:721-733.

Edlund MJ, Sullivan MD, Han X, and Booth BM (2013) Days with pain and substance use disorders: is there an association? Clin J Pain 29:689-695.

Edwards S, Guerrero M, Ghoneim OM, Roberts E, and Koob GF (2012a) Evidence that vasopressin $\mathrm{V} 1 \mathrm{~b}$ receptors mediate the transition to excessive drinking in ethanol-dependent rats. Addict Biol 17:76-85.

Edwards S, Vendruscolo LF, Gilpin NW, Wojnar M, and Witkiewitz K (2020) Alcohol and pain: a translational review of preclinical and clinical findings to inform future treatment strategies. Alcohol Clin Exp Res 44:368-383.

Edwards S, Vendruscolo LF, Schlosburg JE, Misra KK, Wee S, Park PE, Schulteis G, and Koob GF (2012b) Development of mechanical hypersensitivity in rats during heroin and ethanol dependence: alleviation by $\mathrm{CRF}_{1}$ receptor antagonism. Neuropharmacology 62:1142-1151.

Egli M, Koob GF, and Edwards S (2012) Alcohol dependence as a chronic pain disorder. Neurosci Biobehav Rev 36:2179-2192.

Eisenstein TK (2019) The role of opioid receptors in immune system function. Front Immunol 10:2904.

Engelmann M, Wotjak CT, Neumann I, Ludwig M, and Landgraf R (1996) Behavioral consequences of intracerebral vasopressin and oxytocin: focus on learning and memory. Neurosci Biobehav Rev 20:341-358.

Engin E and Treit D (2008) Dissociation of the anxiolytic-like effects of Avpr1a and Avpr1b receptor antagonists in the dorsal and ventral hippocampus. Neuropeptides 42:411-421.

Englund MM, Egeland B, Oliva EM, and Collins WA (2008) Childhood and adolescent predictors of heavy drinking and alcohol use disorders in early adulthood: a longitudinal developmental analysis. Addiction 103 (Suppl 1):23-35.

Enoch MA (2011) The role of early life stress as a predictor for alcohol and drug dependence. Psychopharmacology (Berl) 214:17-31. 
Eriksson K and Pikkarainen PH (1968) Differences between the sexes in voluntary alcohol consumption and liver ADH-activity in inbred strains of mice. Metabolism 17:1037-1042.

Ertl A, Sheats KJ, Petrosky E, Betz CJ, Yuan K, and Fowler KA (2019) Surveillance for violent deaths - national violent death reporting system, 32 states, 2016 MMWR Surveill Summ 68:1-36.

Evans CJ and Cahill CM (2016) Neurobiology of opioid dependence in creating addiction vulnerability. F1000Res 5:F1000 Faculty Rev-1748.

Falk DE, Ryan ML, Fertig JB, Devine EG, Cruz R, Brown ES, Burns H, Salloum IM, Newport DJ, Mendelson J, et al.; National Institute on Alcohol Abuse and Alcoholism Clinical Investigations Group (NCIG) Study Group (2019) Gabapentin enacarbil extended-release for alcohol use disorder: a randomized, double-blind, placebo-controlled, multisite trial assessing efficacy and safety. Alcohol Clin Exp Res 43:158-169.

Farina C, Aloisi F, and Meinl E (2007) Astrocytes are active players in cerebral innate immunity. Trends Immunol 28:138-145.

Follesa P and Ticku MK (1995) Chronic ethanol treatment differentially regulates NMDA receptor subunit mRNA expression in rat brain. Brain Res Mol Brain Res 29:99-106.

Franklin KM, Hauser SR, Lasek AW, McClintick J, Ding ZM, McBride WJ, and Bell RL (2015) Reduction of alcohol drinking of alcohol-preferring $(\mathrm{P})$ and high-alcohol drinking (HAD1) rats by targeting phosphodiesterase-4 (PDE4). Psychopharmacology (Berl) 232:2251-2262.

$\mathrm{Fu} \mathrm{Y}$ and Neugebauer V (2008) Differential mechanisms of CRF1 and CRF2 receptor functions in the amygdala in pain-related synaptic facilitation and behavior. J Neurosci 28:3861-3876

Funk CK, O'Dell LE, Crawford EF, and Koob GF (2006) Corticotropin-releasing factor within the central nucleus of the amygdala mediates enhanced ethanol selfadministration in withdrawn, ethanol-dependent rats. $J$ Neurosci 26:11324-11332.

Funk CK, Zorrilla EP, Lee MJ, Rice KC, and Koob GF (2007) Corticotropin-releasing factor 1 antagonists selectively reduce ethanol self-administration in ethanoldependent rats. Biol Psychiatry 61:78-86.

Gamage TF, Ignatowska-Jankowska BM, Muldoon PP, Cravatt BF, Damaj MI and Lichtman $\mathrm{AH}$ (2015) Differential effects of endocannabinoid catabolic inhibitors on morphine withdrawal in mice. Drug Alcohol Depend 146:7-16.

Gatch MB (2009) Ethanol withdrawal and hyperalgesia. Curr Drug Abuse Rev 2: 41-50.

Gatch MB, Wallis CJ, and Lal H (1999) Effects of NMDA antagonists on ethanolwithdrawal induced "anxiety" in the elevated plus maze. Alcohol 19:207-211.

Gehlert DR, Cippitelli A, Thorsell A, Lê AD, Hipskind PA, Hamdouchi C, Lu J, Hembre EJ, Cramer J, Song M, et al. (2007) 3-(4-Chloro-2-morpholin-4-yl-thiazol-5yl)-8-(1-ethylpropyl)-2,6-dimethyl-imidazo[1,2-b]pyridazine: a novel brainpenetrant, orally available corticotropin-releasing factor receptor 1 antagonist with efficacy in animal models of alcoholism. J Neurosci 27:2718-2726.

George O and Koob GF (2013) Control of craving by the prefrontal cortex. Proc Natl Acad Sci USA 110:4165-4166.

Georgescu D, Zachariou V, Barrot M, Mieda M, Willie JT, Eisch AJ, Yanagisawa M, Nestler EJ, and DiLeone RJ (2003) Involvement of the lateral hypothalamic peptide orexin in morphine dependence and withdrawal. $J$ Neurosci 23:3106-3111.

Gerra G, Leonardi C, Cortese E, D’Amore A, Lucchini A, Strepparola G, Serio G, Farina G, Magnelli F, Zaimovic A, et al. (2007) Human kappa opioid receptor gene (OPRK1) polymorphism is associated with opiate addiction. Am J Med Genet B Neuropsychiatr Genet 144B:771-775.

Gilpin NW and Koob GF (2010) Effects of $\beta$-adrenoceptor antagonists on alcohol drinking by alcohol-dependent rats. Psychopharmacology (Berl) 212:431-439.

Gilpin NW, Misra K, Herman MA, Cruz MT, Koob GF, and Roberto M (2011) Neuropeptide $\mathrm{Y}$ opposes alcohol effects on gamma-aminobutyric acid release in amygdala and blocks the transition to alcohol dependence. Biol Psychiatry 69: 1091-1099.

Gilpin NW, Misra K, and Koob GF (2008) Neuropeptide Y in the central nucleus of the amygdala suppresses dependence-induced increases in alcohol drinking. Pharmacol Biochem Behav 90:475-480.

Gilpin NW, Stewart RB, Murphy JM, Li TK, and Badia-Elder NE (2003) Neuropeptide $\mathrm{Y}$ reduces oral ethanol intake in alcohol-preferring $(\mathrm{P})$ rats following a period of imposed ethanol abstinence. Alcohol Clin Exp Res 27:787-794.

Gold MS, Redmond DE Jr, and Kleber HD (1978) Clonidine blocks acute opiatewithdrawal symptoms. Lancet 2:599-602.

González S, Valenti M, de Miguel R, Fezza F, Fernández-Ruiz J, Di Marzo V, and Ramos JA (2004) Changes in endocannabinoid contents in reward-related brain regions of alcohol-exposed rats, and their possible relevance to alcohol relapse. Br J Pharmacol 143:455-464.

González-Sepúlveda M, Pozo OJ, Marcos J, and Valverde O (2016) Chronic pain causes a persistent anxiety state leading to increased ethanol intake in CD1 mice. $J$ Psychopharmacol 30:188-203.

Gordon AS, Collier K, and Diamond I (1986) Ethanol regulation of adenosine receptor-stimulated cAMP levels in a clonal neural cell line: an in vitro model of cellular tolerance to ethanol. Proc Natl Acad Sci USA 83:2105-2108.

Graeber MB (2010) Changing face of microglia. Science 330:783-788.

Grant BF and Dawson DA (1998) Age of onset of drug use and its association with DSM-IV drug abuse and dependence: results from the National Longitudinal Alcohol Epidemiologic Survey. J Subst Abuse 10:163-173.

Grant BF, Goldstein RB, Saha TD, Chou SP, Jung J, Zhang H, Pickering RP, Ruan WJ, Smith SM, Huang B, et al. (2015) Epidemiology of DSM-5 alcohol use disorder: results from the national epidemiologic Survey on alcohol and related conditions III. JAMA Psychiatry 72:757-766.

Grant BF, Stinson FS, and Harford TC (2001) Age at onset of alcohol use and DSM-IV alcohol abuse and dependence: a 12-year follow-up. J Subst Abuse 13:493-504.

Greenwell TN, Funk CK, Cottone P, Richardson HN, Chen SA, Rice KC, Zorrilla EP, and Koob GF (2009a) Corticotropin-releasing factor-1 receptor antagonists decrease heroin self-administration in long- but not short-access rats. Addict Biol 14: 130-143.
Greenwell TN, Walker BM, Cottone P, Zorrilla EP, and Koob GF (2009b) The $\alpha_{1}$ adrenergic receptor antagonist prazosin reduces heroin self-administration in rats with extended access to heroin administration. Pharmacol Biochem Behav 91: 295-302.

Griebel G and Holsboer F (2012) Neuropeptide receptor ligands as drugs for psychiatric diseases: the end of the beginning? Nat Rev Drug Discov 11:462-478.

Griebel G, Simiand J, Serradeil-Le Gal C, Wagnon J, Pascal M, Scatton B, Maffrand JP, and Soubrie P (2002) Anxiolytic- and antidepressant-like effects of the nonpeptide vasopressin V1b receptor antagonist, SSR149415, suggest an innovative approach for the treatment of stress-related disorders. Proc Natl Acad Sci USA 99: 6370-6375.

Haass-Koffler CL, Henry AT, Melkus G, Simms JA, Naemmuddin M, Nielsen CK, Lasek AW, Magill M, Schwandt ML, Momenan R, et al. (2016) Defining the role of corticotropin releasing factor binding protein in alcohol consumption. Transl Psychiatry 6:e953.

Haass-Koffler CL, Leggio L, and Kenna GA (2014) Pharmacological approaches to reducing craving in patients with alcohol use disorders. CNS Drugs 28:343-360.

Hansson AC, Koopmann A, Uhrig S, Bühler S, Domi E, Kiessling E, Ciccocioppo R, Froemke RC, Grinevich V, Kiefer F, et al. (2018) Oxytocin reduces alcohol cuereactivity in alcohol-dependent rats and humans. Neuropsychopharmacology 43 : $1235-1246$

Hao S, Liu S, Zheng X, Zheng W, Ouyang H, Mata M, and Fink DJ (2011) The role of $\mathrm{TNF} \alpha$ in the periaqueductal gray during naloxone-precipitated morphine withdrawal in rats. Neuropsychopharmacology 36:664-676.

Harris AC and Gewirtz JC (2005) Acute opioid dependence: characterizing the early adaptations underlying drug withdrawal. Psychopharmacology (Berl) 178:353-366. Harris AC, Pentel PR, Burroughs D, Staley MD, and Lesage MG (2011) A lack of association between severity of nicotine withdrawal and individual differences in compensatory nicotine self-administration in rats. Psychopharmacology (Berl) 217: $153-166$.

Hata T, Chen J, Ebihara K, Date Y, Ishida Y, and Nakahara D (2011) Intra-ventral tegmental area or intracerebroventricular orexin-A increases the intra-cranial selfstimulation threshold via activation of the corticotropin-releasing factor system in rats. Eur J Neurosci 34:816-826.

Hawley RJ, Major LF, Schulman EA, and Lake CR (1981) CSF levels of norepinephrine during alcohol withdrawal. Arch Neurol 38:289-292.

Hedegaard H, Miniño AM, and Warner M (2020) Drug overdose deaths in the United States, 1999-2018. NCHS Data Brief, no 356. Hyattsville, MD: National Center for Health Statistics.

Heilig M (2004) The NPY system in stress, anxiety and depression. Neuropeptides 38: $213-224$

Heilig M and Koob GF (2007) A key role for corticotropin-releasing factor in alcohol dependence. Trends Neurosci 30:399-406.

Heimer L and Alheid GF (1991) Piecing together the puzzle of basal forebrain anatomy, in The Basal Forebrain (Napier TC, Kalivas PW, and Hanin I eds) pp 1-42, Plenum Press, New York.

Heinrichs SC, Menzaghi F, Schulteis G, Koob GF, and Stinus L (1995) Suppression of corticotropin-releasing factor in the amygdala attenuates aversive consequences of morphine withdrawal. Behav Pharmacol 6:74-80.

Hermann D, Weber-Fahr W, Sartorius A, Hoerst M, Frischknecht U, TuncSkarka N, Perreau-Lenz S, Hansson AC, Krumm B, Kiefer F, et al. (2012) Translational magnetic resonance spectroscopy reveals excessive central glutamate levels during alcohol withdrawal in humans and rats. Biol Psychiatry 71:1015-1021

Heyser CJ, Schulteis G, Durbin P, and Koob GF (1998) Chronic acamprosate eliminates the alcohol deprivation effect while having limited effects on baseline responding for ethanol in rats. Neuropsychopharmacology 18:125-133.

Hikosaka O (2010) The habenula: from stress evasion to value-based decisionmaking. Nat Rev Neurosci 11:503-513.

Himmelsbach CK (1943) Can the euphoric, analgetic, and physical dependence effects of drugs be separated? IV. With reference to physical dependence. Fed Proc 2:201-203.

Hingson R, Heeren T, Zakocs R, Winter M, and Wechsler H (2003) Age of first intoxication, heavy drinking, driving after drinking and risk of unintentional injury among U.S. college students. $J$ Stud Alcohol 64:23-31.

Hipólito L, Wilson-Poe A, Campos-Jurado Y, Zhong E, Gonzalez-Romero J, Virag L, Whittington R, Comer SD, Carlton SM, Walker BM, et al. (2015) Inflammatory pain promotes increased opioid self-administration: role of dysregulated ventra tegmental area $\mu$ opioid receptors. $J$ Neurosci 35:12217-12231.

Ho A and Dole VP (1979) Pain perception in drug-free and in methadone-maintained human ex-addicts. Proc Soc Exp Biol Med 162:392-395.

Hoffman HS and Solomon RL (1974) An opponent-process theory of motivation: III. Some affective dynamics in imprinting. Learn Motiv 5:149-164.

Hoffman PL, Ishizawa H, Giri PR, Dave JR, Grant KA, Liu LI, Gulya K, and Tabakoff B (1990) The role of arginine vasopressin in alcohol tolerance. Ann Med 22: 269-274

Hoffman PL, Ritzmann RF, Walter R, and Tabakoff B (1978) Arginine vasopressin maintains ethanol tolerance. Nature 276:614-616.

Holahan CJ, Moos RH, Holahan CK, Cronkite RC, and Randall PK (2001) Drinking to cope, emotional distress and alcohol use and abuse: a ten-year model. J Stud Alcohol 62:190-198.

Hölter SM, Henniger MS, Lipkowski AW, and Spanagel R (2000) Kappa-opioid receptors and relapse-like drinking in long-term ethanol-experienced rats. Psychopharmacology (Berl) 153:93-102.

Horvath RJ, Romero-Sandoval EA, and De Leo JA (2010) Inhibition of microglial $\mathrm{P} 2 \mathrm{X} 4$ receptors attenuates morphine tolerance, Iba1, GFAP and mu opioid receptor protein expression while enhancing perivascular microglial ED2. Pain 150 401-413.

Hua Z, Liu L, Shen J, Cheng K, Liu A, Yang J, Wang L, Qu T, Yang H, Li Y, et al. (2016) Mesenchymal stem cells reversed morphine tolerance and opioid-induced hyperalgesia. Sci Rep 6:32096. 
Hummel M, Cummons T, Lu P, Mark L, Harrison JE, Kennedy JD, and Whiteside GT (2010) Pain is a salient "stressor" that is mediated by corticotropin-releasing factor-1 receptors. Neuropharmacology 59:160-166.

Hwa L, Besheer J, and Kash T (2017) Glutamate plasticity woven through the progression to alcohol use disorder: a multi-circuit perspective. F1000 Res 6:298.

Jang CG, Whitfield T, Schulteis G, Koob GF, and Wee S (2013a) A dysphoric-like state during early withdrawal from extended access to methamphetamine selfadministration in rats. Psychopharmacology (Berl) 225:753-763.

Jang E, Kim JH, Lee S, Kim JH, Seo JW, Jin M, Lee MG, Jang IS, Lee WH, and Suk K (2013b) Phenotypic polarization of activated astrocytes: the critical role of lipocalin-2 in the classical inflammatory activation of astrocytes. J Immunol 191:5204-5219.

Ji G, Fu Y, Adwanikar H, and Neugebauer V (2013) Non-pain-related CRF1 activation in the amygdala facilitates synaptic transmission and pain. Mol Pain 9:2.

Ji G, Fu Y, Ruppert KA, and Neugebauer V (2007) Pain-related anxiety-like behavior requires CRF1 receptors in the amygdala. Mol Pain $\mathbf{3}: 13$.

Jochum T, Boettger MK, Burkhardt C, Juckel G, and Bär KJ (2010) Increased pain sensitivity in alcohol withdrawal syndrome. Eur J Pain 14:713-718.

Jodogne C, Tirelli E, Klingbiel P, and Legros JJ (1991) Oxytocin attenuates tolerance not only to the hypothermic but also to the myorelaxant and akinesic effects of ethanol in mice. Pharmacol Biochem Behav 40:261-265.

Johnson PL, Samuels BC, Fitz SD, Lightman SL, Lowry CA, and Shekhar A (2012) Activation of the orexin 1 receptor is a critical component of $\mathrm{CO}_{2}$-mediated anxiety and hypertension but not bradycardia. Neuropsychopharmacology 37:1911-1922.

Johnston IN, Milligan ED, Wieseler-Frank J, Frank MG, Zapata V, Campisi J, Langer S, Martin D, Green P, Fleshner M, et al. (2004) A role for proinflammatory cytokines and fractalkine in analgesia, tolerance, and subsequent pain facilitation induced by chronic intrathecal morphine. J Neurosci 24:7353-7365.

Johnstone LE, Brown CH, Meeren HK, Vuijst CL, Brooks PJ, Leng G, and Russell JA (2000) Local morphine withdrawal increases c-fos gene, Fos protein, and oxytocin gene expression in hypothalamic magnocellular neurosecretory cells. $J$ Neurosci 20:1272-1280

Jonas DE, Amick HR, Feltner C, Bobashev G, Thomas K, Wines R, Kim MM, Shanahan E, Gass CE, Rowe CJ, et al. (2014) Pharmacotherapy for adults with alcohol use disorders in outpatient settings: a systematic review and meta-analysis. JAMA 311:1889-1900.

Jones BE and Prada JA (1977) Effects of methadone and morphine maintenance on drug-seeking behavior in the dog. Psychopharmacology (Berl) 54:109-112.

Kalange AS, Kokare DM, Singru PS, Upadhya MA, Chopde CT, and Subhedar NK (2007) Central administration of selective melanocortin 4 receptor antagonist HS014 prevents morphine tolerance and withdrawal hyperalgesia. Brain Res 1181:10-20.

Kallupi M, Carrette LLG, Kononoff J, Solberg Woods LC, Palmer AA, Schweitzer P, George O, and de Guglielmo G (2020) Nociceptin attenuates the escalation of oxycodone self-administration by normalizing CeA-GABA transmission in highly addicted rats. Proc Natl Acad Sci USA 117:2140-2148.

Kang S, Li J, Zuo W, Chen P, Gregor D, Fu R, Han X, Bekker A, and Ye JH (2019) Downregulation of M-channels in lateral habenula mediates hyperalgesia during alcohol withdrawal in rats. Sci Rep 9:2714.

Karkhanis AN and Al-Hasani R (2020) Dynorphin and its role in alcohol use disorder. Brain Res 1735:146742.

Karkhanis AN, Huggins KN, Rose JH, and Jones SR (2016) Switch from excitatory to inhibitory actions of ethanol on dopamine levels after chronic exposure: role of kappa opioid receptors. Neuropharmacology 110:190-197.

Karoum F, Wyatt RJ, and Majchrowicz E (1976) Brain concentrations of biogenic amine metabolites in acutely treated and ethanol-dependent rats. Br J Pharmacol 56:403-411.

Katz JL and Higgins ST (2003) The validity of the reinstatement model of craving and relapse to drug use [published correction appears in Psychopharmacology (Berl) (2003) 168:244]. Psychopharmacology (Berl) 168:21-30.

Kaufmann JE, Oksche A, Wollheim CB, Günther G, Rosenthal W, and Vischer UM (2000) Vasopressin-induced von Willebrand factor secretion from endothelial cells involves V2 receptors and cAMP. J Clin Invest 106:107-116.

Kelley SP, Nannini MA, Bratt AM, and Hodge CW (2001) Neuropeptide-Y in the paraventricular nucleus increases ethanol self-administration. Peptides 22:515-522.

Kelsey JE, Verhaak AMS, and Schierberl KC (2015) The kappa-opioid receptor antagonist, nor-binaltorphimine (nor-BNI), decreases morphine withdrawal and the consequent conditioned place aversion in rats. Behav Brain Res 283:16-21.

Kenny PJ, Chen SA, Kitamura O, Markou A, and Koob GF (2006) Conditioned withdrawal drives heroin consumption and decreases reward sensitivity. $J$ Neurosci 26:5894-5900.

Kettenmann H, Kirchhoff F, and Verkhratsky A (2013) Microglia: new roles for the synaptic stripper. Neuron 77:10-18.

Khakh BS and Sofroniew MV (2015) Diversity of astrocyte functions and phenotypes in neural circuits. Nat Neurosci 18:942-952.

Khantzian EJ (1985) The self-medication hypothesis of addictive disorders: focus on heroin and cocaine dependence. Am J Psychiatry 142:1259-1264.

Khantzian EJ (1997) The self-medication hypothesis of substance use disorders: a reconsideration and recent applications. Harv Rev Psychiatry 4:231-244.

Khantzian EJ (2012) Reflections on treating addictive disorders: a psychodynamic perspective. Am J Addict 21:274-279; discussion 279.

Khantzian EJ (2013) Addiction as a self-regulation disorder and the role of selfmedication. Addiction 108:668-669.

Khoury L, Tang YL, Bradley B, Cubells JF, and Ressler KJ (2010) Substance use, childhood traumatic experience, and Posttraumatic Stress Disorder in an urban civilian population. Depress Anxiety 27:1077-1086.

Kieffer BL and Gavériaux-Ruff C (2002) Exploring the opioid system by gene knockout. Prog Neurobiol 66:285-306

King CE and Becker HC (2019) Oxytocin attenuates stress-induced reinstatement of alcohol seeking behavior in male and female mice. Psychopharmacology (Berl) 236 2613-2622.

King CE, Griffin WC, Luderman LN, Kates MM, McGinty JF, and Becker HC (2017) Oxytocin reduces ethanol self-administration in mice. Alcohol Clin Exp Res 41: 955-964.
Kirkman S and Nelson DH (1988) Alcohol-induced pseudo-Cushing's disease: a study of prevalence with review of the literature. Metabolism 37:390-394.

Kissler JL, Sirohi S, Reis DJ, Jansen HT, Quock RM, Smith DG, and Walker BM (2014) The one-two punch of alcoholism: role of central amygdala dynorphins/ kappa-opioid receptors. Biol Psychiatry 75:774-782.

Knapp DJ, Overstreet DH, Moy SS, and Breese GR (2004) SB242084, flumazenil, and CRA1000 block ethanol withdrawal-induced anxiety in rats. Alcohol 32:101-111.

Knapp DJ, Whitman BA, Wills TA, Angel RA, Overstreet DH, Criswell HE, Ming Z, and Breese GR (2011) Cytokine involvement in stress may depend on corticotrophin releasing factor to sensitize ethanol withdrawal anxiety. Brain Behav Immun 25 (Suppl 1):S146-S154.

Knobloch HS, Charlet A, Hoffmann LC, Eliava M, Khrulev S, Cetin AH, Osten P, Schwarz MK, Seeburg PH, Stoop R, et al. (2012) Evoked axonal oxytocin release in the central amygdala attenuates fear response. Neuron 73:553-566.

Koob GF (1999) Corticotropin-releasing factor, norepinephrine, and stress. Biol Psychiatry 46:1167-1180.

Koob GF (2008) A role for brain stress systems in addiction. Neuron 59:11-34

Koob GF (2015) The dark side of emotion: the addiction perspective. Eur J Pharmacol 753:73-87.

Koob GF (2019) Neurobiology of opioid addiction: opponent process, hyperkatifeia and negative reinforcement. Biol Psychiatry 87:44-53.

Koob GF, Arends MA, McCracken M, and Le Moal M (2019) Introduction to Addiction, Elsevier, New York

Koob GF and Bloom FE (1988) Cellular and molecular mechanisms of drug dependence. Science 242:715-723.

Koob GF, Buck CL, Cohen A, Edwards S, Park PE, Schlosburg JE, Schmeichel B, Vendruscolo LF, Wade CL, Whitfield TW Jr, et al. (2014) Addiction as a stress surfeit disorder. Neuropharmacology 76:370-382.

Koob G and Kreek MJ (2007) Stress, dysregulation of drug reward pathways, and the transition to drug dependence. Am J Psychiatry 164:1149-1159.

Koob GF and Le Moal M (1997) Drug abuse: hedonic homeostatic dysregulation. Science 278:52-58.

Koob GF and Le Moal M (2001) Drug addiction, dysregulation of reward, and allostasis. Neuropsychopharmacology 24:97-129.

Koob GF and Le Moal M (2005) Plasticity of reward neurocircuitry and the 'dark side' of drug addiction. Nat Neurosci 8:1442-1444

Koob GF and Le Moal M (2008) Addiction and the brain antireward system. Annu Rev Psychol 59:29-53.

Koob GF and Mason BJ (2016) Existing and future drugs for the treatment of the dark side of addiction. Annu Rev Pharmacol Toxicol 56:299-322.

Koob GF, Sanna PP, and Bloom FE (1998) Neuroscience of addiction. Neuron 21: $467-476$

Koob GF and Schulkin J (2019) Addiction and stress: an allostatic view. Neurosci Biobehav Rev 106:245-262.

Koob GF and Volkow ND (2010) Neurocircuitry of addiction [published correction appears in Neuropsychopharmacology (2010) 35:1051]. Neuropsychopharmacology 35:217-238.

Koppert W, Sittl R, Scheuber K, Alsheimer M, Schmelz M, and Schüttler J (2003) Differential modulation of remifentanil-induced analgesia and postinfusion hyperalgesia by S-ketamine and clonidine in humans. Anesthesiology 99:152-159.

Kosten TA (1994) Clonidine attenuates conditioned aversion produced by naloxoneprecipitated opiate withdrawal. Eur $J$ Pharmacol 254:59-63.

Kosten TR and George TP (2002) The neurobiology of opioid dependence: implications for treatment. Sci Pract Perspect 1:13-20.

Kotlinska J, Dylag T, Rafalski P, Talarek S, Kosior M, and Silberring J (2004) Influence of nociceptin(1-17) fragments and its tyrosine-substituted derivative on morphine-withdrawal signs in rats. Neuropeptides 38:277-282.

Kotlińska J, Suder P, Legowska A, Rolka K, and Silberring J (2000) Orphanin FQ/ nociceptin inhibits morphine withdrawal. Life Sci 66:PL119-PL123.

Kovács CL and Van Ree JM (1985) Behaviorally active oxytocin fragments simultaneously attenuate heroin self-administration and tolerance in rats. Life Sci 37:1895-1900.

Kovács GL, Borthaiser Z, and Telegdy G (1985) Oxytocin reduces intravenous heroin self-administration in heroin-tolerant rats. Life Sci 37:17-26.

Kovács GL, Izbéki F, Horváth Z, and Telegdy G (1984) Effects of oxytocin and a derivative (Z-prolyl-D-leucine) on morphine tolerance/withdrawal are mediated by the limbic system. Behav Brain Res 14:1-8.

Kovács GL, Sarnyai Z, and Szabó G (1998) Oxytocin and addiction: a review. Psychoneuroendocrinology 23:945-962.

Kovács KJ (2013) CRH: the link between hormonal-, metabolic- and behavioral responses to stress. $J$ Chem Neuroanat 54:25-33.

Kreek MJ (1973) Medical safety and side effects of methadone in tolerant individuals. JAMA 223:665-668.

Kreek MJ and Koob GF (1998) Drug dependence: stress and dysregulation of brain reward pathways. Drug Alcohol Depend 51:23-47.

Kuikka JT, Repo E, Bergström KA, Tupala E, and Tiihonen J (2000) Specific binding and laterality of human extrastriatal dopamine D2/D3 receptors in late onset type 1 alcoholic patients. Neurosci Lett 292:57-59.

Kuntz-Melcavage KL, Brucklacher RM, Grigson PS, Freeman WM, and Vrana KE (2009) Gene expression changes following extinction testing in a heroin behavioral incubation model. BMC Neurosci 10:95.

Kuzmin A, Bazov I, Sheedy D, Garrick T, Harper C, and Bakalkin G (2009) Expression of pronociceptin and its receptor is downregulated in the brain of human alcoholics. Brain Res 1305 (Suppl):S80-S85.

Kwako LE and Koob GF (2017) Neuroclinical framework for the role of stress in addiction. Chronic Stress (Thousand Oaks) 1:1-14.

Kwako LE, Momenan R, Litten RZ, Koob GF, and Goldman D (2016) Addictions neuroclinical assessment: a neuroscience-based framework for addictive disorders. Biol Psychiatry 80:179-189.

Kwako LE, Schwandt ML, Ramchandani VA, Diazgranados N, Koob GF, Volkow ND, Blanco C, and Goldman D (2019) Neurofunctional domains derived from deep behavioral phenotyping in alcohol use disorder. Am J Psychiatry 176:744-753. 
Laorden ML, Ferenczi S, Pintér-Kübler B, González-Martín LL, Lasheras MC, Kovács KJ, Milanés MV, and Núñez C (2012) Hypothalamic orexin--a neurons are involved in the response of the brain stress system to morphine withdrawal. PLoS One 7:e36871.

Laorden ML, Milanés MV, Chapleur-Château M, and Burlet A (1998) Changes in oxytocin content in rat brain during morphine withdrawal. Neuropeptides 32: $67-71$

Larson MJ, Paasche-Orlow M, Cheng DM, Lloyd-Travaglini C, Saitz R, and Samet JH (2007) Persistent pain is associated with substance use after detoxification: a prospective cohort analysis. Addiction 102:752-760.

Laska EM, Siegel CE, Lin Z, Bogenschutz M, and Marmar CR (2020) Gabapentin enacarbil extended-release versus placebo: a likely responder reanalysis of a randomized clinical trial. Alcohol Clin Exp Res 44:1875-1884.

Laulin JP, Célèrier E, Larcher A, Le Moal M, and Simonnet G (1999) Opiate tolerance to daily heroin administration: an apparent phenomenon associated with enhanced pain sensitivity. Neuroscience 89:631-636.

Laulin JP, Larcher A, Célèrier E, Le Moal M, and Simonnet G (1998) Long-lasting increased pain sensitivity in rat following exposure to heroin for the first time. Eur $J$ Neurosci 10:782-785.

Laulin JP, Maurette P, Corcuff JB, Rivat C, Chauvin M, and Simonnet G (2002) The role of ketamine in preventing fentanyl-induced hyperalgesia and subsequent acute morphine tolerance. Anesth Analg 94:1263-1269.

Lawrence AJ, Cowen MS, Yang HJ, Chen F, and Oldfield B (2006) The orexin system regulates alcohol-seeking in rats. Br J Pharmacol 148:752-759.

Lawton J and Simpson J (2009) Predictors of alcohol use among people experiencing chronic pain. Psychol Health Med 14:487-501.

Lê AD, Kalant H, and Khanna JM (1982) Interaction between des-glycinamide9[Arg8]vasopressin and serotonin on ethanol tolerance. Eur $J$ Pharmacol 80 : 337-345.

Le Doux J (2000) Cognitive-emotional interactions: listen to the brain, in Cognitive Neuroscience of Emotion (Lane RD and Nadel L eds) pp 267-289, Oxford University Press, New York.

Lee MR, Scheidweiler KB, Diao XX, Akhlaghi F, Cummins A, Huestis MA, Leggio L, and Averbeck BB (2018) Oxytocin by intranasal and intravenous routes reaches the cerebrospinal fluid in rhesus macaques: determination using a novel oxytocin assay. Mol Psychiatry 23:115-122.

Lee MR, Schwandt ML, Sankar V, Suchankova P, Sun H, and Leggio L (2017) Effect of alcohol use disorder on oxytocin peptide and receptor mRNA expression in human brain: a post-mortem case-control study. Psychoneuroendocrinology 85:14-19.

Lee MR, Shnitko TA, Blue SW, Kaucher AV, Winchell AJ, Erikson DW, Grant KA, and Leggio L (2020) Labelled oxytocin administered via the intranasal route reaches the brain in rhesus macaques. Nat Commun 11:2783.

Lee MR and Weerts EM (2016) Oxytocin for the treatment of drug and alcohol use disorders. Behav Pharmacol 27:640-648.

Leitl MD, Onvani S, Bowers MS, Cheng K, Rice KC, Carlezon WA Jr, Banks ML, and Negus SS (2014) Pain-related depression of the mesolimbic dopamine system in rats: expression, blockade by analgesics, and role of endogenous к-opioids. Neuropsychopharmacology 39:614-624.

Le Magnen J, Tran G, Durlach J, and Martin C (1987) Dose-dependent suppression of the high alcohol intake of chronically intoxicated rats by Ca-acetyl homotaurinate. Alcohol 4:97-102.

Le Moal M, Dantzer R, Mormède P, Baduel A, Lebrun C, Ettenberg A, van der Kooy D, Wenger J, Deyo S, Koob GF, et al. (1984) Behavioral effects of peripheral administration of arginine vasopressin: a review of our search for a mode of action and a hypothesis. Psychoneuroendocrinology 9:319-341.

Lenoir M, Cantin L, Vanhille N, Serre F, and Ahmed SH (2013) Extended heroin access increases heroin choices over a potent nondrug alternative. Neuropsychopharmacology 38:1209-1220.

Leri F, Tremblay A, Sorge RE, and Stewart J (2004) Methadone maintenance reduces heroin- and cocaine-induced relapse without affecting stress-induced relapse in a rodent model of poly-drug use. Neuropsychopharmacology 29 $1312-1320$.

Levran O, Randesi M, Li Y, Rotrosen J, Ott J, Adelson M, and Kreek MJ (2014) Drug addiction and stress-response genetic variability: association study in African Americans. Ann Hum Genet 78:290-298.

Lewis MJ (1996) Alcohol reinforcement and neuropharmacological therapeutics. $A l$ cohol Alcohol 31 (Suppl 1):17-25.

Li TK and Lumeng L (1984) Alcohol preference and voluntary alcohol intakes of inbred rat strains and the National Institutes of Health heterogeneous stock of rats. Alcohol Clin Exp Res 8:485-486.

Lijffijt M, Hu K, and Swann AC (2014) Stress modulates illness-course of substance use disorders: a translational review. Front Psychiatry 5:83.

Liu J, Yang AR, Kelly T, Puche A, Esoga C, June HL Jr, Elnabawi A, Merchenthaler I, Sieghart W, June HL Sr, et al. (2011) Binge alcohol drinking is associated with GABAA alpha2-regulated Toll-like receptor 4 (TLR4) expression in the central amygdala. Proc Natl Acad Sci USA 108:4465-4470.

Lopez MF, Grahame NJ, and Becker HC (2011) Development of ethanol withdrawalrelated sensitization and relapse drinking in mice selected for high- or low-ethanol preference. Alcohol Clin Exp Res 35:953-962.

Lopez MF, Moorman DE, Aston-Jones G, and Becker HC (2016) The highly selective orexin/hypocretin 1 receptor antagonist GSK1059865 potently reduces ethanol drinking in ethanol dependent mice. Brain Res 1636:74-80.

Lowery EG, Sparrow AM, Breese GR, Knapp DJ, and Thiele TE (2008) The CRF-1 receptor antagonist, CP-154,526, attenuates stress-induced increases in ethanol consumption by BALB/cJ mice. Alcohol Clin Exp Res 32:240-248.

Lowery-Gionta EG, Navarro M, Li C, Pleil KE, Rinker JA, Cox BR, Sprow GM, Kash TL, and Thiele TE (2012) Corticotropin releasing factor signaling in the central amygdala is recruited during binge-like ethanol consumption in C57BL/6J mice. $J$ Neurosci 32:3405-3413.

Lutz PE and Kieffer BL (2013) Opioid receptors: distinct roles in mood disorders. Trends Neurosci 36:195-206.
Lynch WJ and Carroll ME (1999) Sex differences in the acquisition of intravenously self-administered cocaine and heroin in rats. Psychopharmacology (Berl) 144 $77-82$

Macey DJ, Koob GF, and Markou A (2000) CRF and urocortin decreased brain stimulation reward in the rat: reversal by a CRF receptor antagonist. Brain Res 866:82-91.

MacFadyen K, Loveless R, DeLucca B, Wardley K, Deogan S, Thomas C, and Peris J (2016) Peripheral oxytocin administration reduces ethanol consumption in rats. Pharmacol Biochem Behav 140:27-32.

Mahler SV, Smith RJ, Moorman DE, Sartor GC, and Aston-Jones G (2012) Multiple roles for orexin/hypocretin in addiction. Prog Brain Res 198:79-121.

Maisel NC, Blodgett JC, Wilbourne PL, Humphreys K, and Finney JW (2013) Metaanalysis of naltrexone and acamprosate for treating alcohol use disorders: when are these medications most helpful? Addiction 108:275-293.

Majchrowicz E (1975) Induction of physical dependence upon ethanol and the associated behavioral changes in rats. Psychopharmacology (Berl) 43:245-254

Mäkelä P, Raitasalo K, and Wahlbeck K (2015) Mental health and alcohol use: a cross-sectional study of the Finnish general population. Eur J Public Health 25: $225-231$.

Makino S, Gold PW, and Schulkin J (1994a) Effects of corticosterone on CRH mRNA and content in the bed nucleus of the stria terminalis; comparison with the effects in the central nucleus of the amygdala and the paraventricular nucleus of the hypothalamus. Brain Res 657:141-149.

Makino S, Gold PW, and Schulkin J (1994b) Corticosterone effects on corticotropinreleasing hormone mRNA in the central nucleus of the amygdala and the parvocellular region of the paraventricular nucleus of the hypothalamus. Brain Res 640 : 105-112.

Maldonado R (1997) Participation of noradrenergic pathways in the expression of opiate withdrawal: biochemical and pharmacological evidence. Neurosci Biobehav Rev 21:91-104.

Manwell LA, Satvat E, Lang ST, Allen CP, Leri F, and Parker LA (2009) FAAH inhibitor, URB-597, promotes extinction and CB(1) antagonist, SR141716, inhibits extinction of conditioned aversion produced by naloxone-precipitated morphine withdrawal, but not extinction of conditioned preference produced by morphine in rats. Pharmacol Biochem Behav 94:154-162.

Maric T, Tobin S, Quinn T, and Shalev U (2008) Food deprivation-like effects of neuropeptide $\mathrm{Y}$ on heroin self-administration and reinstatement of heroin seeking in rats. Behav Brain Res 194:39-43.

Marlatt G and Gordon J (1980) Determinants of relapse: implications for the maintenance of behavioral change, in Behavioral Medicine: Changing Health Lifestyles (Davidson P and Davidson S eds) pp 410-452, Brunner/Mazel, New York.

Martin TJ and Ewan E (2008) Chronic pain alters drug self-administration: implications for addiction and pain mechanisms. Exp Clin Psychopharmacol 16 357-366.

Martin TJ, Kim SA, Buechler NL, Porreca F, and Eisenach JC (2007) Opioid selfadministration in the nerve-injured rat: relevance of antiallodynic effects to drug consumption and effects of intrathecal analgesics. Anesthesiology 106:312-322.

Martin TJ, Kim SA, and Eisenach JC (2006) Clonidine maintains intrathecal selfadministration in rats following spinal nerve ligation. Pain 125:257-263.

Martin WR (1968) A homeostatic and redundancy theory of tolerance to and dependence on narcotic analgesics, in The Addictive States (Wikler A ed) pp 206-225, Williams and Wilkins, Baltimore, MD.

Martin-Fardon R, Zorrilla EP, Ciccocioppo R, and Weiss F (2010) Role of innate and drug-induced dysregulation of brain stress and arousal systems in addiction: focus on corticotropin-releasing factor, nociceptin/orphanin $\mathrm{FQ}$, and orexin/hypocretin Brain Res 1314:145-161.

Mason BJ (2003) Acamprosate and naltrexone treatment for alcohol dependence: an evidence-based risk-benefits assessment. Eur Neuropsychopharmacol 13:469-475.

Mason BJ, Light JM, Williams LD, and Drobes DJ (2009) Proof-of-concept human laboratory study for protracted abstinence in alcohol dependence: effects of gabapentin. Addict Biol 14:73-83.

Mason BJ, Quello S, Goodell V, Shadan F, Kyle M, and Begovic A (2014) Gabapentin treatment for alcohol dependence: a randomized clinical trial. JAMA Intern Med 174:70-77.

Massaly N, Copits BA, Wilson-Poe AR, Hipólito L, Markovic T, Yoon HJ, Liu S, Walicki MC, Bhatti DL, Sirohi S, et al. (2019) Pain-induced negative affect is mediated via recruitment of the nucleus accumbens kappa opioid system. Neuron 102:564-573.e6.

Massaly N, Morón JA, and Al-Hasani R (2016) A trigger for opioid misuse: chronic pain and stress dysregulate the mesolimbic pathway and kappa opioid system. Front Neurosci 10:480.

Masten LW, Hine CH, and Way EL (1978) Tolerance, dependence and lethality in morphine-dependent mice after repeated oral administration of methadone. Drug Alcohol Depend 3:405-418.

Matsumoto M and Hikosaka O (2007) Lateral habenula as a source of negative reward signals in dopamine neurons. Nature 447:1111-1115.

McCown TJ and Breese GR (1990) Multiple withdrawals from chronic ethanol "kindles" inferior collicular seizure activity: evidence for kindling of seizures associated with alcoholism. Alcohol Clin Exp Res 14:394-399.

McEwen BS and Akil H (2020) Revisiting the stress concept: implications for affective disorders. J Neurosci 40:12-21.

McNally GP and Akil H (2002) Role of corticotropin-releasing hormone in the amygdala and bed nucleus of the stria terminalis in the behavioral, pain modulatory, and endocrine consequences of opiate withdrawal. Neuroscience 112: 605-617.

McQuay HJ (1988) Pharmacological treatment of neuralgic and neuropathic pain Cancer Surv 7:141-159.

Mechling AE, Arefin T, Lee HL, Bienert T, Reisert M, Ben Hamida S, Darcq E, Ehrlich A, Gaveriaux-Ruff C, Parent MJ, et al. (2016) Deletion of the mu opioid receptor gene in mice reshapes the reward-aversion connectome. Proc Natl Acad Sci USA 113:11603-11608. 
Meijer OC, Steenbergen PJ, and De Kloet ER (2000) Differential expression and regional distribution of steroid receptor coactivators SRC-1 and SRC-2 in brain and pituitary. Endocrinology 141:2192-2199.

Melby K, Gråwe RW, Aamo TO, Salvesen Ø, and Spigset O (2019) Effect of intranasal oxytocin on alcohol withdrawal syndrome: a randomized placebo-controlled doubleblind clinical trial. Drug Alcohol Depend 197:95-101.

Melis M, Camarini R, Ungless MA, and Bonci A (2002) Long-lasting potentiation of GABAergic synapses in dopamine neurons after a single in vivo ethanol exposure. J Neurosci 22:2074-2082.

Mello NK, Bree MP, and Mendelson JH (1983) Comparison of buprenorphine and methadone effects on opiate self-administration in primates. $J$ Pharmacol Exp Ther 225:378-386.

Mello NK and Mendelson JH (1980) Buprenorphine suppresses heroin use by heroin addicts. Science 207:657-659.

Merlo Pich E, Lorang M, Yeganeh M, Rodriguez de Fonseca F, Raber J, Koob GF, and Weiss F (1995) Increase of extracellular corticotropin-releasing factor-like immunoreactivity levels in the amygdala of awake rats during restraint stress and ethanol withdrawal as measured by microdialysis. J Neurosci 15:5439-5447.

Mhatre MC, Pena G, Sieghart W, and Ticku MK (1993) Antibodies specific for GABAA receptor alpha subunits reveal that chronic alcohol treatment downregulates alpha-subunit expression in rat brain regions. $J$ Neurochem 61 $1620-1625$.

Mingione CJ, Heffner JL, Blom TJ, and Anthenelli RM (2012) Childhood adversity, serotonin transporter (5-HTTLPR) genotype, and risk for cigarette smoking and nicotine dependence in alcohol dependent adults. Drug Alcohol Depend 123: 201-206

Mitchell JM, Arcuni PA, Weinstein D, and Woolley JD (2016) Intranasal oxytocin selectively modulates social perception, craving, and approach behavior in subjects with alcohol use disorder. J Addict Med 10:182-189.

Moeini M, Omidi A, Sehat M, and Banafshe HR (2019) The effects of oxytocin on withdrawal, craving and stress response in heroin-dependent patients: a randomized, double-blind clinical trial. Eur Addict Res 25:41-47.

Mollereau C and Mouledous L (2000) Tissue distribution of the opioid receptor-like (ORL1) receptor. Peptides 21:907-917.

Moore CF and Lynch WJ (2015) Alcohol preferring (P) rats as a model for examining sex differences in alcohol use disorder and its treatment. Pharmacol Biochem Behav 132:1-9.

Moore CF, Sabino V, Koob GF, and Cottone P (2019) Dissecting compulsive eating behavior into three elements, in Compulsive Eating Behavior and Food Addiction Emerging Pathological Constructs (Cottone P, Sabino V, Moore CF, and Koob GF eds) pp 41-81, Elsevier, New York.

Moore CF, Sabino V, Koob GF, and Cottone P (2017) Pathological overeating: emerging evidence for a compulsivity construct. Neuropsychopharmacology $\mathbf{4 2}$ $1375-1389$

Moreton JE, Roehrs T, and Khazan N (1976) Drug self-administration and sleepawake activity in rats dependent on morphine, methadone, or l-alpha-acetylmethadol. Psychopharmacology (Berl) 47:237-241.

Morganstern I, Chang GQ, Barson JR, Ye Z, Karatayev O, and Leibowitz SF (2010) Differential effects of acute and chronic ethanol exposure on orexin expression in the perifornical lateral hypothalamus. Alcohol Clin Exp Res 34:886-896.

Moskal D, Maisto SA, De Vita M, and Ditre JW (2018) Effects of experimental pain induction on alcohol urge, intention to consume alcohol, and alcohol demand. Exp Clin Psychopharmacol 26:65-76.

Murphy NP, Onaka T, Brown CH, and Leng G (1997) The role of afferent inputs to supraoptic nucleus oxytocin neurons during naloxone-precipitated morphine withdrawal in the rat. Neuroscience 80:567-577.

Muscoli C, Doyle T, Dagostino C, Bryant L, Chen Z, Watkins LR, Ryerse J, Bieberich E, Neumman W, and Salvemini D (2010) Counter-regulation of opioid analgesia by glial-derived bioactive sphingolipids. J Neurosci 30:15400-15408.

Mutschler J, Abbruzzese E, von der Goltz C, Dinter C, Mobascher A, Thiele H, DiazLacava A, Dahmen N, Gallinat J, Majic T, et al. (2012) Genetic variation in the neuropeptide $\mathrm{Y}$ gene promoter is associated with increased risk of tobacco smoking. Eur Addict Res 18:246-252.

Muzyk AJ, Fowler JA, Norwood DK, and Chilipko A (2011) Role of $\alpha 2$-agonists in the treatment of acute alcohol withdrawal. Ann Pharmacother 45:649-657.

Nader K and van der Kooy D (1996) Clonidine antagonizes the aversive effects of opiate withdrawal and the rewarding effects of morphine only in opiate withdrawn rats. Behav Neurosci 110:389-400.

Narita M, Kaneko C, Miyoshi K, Nagumo Y, Kuzumaki N, Nakajima M, Nanjo K, Matsuzawa K, Yamazaki M, and Suzuki T (2006) Chronic pain induces anxiety with concomitant changes in opioidergic function in the amygdala. Neuropsychopharmacology 31:739-750.

Narita M, Kishimoto Y, Ise Y, Yajima Y, Misawa K, and Suzuki T (2005) Direct evidence for the involvement of the mesolimbic kappa-opioid system in the morphine-induced rewarding effect under an inflammatory pain-like state. $\mathrm{Neu}$ ropsychopharmacology 30:111-118.

Nation KM, De Felice M, Hernandez PI, Dodick DW, Neugebauer V, Navratilova E, and Porreca F (2018) Lateralized kappa opioid receptor signaling from the amygdala central nucleus promotes stress-induced functional pain. Pain 159:919-928.

National Institute on Alcohol Abuse and Alcoholism (2004) NIAAA Council Approves Definition of Binge Drinking. NIAAA Newsletter, No. 3 (NIH Pub. No. 04-5346), National Institute on Alcohol Abuse and Alcoholism, Bethesda, MD.

National Survey on Drug Use, Health (US), United States; Substance Abuse and Mental Health Services Administration (2007) Results from the 2007 National Survey on Drug Use and Health: National Findings, Department of Health and Human Services, Substance Abuse and Mental Health Services Administration, Office of Applied Studies, Rockville, MD.

Natividad LA, Buczynski MW, Herman MA, Kirson D, Oleata CS, Irimia C, Polis I, Ciccocioppo R, Roberto M, and Parsons LH (2017) Constitutive increases in amygdalar corticotropin-releasing factor and fatty acid amide hydrolase drive an anxious phenotype. Biol Psychiatry 82:500-510.
Navarro M, Chowen J, Rocío A Carrera M, del Arco I, Villanúa MA, Martin Y, Roberts AJ, Koob GF, and de Fonseca FR (1998) CB1 cannabinoid receptor antagonist-induced opiate withdrawal in morphine-dependent rats. Neuroreport $\mathbf{9}$ 3397-3402.

Nealey KA, Smith AW, Davis SM, Smith DG, and Walker BM (2011) к-opioid receptors are implicated in the increased potency of intra-accumbens nalmefene in ethanol-dependent rats. Neuropharmacology 61:35-42.

Negus SS and Banks ML (2018) Modulation of drug choice by extended drug access and withdrawal in rhesus monkeys: implications for negative reinforcement as a driver of addiction and target for medications development. Pharmacol Biochem Behav 164:32-39.

Negus SS and Rice KC (2009) Mechanisms of withdrawal-associated increases in heroin self-administration: pharmacologic modulation of heroin vs food choice in heroin-dependent rhesus monkeys. Neuropsychopharmacology 34:899-911.

Negus SS, Zuzga DS, and Mello NK (2002) Sex differences in opioid antinociception in rhesus monkeys: antagonism of fentanyl and U50,488 by quadazocine. J Pain 3 $218-226$.

Nestler EJ (2004) Historical review: molecular and cellular mechanisms of opiate and cocaine addiction. Trends Pharmacol Sci 25:210-218.

Neugebauer V, Li W, Bird GC, and Han JS (2004) The amygdala and persistent pain. Neuroscientist 10:221-234.

Neumann ID, Maloumby R, Beiderbeck DI, Lukas M, and Landgraf R (2013) Increased brain and plasma oxytocin after nasal and peripheral administration in rats and mice. Psychoneuroendocrinology 38:1985-1993.

Nikolaou K, Kapoukranidou D, Ndungu S, Floros G, and Kovatsi L (2017) Severity of withdrawal symptoms, plasma oxytocin levels, and treatment outcome in heroin users undergoing acute withdrawal. J Psychoactive Drugs 49:233-241.

Nutt DJ (2014) The role of the opioid system in alcohol dependence. $J$ Psychopharmacol 28:8-22.

Nylander I, Vlaskovska M, and Terenius L (1995) The effects of morphine treatment and morphine withdrawal on the dynorphin and enkephalin systems in SpragueDawley rats. Psychopharmacology (Berl) 118:391-400.

Okahisa Y, Ujike H, Kotaka T, Morita Y, Kodama M, Inada T, Yamada M, Iwata N, Iyo M, Sora I, et al. (2009) Association between neuropeptide Y gene and its receptor Y1 gene and methamphetamine dependence. Psychiatry Clin Neurosci 63: $417-422$.

Olive MF, Koenig HN, Nannini MA, and Hodge CW (2002) Elevated extracellular CRF levels in the bed nucleus of the stria terminalis during ethanol withdrawa and reduction by subsequent ethanol intake. Pharmacol Biochem Behav 72: $213-220$.

Opitz K (1990) The effect of clonidine and related substances on voluntary ethanol consumption in rats. Drug Alcohol Depend 25:43-48.

Overstreet DH, Knapp DJ, and Breese GR (2004a) Similar anxiety-like responses in male and female rats exposed to repeated withdrawals from ethanol. Pharmacol Biochem Behav 78:459-464.

Overstreet DH, Knapp DJ, and Breese GR (2004b) Modulation of multiple ethanol withdrawal-induced anxiety-like behavior by $\mathrm{CRF}$ and CRF1 receptors. Pharmacol Biochem Behav 77:405-413.

Ozaki S, Narita M, Narita M, Iino M, Sugita J, Matsumura Y, and Suzuki T (2002) Suppression of the morphine-induced rewarding effect in the rat with neuropathic pain: implication of the reduction in mu-opioid receptor functions in the ventral tegmental area. $J$ Neurochem 82:1192-1198.

Pandey SC (2004) The gene transcription factor cyclic AMP-responsive element binding protein: role in positive and negative affective states of alcohol addiction. Pharmacol Ther 104:47-58.

Pandey SC, Roy A, and Zhang H (2003) The decreased phosphorylation of cyclic adenosine monophosphate (cAMP) response element binding (CREB) protein in the central amygdala acts as a molecular substrate for anxiety related to ethanol withdrawal in rats. Alcohol Clin Exp Res 27:396-409.

Pandey SC, Roy A, Zhang H, and Xu T (2004) Partial deletion of the cAMP response element-binding protein gene promotes alcohol-drinking behaviors. J Neurosci 24 5022-5030.

Pandey SC, Sakharkar AJ, Tang L, and Zhang H (2015) Potential role of adolescent alcohol exposure-induced amygdaloid histone modifications in anxiety and alcohol intake during adulthood. Neurobiol Dis 82:607-619.

Pandey SC, Ugale R, Zhang H, Tang L, and Prakash A (2008a) Brain chromatin remodeling: a novel mechanism of alcoholism. J Neurosci 28:3729-3737.

Pandey SC, Zhang H, Ugale R, Prakash A, Xu T, and Misra K (2008b) Effector immediateearly gene arc in the amygdala plays a critical role in alcoholism [published correction appears in J Neurosci (2010) 30:7447-7448]. J Neurosci 28:2589-2600.

Parale MP and Kulkarni SK (1986) Studies with alpha 2-adrenoceptor agonists and alcohol abstinence syndrome in rats. Psychopharmacology (Berl) 88:237-239.

Park PE, Schlosburg JE, Vendruscolo LF, Schulteis G, Edwards S, and Koob GF (2015) Chronic $\mathrm{CRF}_{1}$ receptor blockade reduces heroin intake escalation and dependence-induced hyperalgesia. Addict Biol 20:275-284.

Pascual M, Baliño P, Alfonso-Loeches S, Aragón CM, and Guerri C (2011) Impact of TLR4 on behavioral and cognitive dysfunctions associated with alcohol-induced neuroinflammatory damage. Brain Behav Immun 25 (Suppl 1):S80-S91.

Pati D, Marcinkiewcz CA, DiBerto JF, Cogan ES, McElligott ZA, and Kash TL (2020) Chronic intermittent ethanol exposure dysregulates a GABAergic microcircuit in the bed nucleus of the stria terminalis. Neuropharmacology 168:107759.

Pedersen CA, Smedley KL, Leserman J, Jarskog LF, Rau SW, Kampov-Polevoi A, Casey RL, Fender T, and Garbutt JC (2013) Intranasal oxytocin blocks alcohol withdrawal in human subjects. Alcohol Clin Exp Res 37:484-489.

Perney P, Lehert P, and Mason BJ (2012) Sleep disturbance in alcoholism: proposal of a simple measurement, and results from a 24 -week randomized controlled study of alcohol-dependent patients assessing acamprosate efficacy. Alcohol Alcohol 47: 133-139.

Peyron C, Tighe DK, van den Pol AN, de Lecea L, Heller HC, Sutcliffe JG, and Kilduff TS (1998) Neurons containing hypocretin (orexin) project to multiple neuronal systems. J Neurosci 18:9996-10015. 
Pleil KE, Rinker JA, Lowery-Gionta EG, Mazzone CM, McCall NM, Kendra AM, Olson DP, Lowell BB, Grant KA, Thiele TE, et al. (2015) NPY signaling inhibits extended amygdala CRF neurons to suppress binge alcohol drinking. Nat Neurosci 18:545-552.

Podlesnik CA, Ko MC, Winger G, Wichmann J, Prinssen EP, and Woods JH (2011) The effects of nociceptin/orphanin FQ receptor agonist Ro 64-6198 and diazepam on antinociception and remifentanil self-administration in rhesus monkeys. Psychopharmacology (Berl) 213:53-60.

Pothos E, Rada P, Mark GP, and Hoebel BG (1991) Dopamine microdialysis in the nucleus accumbens during acute and chronic morphine, naloxone-precipitated withdrawal and clonidine treatment. Brain Res 566:348-350.

Poulos CX and Cappell H (1991) Homeostatic theory of drug tolerance: a general model of physiological adaptation. Psychol Rev 98:390-408.

Pradhan AA, Tipton AF, Zhang H, Akbari A, and Pandey SC (2019) Effect of histone deacetylase inhibitor on ethanol withdrawal-induced hyperalgesia in rats. Int J Neuropsychopharmacol 22:523-527.

Przewłocka B, Turchan J, Lasoń W, and Przewłocki R (1997) Ethanol withdrawal enhances the prodynorphin system activity in the rat nucleus accumbens. Neurosci Lett 238:13-16.

Puciłowski O, Kostowski W, and Trzaskowska E (1985) The effect of oxytocin and fragment (MIF-I) on the development of tolerance to hypothermic and hypnotic action of ethanol in the rat. Peptides 6:7-10.

Qin L, Wu X, Block ML, Liu Y, Breese GR, Hong JS, Knapp DJ, and Crews FT (2007) Systemic LPS causes chronic neuroinflammation and progressive neurodegeneration. Glia 55:453-462.

Raehal KM and Bohn LM (2014) $\beta$-arrestins: regulatory role and therapeutic potential in opioid and cannabinoid receptor-mediated analgesia. Handb Exp Phar macol 219:427-443.

Ranade R, Wunder J, Terzian M, and Ungureanu I (2020) Opioids and suicide: opportunities for comprehensive prevention. J Public Health Manag Pract 26: 291-293.

Rasmussen DD, Alexander L, Malone J, Federoff D, and Froehlich JC (2014) The $\alpha 2$ adrenergic receptor agonist, clonidine, reduces alcohol drinking in alcoholpreferring (P) rats. Alcohol 48:543-549.

Rassnick S, Heinrichs SC, Britton KT, and Koob GF (1993) Microinjection of a corticotropin-releasing factor antagonist into the central nucleus of the amygdala reverses anxiogenic-like effects of ethanol withdrawal. Brain Res 605:25-32.

Reilly W, Koirala B, and Devaud LL (2009) Sex differences in acoustic startle responses and seizure thresholds between ethanol-withdrawn male and female rats. Alcohol Alcohol 44:561-566.

Ren ZY, Shi J, Epstein DH, Wang J, and Lu L (2009) Abnormal pain response in painsensitive opiate addicts after prolonged abstinence predicts increased drug craving. Psychopharmacology (Berl) 204:423-429.

Richards JK, Simms JA, Steensland P, Taha SA, Borgland SL, Bonci A, and Bartlett SE (2008) Inhibition of orexin-1/hypocretin-1 receptors inhibits yohimbine-induced reinstatement of ethanol and sucrose seeking in Long-Evans rats. Psychophar macology (Berl) 199:109-117.

Richardson HN, Lee SY, O'Dell LE, Koob GF, and Rivier CL (2008) Alcohol selfadministration acutely stimulates the hypothalamic-pituitary-adrenal axis, but alcohol dependence leads to a dampened neuroendocrine state. Eur J Neurosci 28 1641-1653.

Riihioja P, Jaatinen P, Oksanen H, Haapalinna A, Heinonen E, and Hervonen A (1997) Dexmedetomidine alleviates ethanol withdrawal symptoms in the rat. $\mathrm{Al}$ cohol 14:537-544.

Riley JL III and King C (2009) Self-report of alcohol use for pain in a multi-ethnic community sample. J Pain 10:944-952.

Roberto M, Cruz MT, Gilpin NW, Sabino V, Schweitzer P, Bajo M, Cottone P, Madamba SG, Stouffer DG, Zorrilla EP, et al. (2010) Corticotropin releasing factorinduced amygdala gamma-aminobutyric Acid release plays a key role in alcoho dependence. Biol Psychiatry 67:831-839.

Roberto M, Gilpin NW, O'Dell LE, Cruz MT, Morse AC, Siggins GR, and Koob GF (2008) Cellular and behavioral interactions of gabapentin with alcohol dependence. J Neurosci 28:5762-5771.

Roberto M, Schweitzer P, Madamba SG, Stouffer DG, Parsons LH, and Siggins GR (2004) Acute and chronic ethanol alter glutamatergic transmission in rat central amygdala: an in vitro and in vivo analysis. $J$ Neurosci 24:1594-1603.

Roberto M and Varodayan FP (2017) Synaptic targets: chronic alcohol actions. Neuropharmacology 122:85-99.

Roberts AJ, Cole M, and Koob GF (1996) Intra-amygdala muscimol decreases operant ethanol self-administration in dependent rats. Alcohol Clin Exp Res 20:1289-1298.

Robinson SL and Thiele TE (2017) The role of neuropeptide Y (NPY) in alcohol and drug abuse disorders. Int Rev Neurobiol 136:177-197.

Rohrer DK and Kobilka BK (1998) Insights from in vivo modification of adrenergic receptor gene expression. Annu Rev Pharmacol Toxicol 38:351-373.

Roltsch Hellard EA, Impastato RA, and Gilpin NW (2017) Intra-cerebral and intranasal melanocortin-4 receptor antagonist blocks withdrawal hyperalgesia in alcohol-dependent rats. Addict Biol 22:692-701.

Romach MK and Sellers EM (1991) Management of the alcohol withdrawal syndrome. Annu Rev Med 42:323-340.

Rorick-Kehn LM, Ciccocioppo R, Wong CJ, Witkin JM, Martinez-Grau MA, Stopponi S, Adams BL, Katner JS, Perry KW, Toledo MA, et al. (2016) A novel, orally bioavailable nociceptin receptor antagonist, LY2940094, reduces ethanol selfadministration and ethanol seeking in animal models. Alcohol Clin Exp Res $\mathbf{4 0}$ 945-954.

Rose JH, Karkhanis AN, Chen R, Gioia D, Lopez MF, Becker HC, McCool BA, and Jones SR (2016) Supersensitive kappa opioid receptors promotes ethano withdrawal-related behaviors and reduce dopamine signaling in the nucleus accumbens. Int $J$ Neuropsychopharmacol 19:pyv127.

Rossetti ZL, Melis F, Carboni S, Diana M, and Gessa GL (1992) Alcohol withdrawal in rats is associated with a marked fall in extraneuronal dopamine. Alcohol Clin Exp Res 16:529-532.
Russell MAH (1976) What is dependence? in Drugs and Drug Dependence (Edwards G ed) pp 182-187, Lexington Books, Lexington, MA.

Ryan ML, Falk DE, Fertig JB, Rendenbach-Mueller B, Katz DA, Tracy KA, Strain EC, Dunn KE, Kampman K, Mahoney E, et al. (2017) A phase 2, doubleblind, placebo-controlled randomized trial assessing the efficacy of ABT-436, a novel V1b antagonist, for alcohol dependence. Neuropsychopharmacology 42 : 1012-1023.

Sacks JJ, Gonzales KR, Bouchery EE, Tomedi LE, and Brewer RD (2015) $2010 \mathrm{Na}-$ tional and state costs of excessive alcohol consumption. Am J Prev Med 49:e73-e79. Sakurai T, Amemiya A, Ishii M, Matsuzaki I, Chemelli RM, Tanaka H, Williams SC, Richardson JA, Kozlowski GP, Wilson S, et al. (1998) Orexins and orexin receptors: a family of hypothalamic neuropeptides and $\mathrm{G}$ protein-coupled receptors that regulate feeding behavior. Cell 92:573-585

Salomé N, Stemmelin J, Cohen C, and Griebel G (2006) Differential roles of amygdaloid nuclei in the anxiolytic- and antidepressant-like effects of the V1b receptor antagonist, SSR149415, in rats. Psychopharmacology (Berl) 187:237-244.

Scavone JL, Sterling RC, and Van Bockstaele EJ (2013) Cannabinoid and opioid interactions: implications for opiate dependence and withdrawal. Neuroscience 248:637-654.

Schalkwijk S, Undurraga J, Tondo L, and Baldessarini RJ (2014) Declining efficacy in controlled trials of antidepressants: effects of placebo dropout. Int $J$ Neuropsychopharmacol 17:1343-1352.

Schlosburg JE, Whitfield TW Jr, Park PE, Crawford EF, George O, Vendruscolo LF, and Koob GF (2013) Long-term antagonism of $\kappa$ opioid receptors prevents escalation of and increased motivation for heroin intake. $J$ Neurosci 33:19384-19392.

Schmeichel BE, Barbier E, Misra KK, Contet C, Schlosburg JE, Grigoriadis D, Williams JP, Karlsson C, Pitcairn C, Heilig M, et al. (2015) Hypocretin receptor 2 antagonism dose-dependently reduces escalated heroin self-administration in rats. Neuropsychopharmacology 40:1123-1129.

Schmid B, Blomeyer D, Treutlein J, Zimmermann US, Buchmann AF, Schmidt MH, Esser G, Rietschel M, Banaschewski T, Schumann G, et al. (2010) Interacting effects of CRHR1 gene and stressful life events on drinking initiation and progression among 19-year-olds. Int $J$ Neuropsychopharmacol 13:703-714.

Schulkin J, Gold PW, and McEwen BS (1998) Induction of corticotropin-releasing hormone gene expression by glucocorticoids: implication for understanding the states of fear and anxiety and allostatic load. Psychoneuroendocrinology 23: $219-243$

Schulteis G, Ahmed SH, Morse AC, Koob GF, and Everitt BJ (2000) Conditioning and opiate withdrawal. Nature 405:1013-1014.

Schulteis G, Markou A, Cole M, and Koob GF (1995) Decreased brain reward produced by ethanol withdrawal. Proc Natl Acad Sci USA 92:5880-5884.

Schulteis G, Stinus L, Risbrough VB, and Koob GF (1998) Clonidine blocks acquisition but not expression of conditioned opiate withdrawal in rats. Neuropsychopharmacology 19:406-416.

Schwandt ML, Cortes CR, Kwako LE, George DT, Momenan R, Sinha R, Grigoriadis DE, Pich EM, Leggio L, and Heilig M (2016) The CRF1 antagonist verucerfont in anxious alcohol-dependent women: translation of neuroendocrine, but not of anticraving effects. Neuropsychopharmacology 41:2818-2829.

Schwarz JM, Hutchinson MR, and Bilbo SD (2011) Early-life experience decreases drug-induced reinstatement of morphine CPP in adulthood via microglial-specific epigenetic programming of anti-inflammatory IL-10 expression. J Neurosci 31: 17835-17847.

Serrano A and Parsons LH (2011) Endocannabinoid influence in drug reinforcement, dependence and addiction-related behaviors. Pharmacol Ther 132:215-241.

Serrano A, Pavon FJ, Buczynski MW, Schlosburg J, Natividad LA, Polis IY, Stouffer DG, Zorrilla EP, Roberto M, Cravatt BF, et al. (2018) Deficient endocannabinoid signaling in the central amygdala contributes to alcohol dependence-related anxiety-like behavior and excessive alcohol intake. Neuropsychopharmacology 43: $1840-1850$

Shackman AJ and Fox AS (2016) Contributions of the central extended amygdala to fear and anxiety. $J$ Neurosci $\mathbf{3 6}: 8050-8063$.

Sharf R, Sarhan M, and Dileone RJ (2008) Orexin mediates the expression of precipitated morphine withdrawal and concurrent activation of the nucleus accumbens shell. Biol Psychiatry 64:175-183.

Shen N, Mo LQ, Hu F, Chen PX, Guo RX, and Feng JQ (2014) A novel role of spinal astrocytic connexin 43: mediating morphine antinociceptive tolerance by activation of NMDA receptors and inhibition of glutamate transporter-1 in rats. CNS Neurosci Ther 20:728-736.

Shepard JD, Barron KW, and Myers DA (2000) Corticosterone delivery to the amygdala increases corticotropin-releasing factor mRNA in the central amygdaloid nucleus and anxiety-like behavior. Brain Res 861:288-295.

Sher KJ and Levenson RW (1982) Risk for alcoholism and individual differences in the stress-response-dampening effect of alcohol. J Abnorm Psychol 91:350-367.

Shippenberg TS, Zapata A, and Chefer VI (2007) Dynorphin and the pathophysiology of drug addiction. Pharmacol Ther 116:306-321.

Shumilla JA, Liron T, Mochly-Rosen D, Kendig JJ, and Sweitzer SM (2005) Ethanol withdrawal-associated allodynia and hyperalgesia: age-dependent regulation by protein kinase $\mathrm{C}$ epsilon and gamma isoenzymes. J Pain 6:535-549.

Shurman J, Koob GF, and Gutstein HB (2010) Opioids, pain, the brain, and hyperkatifeia: a framework for the rational use of opioids for pain. Pain Med 11: $1092-1098$

Siegel S (1975) Evidence from rats that morphine tolerance is a learned response. J Comp Physiol Psychol 89:498-506.

Simms JA, Nielsen CK, Li R, and Bartlett SE (2014) Intermittent access ethanol consumption dysregulates CRF function in the hypothalamus and is attenuated by the CRF-R1 antagonist, CP-376395. Addict Biol 19:606-611.

Simonnet G and Rivat C (2003) Opioid-induced hyperalgesia: abnormal or normal pain? Neuroreport 14:1-7.

Slade T, Chapman C, Swift W, Keyes K, Tonks Z, and Teesson M (2016) Birth cohort trends in the global epidemiology of alcohol use and alcohol-related harms in men and women: systematic review and metaregression. BMJ Open 6:e 011827. 
Snell LD, Tabakoff B, and Hoffman PL (1993) Radioligand binding to the N-methylD-aspartate receptor/ionophore complex: alterations by ethanol in vitro and by chronic in vivo ethanol ingestion. Brain Res 602:91-98.

Solecki W, Ziolkowska B, Krowka T, Gieryk A, Filip M, and Przewlocki R (2009) Alterations of prodynorphin gene expression in the rat mesocorticolimbic system during heroin self-administration. Brain Res 1255:113-121.

Solomon RL (1980) The opponent-process theory of acquired motivation: the costs of pleasure and the benefits of pain. Am Psychol 35:691-712.

Solomon RL and Corbit JD (1973) An opponent-process theory of motivation. II. Cigarette addiction. J Abnorm Psychol 81:158-171.

Solomon RL and Corbit JD (1974) An opponent-process theory of motivation. I. Temporal dynamics of affect. Psychol Rev 81:119-145

Sommer WH, Rimondini R, Hansson AC, Hipskind PA, Gehlert DR, Barr CS, and Heilig MA (2008) Upregulation of voluntary alcohol intake, behavioral sensitivity to stress, and amygdala $c r h r 1$ expression following a history of dependence. Biol Psychiatry 63:139-145.

Song P and Zhao ZQ (2001) The involvement of glial cells in the development of morphine tolerance. Neurosci Res 39:281-286.

Spierling SR and Zorrilla EP (2017) Don't stress about CRF: assessing the translational failures of $\mathrm{CRF}_{1}$ antagonists. Psychopharmacology (Berl) 234:1467-1481.

Stamatakis AM and Stuber GD (2012) Activation of lateral habenula inputs to the ventral midbrain promotes behavioral avoidance. Nat Neurosci 15:1105-1107.

Stemmelin J, Lukovic L, Salome N, and Griebel G (2005) Evidence that the lateral septum is involved in the antidepressant-like effects of the vasopressin V1b receptor antagonist, SSR149415. Neuropsychopharmacology 30:35-42.

Stephens DN (1995) A glutamatergic hypothesis of drug dependence: extrapolations from benzodiazepine receptor ligands. Behav Pharmacol 6 (5 And 6):425-446.

Stinus L, Cador M, Zorrilla EP, and Koob GF (2005) Buprenorphine and a CRF1 antagonist block the acquisition of opiate withdrawal-induced conditioned place aversion in rats. Neuropsychopharmacology 30:90-98.

Stoop R (2012) Neuromodulation by oxytocin and vasopressin. Neuron 76:142-159.

Stopponi S, Fotio Y, Domi A, Borruto AM, Natividad L, Roberto M, Ciccocioppo R and Cannella N (2018) Inhibition of fatty acid amide hydrolase in the central amygdala alleviates co-morbid expression of innate anxiety and excessive alcohol intake. Addict Biol 23:1223-1232.

Substance Abuse and Mental Health Services Administration (2019) Key substance use and mental health indicators in the United States: results from the 2018 National Survey on Drug Use and Health (HHS Publication No. PEP19-5068, NSDUH Series H-54). Rockville, MD: Center for Behavioral Health Statistics and Quality, Substance Abuse and Mental Health Services Administration.

Sugiura H, Tanaka H, Yasuda S, Takemiya T, and Yamagata K (2009) Transducing neuronal activity into dendritic spine morphology: new roles for p38 MAP kinase and N-cadherin. Neuroscientist 15:90-104.

Sukhtankar DD, Lagorio CH, and Ko MC (2014) Effects of the NOP agonist SCH221510 on producing and attenuating reinforcing effects as measured by drug self-administration in rats. Eur J Pharmacol 745:182-189.

Sutcliffe JG and de Lecea L (2002) The hypocretins: setting the arousal threshold. Nat Rev Neurosci 3:339-349.

Swanson LW, Sawchenko PE, Rivier J, and Vale WW (1983) Organization of ovine corticotropin-releasing factor immunoreactive cells and fibers in the rat brain: an immunohistochemical study. Neuroendocrinology 36:165-186.

Szabó G, Kovács GL, Baláspiri L, and Telegdy G (1987) D-pipecolyl-leucyl-glycinamide, a substituted tripeptide analogue of the C-terminal part of oxytocin, influences tolerance to and dependence on ethanol in mice. Alcohol Drug Res 7:99-105.

Szabo G, Mandrekar P, Petrasek J, and Catalano D (2011) The unfolding web of innate immune dysregulation in alcoholic liver injury. Alcohol Clin Exp Res $\mathbf{3 5}$ $782-786$.

Szabó G, Tabakoff B, and Hoffman PL (1988) Receptors with V1 characteristics mediate the maintenance of ethanol tolerance by vasopressin. J Pharmacol Exp Ther 247:536-541.

Szmigielski A, Guidotti A, and Costa E (1977) Endogenous protein kinase inhibitors. Purification, characterization, and distribution in different tissues. J Biol Chem 252:3848-3853.

Szmigielski A, Szmigielska H, and Wejman I (1989) The effect of prolonged ethanol administration on central alpha 2-adrenoceptors sensitivity. Pol J Pharmacol Pharm 41:263-272

Tanaka A, Furubayashi T, Arai M, Inoue D, Kimura S, Kiriyama A, Kusamori K, Katsumi H, Yutani R, Sakane T, et al. (2018) Delivery of oxytocin to the brain for the treatment of autism spectrum disorder by nasal application. Mol Pharm 15: 1105-1111.

Tanganelli S, Antonelli T, Morari M, Bianchi C, and Beani L (1991) Glutamate antagonists prevent morphine withdrawal in mice and guinea pigs. Neurosci Lett 122:270-272

Taylor AM, Castonguay A, Ghogha A, Vayssiere P, Pradhan AA, Xue L, Mehrabani S, Wu J, Levitt P, Olmstead MC, et al. (2016) Neuroimmune regulation of GABAergic neurons within the ventral tegmental area during withdrawal from chronic morphine. Neuropsychopharmacology 41:949-959.

Theberge FR, Li X, Kambhampati S, Pickens CL, St Laurent R, Bossert JM, Baumann MH, Hutchinson MR, Rice KC, Watkins LR, et al. (2013) Effect of chronic delivery of the Toll-like receptor 4 antagonist (+)-naltrexone on incubation of heroin craving. Biol Psychiatry 73:729-737.

Thompson T, Oram C, Correll CU, Tsermentseli S, and Stubbs B (2017) Analgesic effects of alcohol: a systematic review and meta-analysis of controlled experimental studies in healthy participants. J Pain 18:499-510.

Thorsell A, Repunte-Canonigo V, O'Dell LE, Chen SA, King AR, Lekic D, Koob GF, and Sanna PP (2007) Viral vector-induced amygdala NPY overexpression reverses increased alcohol intake caused by repeated deprivations in Wistar rats. Brain 130:1330-1337.

Thorsell A, Slawecki CJ, and Ehlers CL (2005a) Effects of neuropeptide Y and corticotropin-releasing factor on ethanol intake in Wistar rats: interaction with chronic ethanol exposure. Behav Brain Res 161:133-140.
Thorsell A, Slawecki CJ, and Ehlers CL (2005b) Effects of neuropeptide Y on appetitive and consummatory behaviors associated with alcohol drinking in wistar rats with a history of ethanol exposure. Alcohol Clin Exp Res 29:584-590.

Tilson HA, Rech RH, and Stolman S (1973) Hyperalgesia during withdrawal as a means of measuring the degree of dependence in morphine dependent rats. Psychopharmacology (Berl) 28:287-300.

Tirelli E, Jodogne C, and Legros JJ (1992) Oxytocin blocks the environmentally conditioned compensatory response present after tolerance to ethanol-induced hypothermia in mice. Pharmacol Biochem Behav 43:1263-1267.

Todtenkopf MS, Marcus JF, Portoghese PS, and Carlezon WA Jr (2004) Effects of к-opioid receptor ligands on intracranial self-stimulation in rats. Psychopharmacology (Berl) 172:463-470.

Tokuyama S, Wakabayashi H, and Ho IK (1996) Direct evidence for a role of glutamate in the expression of the opioid withdrawal syndrome. Eur J Pharmacol 295:123-129.

Toll L, Bruchas MR, Calo' G, Cox BM, and Zaveri NT (2016) Nociceptin/orphanin FQ receptor structure, signaling, ligands, functions, and interactions with opioid systems. Pharmacol Rev 68:419-457.

Tori ME, Larochelle MR, and Naimi TS (2020) Alcohol or benzodiazepine coinvolvement with opioid overdose deaths in the United States, 1999-2017. JAMA Netw Open 3:e202361.

Treutlein J, Kissling C, Frank J, Wiemann S, Dong L, Depner M, Saam C, Lascorz J, Soyka M, Preuss UW, et al. (2006) Genetic association of the human corticotropin releasing hormone receptor 1 (CRHR1) with binge drinking and alcohol intake patterns in two independent samples. Mol Psychiatry 11:594-602.

Trevisan L, Fitzgerald LW, Brose N, Gasic GP, Heinemann SF, Duman RS, and Nestler EJ (1994) Chronic ingestion of ethanol up-regulates NMDAR1 receptor subunit immunoreactivity in rat hippocampus. J Neurochem 62:1635-1638.

Trzaskowska E and Kostowski W (1983) Further studies on the role of noradrenergic mechanisms in ethanol withdrawal syndrome in rats. Pol $J$ Pharmacol Pharm 35: 351-358.

Tunstall BJ, Kirson D, Zallar LJ, McConnell SA, Vendruscolo JCM, Ho CP, Oleata CS, Khom S, Manning M, Lee MR, et al. (2019) Oxytocin blocks enhanced motivation for alcohol in alcohol dependence and blocks alcohol effects on GABAergic transmission in the central amygdala. PLoS Biol 17:e2006421.

Umhau JC, Momenan R, Schwandt ML, Singley E, Lifshitz M, Doty L, Adams LJ, Vengeliene V, Spanagel R, Zhang Y, et al. (2010) Effect of acamprosate on magnetic resonance spectroscopy measures of central glutamate in detoxified alcoholdependent individuals: a randomized controlled experimental medicine study. Arch Gen Psychiatry 67:1069-1077.

Urban NB, Kegeles LS, Slifstein M, Xu X, Martinez D, Sakr E, Castillo F, Moadel T, O'Malley SS, Krystal JH, et al. (2010) Sex differences in striatal dopamine release in young adults after oral alcohol challenge: a positron emission tomography imaging study with [ $\left.{ }^{11} \mathrm{C}\right]$ raclopride. Biol Psychiatry 68:689-696.

Valdez GR, Zorrilla EP, Roberts AJ, and Koob GF (2003) Antagonism of corticotropinreleasing factor attenuates the enhanced responsiveness to stress observed during protracted ethanol abstinence. Alcohol 29:55-60.

van der Schrier R, Roozekrans M, Olofsen E, Aarts L, van Velzen M, de Jong M, Dahan A, and Niesters M (2017) Influence of ethanol on oxycodone-induced respiratory depression: a dose-escalating study in young and elderly individuals. Anesthesiology 126:534-542.

Varlinskaya EI and Spear LP (2004) Acute ethanol withdrawal (hangover) and social behavior in adolescent and adult male and female Sprague-Dawley rats. Alcohol Clin Exp Res 28:40-50.

Veinante P and Freund-Mercier MJ (1997) Distribution of oxytocin- and vasopressinbinding sites in the rat extended amygdala: a histoautoradiographic study. J Comp Neurol 383:305-325.

Vela G, Ruiz-Gayo M, and Fuentes JA (1995) Anandamide decreases naloxoneprecipitated withdrawal signs in mice chronically treated with morphine. Neuropharmacology 34:665-668.

Velasquez KM, Molfese DL, and Salas R (2014) The role of the habenula in drug addiction. Front Hum Neurosci 8:174.

Vendruscolo LF, Barbier E, Schlosburg JE, Misra KK, Whitfield TW Jr, Logrip ML, Rivier C, Repunte-Canonigo V, Zorrilla EP, Sanna PP, et al. (2012) Corticosteroid-dependent plasticity mediates compulsive alcohol drinking in rats. J Neurosci 32:7563-7571.

Vendruscolo LF, Estey D, Goodell V, Macshane LG, Logrip ML, Schlosburg JE McGinn MA, Zamora-Martinez ER, Belanoff JK, Hunt HJ, et al. (2015) Glucocorticoid receptor antagonism decreases alcohol seeking in alcohol-dependent individuals. J Clin Invest 125:3193-3197.

Vinod KY, Yalamanchili R, Xie S, Cooper TB, and Hungund BL (2006) Effect of chronic ethanol exposure and its withdrawal on the endocannabinoid system. Neurochem Int 49:619-625.

Volkow ND, Fowler JS, and Wang GJ (2002) Role of dopamine in drug reinforcement and addiction in humans: results from imaging studies. Behav Pharmacol 13: $355-366$

Volkow ND, Wang GJ, Fowler JS, Logan J, Hitzemann R, Ding YS, Pappas N, Shea $\mathrm{C}$, and Piscani K (1996) Decreases in dopamine receptors but not in dopamine transporters in alcoholics. Alcohol Clin Exp Res 20:1594-1598.

Volkow ND, Wang GJ, Telang F, Fowler JS, Logan J, Jayne M, Ma Y, Pradhan K, and Wong $\mathrm{C}$ (2007) Profound decreases in dopamine release in striatum in detoxified alcoholics: possible orbitofrontal involvement. J Neurosci 27:12700-12706.

Vranjkovic O, Pina M, Kash TL, and Winder DG (2017) The bed nucleus of the stria terminalis in drug-associated behavior and affect: a circuit-based perspective. Neuropharmacology 122:100-106.

Waldrop AE, Ana EJ, Saladin ME, McRae AL, and Brady KT (2007) Differences in early onset alcohol use and heavy drinking among persons with childhood and adulthood trauma. Am $J$ Addict 16:439-442.

Walker BM and Koob GF (2008) Pharmacological evidence for a motivational role of к-opioid systems in ethanol dependence. Neuropsychopharmacology 33:643-652.

Walker BM, Rasmussen DD, Raskind MA, and Koob GF (2008) $\alpha_{1}$-noradrenergic receptor antagonism blocks dependence-induced increases in responding for ethanol. Alcohol 42:91-97. 
Walker JR, Terenius L, and Koob GF (2002) Conditioned opioid withdrawal decreases nociceptin/orphanin $\mathrm{FQ}$ levels in the frontal cortex and olfactory tubercle. Neuropsychopharmacology 27:203-211.

Walter M, Gerber H, Kuhl HC, Schmid O, Joechle W, Lanz C, Brenneisen R, Schächinger H, Riecher-Rössler A, Wiesbeck GA, et al. (2013) Acute effects of intravenous heroin on the hypothalamic-pituitary-adrenal axis response: a controlled trial. J Clin Psychopharmacol 33:193-198.

Wang GJ, Volkow ND, Fowler JS, Logan J, Abumrad NN, Hitzemann RJ, Pappas NS, and Pascani K (1997) Dopamine D2 receptor availability in opiate-dependent subjects before and after naloxone-precipitated withdrawal. Neuropsychopharmacology 16:174-182.

Wang Z, Gardell LR, Ossipov MH, Vanderah TW, Brennan MB, Hochgeschwender U, Hruby VJ, Malan TP Jr, Lai J, and Porreca F (2001) Pronociceptive actions of dynorphin maintain chronic neuropathic pain. J Neurosci 21:1779-1786.

Watanabe T, Nakagawa T, Yamamoto R, Maeda A, Minami M, and Satoh M (2003) Involvement of noradrenergic system within the central nucleus of the amygdala in naloxone-precipitated morphine withdrawal-induced conditioned place aversion in rats. Psychopharmacology (Berl) 170:80-88.

Watanabe T, Yamamoto R, Maeda A, Nakagawa T, Minami M, and Satoh M (2002) Effects of excitotoxic lesions of the central or basolateral nucleus of the amygdala on naloxone-precipitated withdrawal-induced conditioned place aversion in morphine-dependent rats. Brain Res 958:423-428.

Watkins LR, Hutchinson MR, Milligan ED, and Maier SF (2007) "Listening" and "talking" to neurons: implications of immune activation for pain control and increasing the efficacy of opioids. Brain Res Brain Res Rev 56:148-169.

Watkins LR, Hutchinson MR, Rice KC, and Maier SF (2009) The "toll" of opioidinduced glial activation: improving the clinical efficacy of opioids by targeting glia Trends Pharmacol Sci 30:581-591.

Weiss F, Ciccocioppo R, Parsons LH, Katner S, Liu X, Zorrilla EP, Valdez GR, BenShahar O, Angeletti S, and Richter RR (2001) Compulsive drug-seeking behavior and relapse: neuroadaptation, stress, and conditioning factors, in The Biological Basis of Cocaine Addiction (Quinones-Jenab V ed) pp 1-26, New York Academy of Sciences, New York.

Weiss F, Parsons LH, Schulteis G, Hyytiä P, Lorang MT, Bloom FE, and Koob GF (1996) Ethanol self-administration restores withdrawal-associated deficiencies in accumbal dopamine and 5-hydroxytryptamine release in dependent rats. J Neurosci 16:3474-3485.

Weissman BA and Zamir N (1987) Differential effects of heroin on opioid levels in the rat brain. Eur J Pharmacol 139:121-123.

Wen YR, Tan PH, Cheng JK, Liu YC, and Ji RR (2011) Microglia: a promising target for treating neuropathic and postoperative pain, and morphine tolerance. J Formos Med Assoc 110:487-494.

Wetherill L, Schuckit MA, Hesselbrock V, Xuei X, Liang T, Dick DM, Kramer J, Nurnberger JI Jr, Tischfield JA, Porjesz B, et al. (2008) Neuropeptide Y receptor genes are associated with alcohol dependence, alcohol withdrawal phenotypes, and cocaine dependence. Alcohol Clin Exp Res 32:2031-2040.

White A, Castle IJ, Chen CM, Shirley M, Roach D, and Hingson R (2015) Converging patterns of alcohol use and related outcomes among females and males in the United States, 2002 to 2012. Alcohol Clin Exp Res 39:1712-1726.

White AM, Castle IP, Hingson RW, and Powell PA (2020) Using death certificates to explore changes in alcohol-related mortality in the United States, 1999 to 2017. Alcohol Clin Exp Res 44:178-187.

White AM, Slater ME, Ng G, Hingson R, and Breslow R (2018) Trends in alcoholrelated emergency department visits in the United States: results from the Nationwide Emergency Department Sample, 2006 to 2014. Alcohol Clin Exp Res 42 352-359.

Wieseler-Frank J, Maier SF, and Watkins LR (2005) Immune-to-brain communication dynamically modulates pain: physiological and pathological consequences. Brain Behav Immun 19:104-111.

Wilkerson JL, Ghosh S, Mustafa M, Abdullah RA, Niphakis MJ, Cabrera R, Maldonado RL, Cravatt BF, and Lichtman $\mathrm{AH}$ (2017) The endocannabinoid hydrolysis inhibitor SA-57: intrinsic antinociceptive effects, augmented morphine-induced antinociception, and attenuated heroin seeking behavior in mice. Neuropharmacology 114:156-167.

Williams JT, Ingram SL, Henderson G, Chavkin C, von Zastrow M, Schulz S, Koch T, Evans CJ, and Christie MJ (2013) Regulation of $\mu$-opioid receptors: desensitization, phosphorylation, internalization, and tolerance. Pharmacol Rev 65: $223-254$.

Wills KL, Petrie GN, Millett G, Limebeer CL, Rock EM, Niphakis MJ, Cravatt BF, and Parker LA (2016) Double dissociation of monoacylglycerol lipase inhibition and CB1 antagonism in the central amygdala, basolateral amygdala, and the in teroceptive insular cortex on the affective properties of acute naloxone-precipitated morphine withdrawal in rats. Neuropsychopharmacology 41:1865-1873.
Wills KL, Vemuri K, Kalmar A, Lee A, Limebeer CL, Makriyannis A, and Parker LA (2014) CB1 antagonism: interference with affective properties of acute naloxoneprecipitated morphine withdrawal in rats. Psychopharmacology (Berl) 231 4291-4300.

Winsky-Sommerer R, Boutrel B, and de Lecea L (2005) Stress and arousal: the corticotrophin-releasing factor/hypocretin circuitry. Mol Neurobiol 32:285-294.

Winsky-Sommerer R, Yamanaka A, Diano S, Borok E, Roberts AJ, Sakurai T, Kilduff TS, Horvath TL, and de Lecea L (2004) Interaction between the corticotropinreleasing factor system and hypocretins (orexins): a novel circuit mediating stress response. J Neurosci 24:11439-11448.

Wise RA and Koob GF (2014) The development and maintenance of drug addiction. Neuropsychopharmacology 39:254-262.

Witkiewitz K, Maisto SA, and Donovan DM (2010) A comparison of methods for estimating change in drinking following alcohol treatment. Alcohol Clin Exp Res 34:2116-2125.

Witkiewitz K, Vowles KE, McCallion E, Frohe T, Kirouac M, and Maisto SA (2015) Pain as a predictor of heavy drinking and any drinking lapses in the COMBINE study and the UK Alcohol Treatment Trial. Addiction 110:1262-1271.

Woldbye DP, Klemp K, and Madsen TM (1998) Neuropeptide Y attenuates naloxoneprecipitated morphine withdrawal via Y5-like receptors. J Pharmacol Exp Ther 284:633-636.

World Health Organization (1992) International Statistical Classification of Diseases and Related Health Problems, 10th Revision, World Health Organization, Geneva, Switzerland

Xi ZX, Fuller SA, and Stein EA (1998) Dopamine release in the nucleus accumbens during heroin self-administration is modulated by kappa opioid receptors: an in vivo fast-cyclic voltammetry study. J Pharmacol Exp Ther $\mathbf{2 8 4}$ 151-161.

Yamaguchi T, Hagiwara Y, Tanaka H, Sugiura T, Waku K, Shoyama Y, Watanabe S, and Yamamoto T (2001) Endogenous cannabinoid, 2-arachidonoylglycerol, attenuates naloxone-precipitated withdrawal signs in morphine-dependent mice. Brain Res 909:121-126.

Yang L, Wang F, Wang M, Han M, Hu L, Zheng M, Ma J, Kang Y, Wang P, Sun H, et al. (2017) Association between oxytocin and receptor genetic polymorphisms and aggression in a northern Chinese Han population with alcohol dependence. Neurosci Lett 636:140-144.

Young GA, Steinfels GF, and Khazan N (1978) Transitional patterns of selfadministration following substitution of methadone or l-alpha-acetylmethadol (LAAM) for morphine in dependent rats. Drug Alcohol Depend 3:273-279.

Yuferov V, Fussell D, LaForge KS, Nielsen DA, Gordon D, Ho A, Leal SM, Ott J, and Kreek MJ (2004) Redefinition of the human kappa opioid receptor gene (OPRK1) structure and association of haplotypes with opiate addiction. Pharmacogenetics 14:793-804.

Zale EL, Maisto SA, and Ditre JW (2015) Interrelations between pain and alcohol: an integrative review. Clin Psychol Rev 37:57-71.

Zanos P, Georgiou P, Wright SR, Hourani SM, Kitchen I, Winsky-Sommerer R, and Bailey A (2014) The oxytocin analogue carbetocin prevents emotional impairment and stress-induced reinstatement of opioid-seeking in morphineabstinent mice. Neuropsychopharmacology 39:855-865.

Zhou Y, Colombo G, Carai MA, Ho A, Gessa GL, and Kreek MJ (2011) Involvement of arginine vasopressin and V1b receptor in alcohol drinking in Sardinian alcoholpreferring rats. Alcohol Clin Exp Res 35:1876-1883.

Zhou Y, Colombo G, Gessa GL, and Kreek MJ (2013a) Effects of voluntary alcohol drinking on corticotropin-releasing factor and preprodynorphin mRNA levels in the central amygdala of Sardinian alcohol-preferring rats. Neurosci Lett 554: $110-114$

Zhou Y, Leri F, Cummins E, Hoeschele M, and Kreek MJ (2008) Involvement of arginine vasopressin and $\mathrm{V} 1 \mathrm{~b}$ receptor in heroin withdrawal and heroin seeking precipitated by stress and by heroin. Neuropsychopharmacology $\mathbf{3 3}$ $226-236$.

Zhou Y, Leri F, Grella SL, Aldrich JV, and Kreek MJ (2013b) Involvement of dynorphin and kappa opioid receptor in yohimbine-induced reinstatement of heroin seeking in rats. Synapse 67:358-361.

Zhou Y, Proudnikov D, Yuferov V, and Kreek MJ (2010) Drug-induced and genetic alterations in stress-responsive systems: implications for specific addictive diseases. Brain Res 1314:235-252.

Zijlstra F, Booij J, van den Brink W, and Franken IH (2008) Striatal dopamine D2 receptor binding and dopamine release during cue-elicited craving in recently abstinent opiate-dependent males. Eur Neuropsychopharmacol 18:262-270.

Zuo W, Wu L, Mei Q, Zuo Q, Zhou Z, Fu R, Li W, Wu W, Matthew L, and Ye JH (2019) Adaptation in $5-\mathrm{HT}_{2}$ receptors-CaMKII signaling in lateral habenula underlies increased nociceptive-sensitivity in ethanol-withdrawn rats. Neuropharmacology 158: 107747 . 